
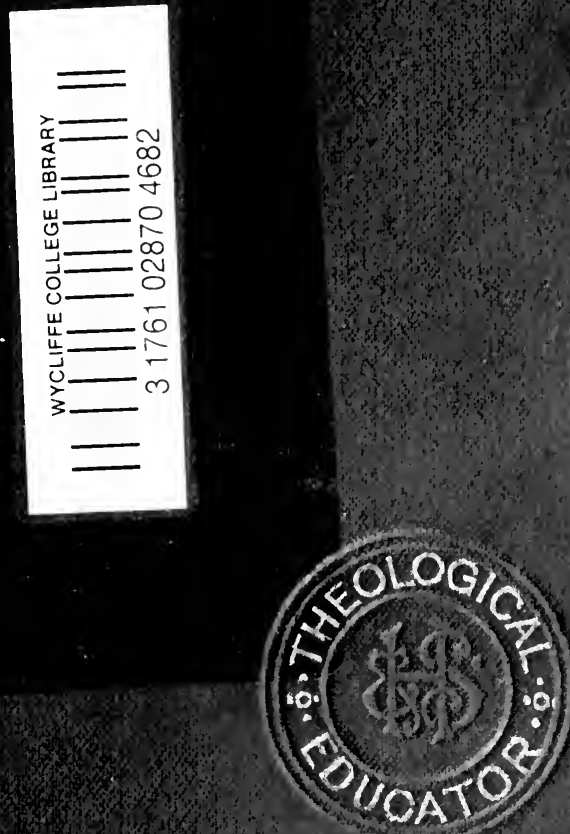


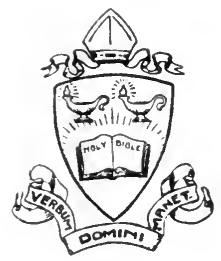

LIBRARY

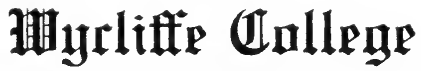

TORONTO

Shelf No.BS. 2385 W23

Register No.. 8335 

THE

\section{THEOLOGICAL EDUCATOR}

Edited by the Rev

W. ROBERTSON NICOLL, M.A., LL.D.

Editor of "The Expositor"

PROFESSOR WARFIELD'S

TEXTUAL CRITICISM OF THE NEW TESTAMENT

\section{Equadr \\ HODDER AND STOUGHTON}

27, PATERNOSTER ROW

MDcccxcvI 


\section{Jhe $\mathbb{U}$ hrological exducatox.}

Fcap. 8vo, price 2s. 6d. each volume.

Christianity and Evolution.

By James Iverach, D.D.

The Theology of the New Testament.

By W. F. Adeney, M.A.

An Introduction to the Old Testament.

By the Rev. C. H. H. WRight, D.D.

The Writers of the New Testament: Their Style and Characteristics.

By the Rev. William Henry Simcox, M.A.

The Language of the New Testament.

By the same Author.

Outlines of Christian Doctrine.

By the Rev. H. C. G. Moule, M.A., D.D.

A Manual of Christian Evidences.

By the Rev. C. A. Row, M.A., Prebendary of St. Paul's.

A Manual of Church History.

By the Rev. A. C. Jennings, M.A. In Two Volumes.

Vol. I. From the First to the Tenth Century.

Vol. II. From the Eleventh to the Nineteenth Century.

An Introduction to the New Testament.

By the Rev. Prof. Marcus Dods, D.D.

An Introduction to the Textual Criticism of the New Testament.

By the Rev. Prof. B. B. WArfield, D.D.

An Exposition of the Apostles' Creed.

By the Rev. J. E. Yonge, M.A.

A Hebrew Grammar.

By the Rev. W. H. Lowe, M.A.

A Manual of the Book of Common Prayer.

By the Rev. C. Hole, B.A.

LONDON: HODDER AND STOUGHTON, 27, Paternoster Row. 


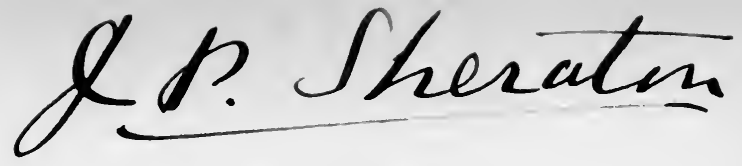

AN INTRODUCTION

TO THE

TEXTUAL CRITICISM

OF THE

NEW TESTAMENT

BY THE REV.

BENJAMIN B. WARFIELD, D.D.

Professor of New Testament Criticism in the Western Theological

Seminary, Allegheny, U.S.A.

FIFTH EDITION

בُondon
HODDER AND STOUGHTON

27, PATERNOSTER ROW

MDCCCXCVI 
Printed by Hazell, Watson, \&o Viney, Ld., London and Aylesbury. 


\section{P R E F A C E.}

$r$ HIS little treatise purports to be a primer, and

a primer to the art of textual criticism rather than to the science. Its purpose will be served if the reader is prepared by it to exercise the art in the usual processes, and to enter upon the study of the science in such books as Dr. Hort's "Introduction," and Dr. Gregory's "Prolegomena" to Tischendorf's eighth edition. In such a primary treatise, and where no claim to originality is made; obligations to previous works can scarcely be acknowledged. The author hopes that his general confession of having made use of everything that he could lay his hands upon that served his purpose, will be deemed sufficient acknowledgment of the many debts he is conscious of, and would like, if occasion served, to confess in detail. 



\section{CONTENTS.}

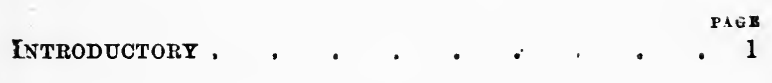

CHAPTER I

The Matter of Criticism . . . . . . 16

CHAPTER II.

The Methods of Criticism . . • • . . 82

CHAPTER III.

The Praxis of Criticism . $\quad$ - $\quad$ - 182

CHAPTER IV.

The History of Criticism . . . . . . . 211 


\section{INTRODUCTORY.}

THE word "text" properly denotes a literary 1 work, conceived of as a mere thing, as a texture woven of words instead of threads. It designates neither, on the one side, the book which contains the text, nor, on the other side, the senso which the text conveys. It is not the matter of the discourse, nor the manner of it, whether logical, rhetorical, or grammatical. It is simply the web of words itself. It is with this understanding that the text of any work is concisely defined as the ipsissima verba of that work.

The word, which came into Middle English from the French where it stands as the descendant of the Latin word textum, retains in English the figurativo sense only of its primitive, yet owes it to its origin that it describes a composition as a woven thing, as a curiously interwoven cloth or tissue of words. Once a part of the English language, it has grown with the growth of that tongue, and has acquired certain special usages. We usually need to speak of the exact words of an author only in contrast with something else, and thus "text" has come to designate a composition upon which a commentary has been written, so that it distinguishes the words commented on from tho 
comments that have been added. Thus we speak of the text of the Talmud as lost in the comment. And thus, too, by an extreme extension, we speak of the text of a sermon, meaning, not the ipsissima verba of the sermon, but the little piece of the original author on which the sermon professes to be a comment. By a somewhat similar extension we speak of texts of Scripture, meaning, not various editions of its ipsissima verba, but brief extracts from Scripture, as for example proof texts and the like;-a usage which appears to have grown up under the conception that all developed theology is of the nature of a comment on Scripture. Such secondary senses of the word need not disturb us here. They are natural developments out of the ground meaning, as applied to special cases. We are to use the word in its general and original sense, in which it designates the ipsissima verba, the woven web of words, which constitutes the concrete thing by which a book is made a work, but which has nothing directly to do with the sense, correctness, or the value of the work.

There is an important distinction, however, which we should grasp at the outset, between the text of a document and the text of a work. A document can have but one text; its ipsissima verba are its ipsissima verba, and there is nothing further to say about it. But a work may exist in several copies, each of which has its own ipsissima verba, which may, or may not, tally with one another. The text of any copy of Shakespeare that is placed in my hands is plainly before me. But the text of Shakespeare is a different matter. No two copies of Shakespeare,-or now, since 
we have to reckon with the printing press, we must rather say no two editions,- - have precisely the same text. There are all kinds of causes that work differences : badness of copy, carelessness of compositors, folly of editors, imperfection of evidence, frailty of humanity. We know what the text of Karl Elze's Hamlet is. But what is the text of Hamlet? We cannot choose any one edition, and say that it is the text of IIamlet; it is one text of Hamlet, but not necessarily the text of IIamlet. We cannot choose one manuscript of Homer, and say that it is the text of Homer. It is a text of Homer, but the text of Homer may be something very different. We note, then, that the text of a document and the text of a work may be very different matters. The text of a document is the ipsissima verba of that document, and is to be had by simply looking at it; whatever stands actually written in it is its text. The text of a work, again, is the ipsissima verba of that work, but it caunot be obtained by simply looking at it. We cannot look at the work, but only at the documents or "copies" that represent it; and what stands written in them, individually or even collectively, may not be the ipsissima verba of the work,-by exactly the amount, in each case, in which it is altered or corrupted from what the author intended to write, is not the ipsissima verba of the work. If, then, the text of a document or copy of any work is the ipsissima verba of that document or copy, the text of the work is what ought to be the ipsissima verba of all the documents or copies that profess to represent it,-it is the original, or; better still, the intended ipsissima verba of the 
author. It may not lie in the document before us, or in any document. All existing documents, taken collectively, may fail to contain it. It may never have lain, perfect and pure, in any document. But if an element of ideality thus attaches to it, it is none the less a very real thing and a very legitimate object of search. It is impossible, no doubt, to avoid a certain looseness of speech, by which we say, for example, "The text of Nonius is in a very bad state ;" and thus identify the text of a work with some transitory state of it, or it may be with the permanent loss of it. What we mean is that the text in this or that document or edition, or in all existing documents or editions, is a very bad and corrupt representation of the text of Nonius, - is not the text of Nonius at all, in fact, but departs from, and fails to be, that in many particulars. The text of Nonius, in a word, is just what we have not and are in search of.

It is clear, therefore, that the text of a work as distinguished from the text of a document can be had only through a critical process. What is necessary for obtaining it is a critical examination of the texts of the various documents that lie before us as its representatives, with a view to discovering from them whether and wherein it has become corrupted, and of proving them to preserve it or else restoring it from their corruptions to its originally intended form. This is what is meant by "textual criticism," which may be defined as the careful, critical examination of a text, with a view to discovering its condition, in order that we may test its correctness on the one hand, and, on the other, emend its errors. 
Obviously this is, if not a bold and unsafe kina of work, yet one sufficiently nice to engage our best powers. It is not, however, so unwonted a procedure as it may seem at first sight; and more of us than suspect it are engaged in it daily. Whenever, for instance, we make a correction in the margin of a book we chance to be reading, because we observe a misplaced letter or a misspelled word, or any other obvious typographical error, we are engaging in pro. cesses of textual criticism. Or, perhaps, we receive a letter from a friend, read it carefully, suddenly come upon a sentence that puzzles us, observe it more closely, and say, "Oh, I see! a word has been left out here!" There is no one of us who has not had this experience, or who has not supplied the word which he determines to be needed, and gone on satisfied. Let us take an apposite example or two from printed books. When we read in Archdeacon Farrar's Messages of the Books (p. 145, note ${ }^{1}$ ): “That God chose His own fit instruments" for writing the books of the New Testament, "and that the sacredness of the books was due to the prior position of these writers is clear from the fact that only four of the writers were apostles" - few of us will hesitate to insert the "not" before "due," the lack of which throws the sentence into logical confusion. So, when we read in the admirable International Revision Commentary on John's Gospel, by Drs. Milligan and Moulton (p. 341): "Yet we should overlook the immediate reference," the context tells us at once that a "not" has been omitted before "overlook." In an edition of King James' Bible, printed by Barker \& Bill, in 
1631, men read the seventh commandment (Exod. xx. 14): "Thou shalt commit adultery," not without perceiving, we may be sure, that a "not" had fallen out, and mentally replacing it all the more emphatic. ally that it was not there. But all this is textual criticism of the highest and most delicate kind. We have, in each case, examined the text before us critically, determined that it was in error, and restored the originally intended text by a critical process. Yet we do all this confidently, with no feeling that we are trenching on learned ground, and with results that are entirely satisfactory to ourselves, and on which we are willing to act in business or social life. The cases that have been adduced involve, indeed, the very nicest and most uncertain of the critical processes : they are all samples of what is called "conjectural emendation"-i.e., the text has been emended in each case by pure conjecture, the context alone hinting that it was in error or suggesting the remedy. The dangers that attend the careless or uninstructed use of so delicate an instrument are well illustrated by a delightful story (which Mr. Frederic Harrison attributes to Mr. Andrew Lang) of a printer who found in his "copy" some reference to "the Scapin of Poquelin." The printer was not a pedant; Molière he knew, but who was Poquelin? At last a bright idea struck his inventive mind, and he printed it: "the Scapin of M. Coquelin." This is "conjectural emendation" too; and unhappily it is the type of a great part of what is called by that name.

In this higher way every reader of books is a textual critic. In a lower way, every proof-reader is a textual 
critic; for the correction of a text that lies before him by the readings of another, given him as a model, is simply the lowest variety of this art. The art of textual criticism is thus seen to be the art of detecting and emending errors in documents. The science is the orderly discussion and systematisation of the principles on which this art ought to proceed.

The inference lies very clo:e, from what has been said, that the sphere of the legitimate application of textual criticism is circumscribed only by the bounds of written matter. Such are the limitations of human powers in reproducing writings, that apparently no lengthy writing can be duplicated without error. Nay, such are the limitations of human powers of attention, that probably few manuscripts of any extent are written exactly correctly at first hand. The author himself fails to put correctly on paper the words that lie in his mind. And even when the document that lies before us is written with absolutely exact correctness, it requires the application of textual criticism, i.e., a careful critical examination, to discover and certify this fact. Let us repeat it, then: wherever written matter exists, textual criticism is not only legitimate, but an unavoidable task; when the writing is important, such as a deed, or a will, or a charter, or the Bible, it is an indefeasible duty. No doubt, differences may exist between writings, in their nature or the conditions under which they were produced or transmitted, which may demand for them somewhat different treatments. The conditions under which a work is transmitted by the printing press differ materially from those under 
which one is transmitted by hand-copying; and the practice of textual criticism may be affected by this difference. One work may lie before us in a single copy, another in a thousand copies, and differences may thence arise in the processes of criticism that are applicable to them. But all writings have this in common : they are all open to criticism, and are all to be criticised. An autograph writing is open to criticism; we must examine it to see whether the writer's hand has been faultless handmaid to his thought, and to correct his erroneous writing of what he intended. A printed work is open to criticism: we must examine it to see what of the aimless altera. tion that has been wrought by a compositor's nimble but not infallible fingers, and what of the foolish alteration which the semi-unconscious working of his mind has inserted into his copy, the proof-reader has allowed to stand. A writing propagated by manuscript is especially open to criticism : here so many varying minds, and so many varying hands, have repeated each its predecessor's errors, and invented new ones, that criticism must dig through repeated strata of corruption on corruption before it can reach the bed-rcck of truth.

Nor is the arc a wide one through which even the processes of criticism which are applicable to these various kinds of writings can librate. The existence of corruptions in a writing can be suggested to us by only two kinds of evidence. One of these is illustrated by our detection of misprints in the books we read or of errors in the letters we receive. 'The most prominent form of it is the evidence of the 
context or general sense; to this is to be added, as of the same generic kind, the evidence of the style, vocabulary or usage of the author, or of the time in which he wrote, and the like,-all the evidence, in a word, that arises from the consideration of what the author is likely to have written. The name that is given to this is internal evidence, and it is the only kind of evidence that is available for an autographic writing, or any other that exists only in a single copy. But if two or more copies are extant, another kind of evidence becomes available. We may compare the copies together, and wherever they differ one or the other testimony is certainly at fault, and critical examination and reconstruction is necessary. This is external evidence. When we proceed from the detection of error to its correction, we remain dependent on these same two kinds of evidenceinternal and external. But internal evidence splits here into two well-marked and independent varieties, much to our help. We may appeal to the evidence of the context or other considerations that rest on the question, What is the author likely to have written? to suggest to us what ought to stand in the placo where a corruption is suspected or known; and this is called intrinsic (internal) evidence. Or we may appeal to the fortunes of reproduction, to the known habits of stone-cutters, copyists, or compositors, to suggest what the rearling or readings known or suspected to be corruptions may have grown out of, or what reading, on the supposition of its originality, will account best for the origin of all others; and this is called transcriptional (internal) evidence. On 
the other hand, we may collate all known copies, and appeal to the evidence that a great majority of them have one reading, and only a few the others; or all the good and careful ones have one, and only the bad the others; or several derived from independent sources have one, and only such as can be shown to come from a single fountain have the others; and so marshal the external evidence. If we allow for their broad and inadequate statement, proper to this summary treatment, we may say that it matters not whether the writing before us be a letter from a friend, or an inscription from Carchemish, or a copy of a morning newspaper, or Shakespeare, or Homer, or the Bible, these and only these are the kinds of evidence applicable. And so far as they are applicable they are valid. It would be absurd to apply them to Homer, and refuse to apply them to Herodotus ; to apply them to Nonius, whose text is proverbially corrupt, and refuse to apply them to the New Testament, the text of which is incomparably correct. It is by their application alone that we know what is corrupt and what is correct; and if it is right to apply them to a secular book, it is right to apply them to a sacred one-nay, it is wrong not to.

It is clear, moreover, that the duty of applying textual criticism-say, for instance, to the New Testament-is entirely independent of the number of errors in its ordinarily current text which criticism may be expected to detect. It is as important to certify ourselves of the correctness of our text as it is to correct it if erroneous; and the former is as much the function of criticism as the latter. Nor is textual 
error to be thought to be commensurable with error in sense. The text conveys the sense; but the textual critic has nothing to do, primarily, with the sense. It is for him to restore the text, and for the interpreter who follows him to reap the new meaning. Divergencies which leave the sense wholly unaffected may be to him very substantial errors. It is even possible that he may find a copy painfully corrupt, from which, nevertheless, precisely the same sense flows as if it had been written with perfect accuracy. It is of the deepest interest, nevertheless, to inquire, even with this purely textual meaning, how much correction the texts of the New Testament in general circulation need before they are restored substantially to their original form. The reply will necessarily vary according to the standard of comparison which we assume. If we take an ordinarily well printed modern book as a standard, the New Testament, in its commonly current text, will appear sorely corrupt. This is due to the different conditions under which an ancient and a modern book come before a modern audience. The repeated proof-correcting by expert readers and author alike in a modern printing-office, as preliminary to the issue of a single copy; the ability to issue thousands of identical copies from the same plates; the opportunities given to correct the plates for new issues, so that each new issue is sure to be an improvement on the last: all this conspires to the attainment of a very high degree of accuracy. But in ancient times each copy was slowly and painfully made, independently of all others; each copy necessarily introduced its own special errors besides 
repeating those of its predecessor; each fresh copy that was called for, instead of being struck off from the old and now newly corrected plates, was made laboriously and erroneously from a previous one, perpetuating its errors, old and new, and introducing still newer ones of its own manufacture. A long line of ancestry gradually grows up behind each copy in such circumstances, and the race gradually but inevitably degenerates, until, after a thousand years or so, the number of fixed errors becomes considerable. When at last the printing press is invented, and the work put through it, not the author's autograph, but the latest manuscript is printer's copy, and no author's eye can overlook the sheets. The best the press can do is measurably to stop the growth of corruption and faithfully to perpetuate all that has already grown. No wonder that the current New Testament text must be adjudged, in comparison with a well printed modern book, extremely corrupt.

On the other hand, if we compare the present state of the New Testament text with that of any other ancient writing, we must render the opposite verdict, and declare it to be marvellously correct. Such has been the care with which the New Testament has been copied,-a care which has doubtless grown out of true reverence for its holy words,- - such has been the providence of God in preserving for His Church in each and every age a competently exact text of the Scriptures, that not only is the New Testament unrivalled among ancient writings in the purity of its text as actually transmitted and kept in use, but also in the abundance of testimony which has come down 
to us for castigating its comparatively infrequent blemishes. The divergence of its current text from the autograph may shock a modern printer of modern books; its wonderful approximation to its autograph is the undisguised envy of every modern reader of ancient books.

When we attempt to state the amount of corruption which the New Testament has suffered in its transmission through two millenniums, absolutely instead of thus relatively, we reach scarcely more intelligible results. Roughly speaking, there have been counted in it some hundred and eighty or two hundred thousand "various readings"-that is, actual variations of reading in existing documents. These are, of course, the result of corruption, and hence the measure of corruption. But we must guard against being misled by this very misleading statement. It is not meant that there are nearly two hundred thousand places in the New Testament where various readings oceur; but only that there are nearly two hundred thousand various readings all told; and in many cases the documents so differ among themsclves that many are counted on a single word. For each document is compared in turn with the one standard, and the number of its divergences ascertained; then these sums are themselves added together, and the result given as the number of actually observed variations. It is obvious that each place where a variation occurs is counted as many times over, not only as distinct variations occur upon it, but also as the same variation oecurs in different manuscripts. This sum includes, moreover, all variations of all 
kinds and in all sources, even those that are singular to a single document of infinitesimal weight as a witness, and even those that affect such very minor matters as the spelling of a word. Dr. Ezra Abbot was accustomed to say that about nineteen-twentieths of them have so little support that, although they are various readings, no one would think of them as rival readings; and nineteen-twentieths of the remainder are of so little importance that their adoption or rejection would cause no appreciable difference in the sense of the passages where they occur. Dr. Hort's way of stating it is that upon about one word in every eight various readings exist supported by sufficient evidence to bid us pause and look at it; that about one word in sixty has various readings upon it supported by such evidence as to render our decision nice and difficult; but that so many of these variations are trivial that only about one word in every thousand has upon it substantial variation supported by such evidence as to call out the efforts of the critic in deciding between the readings.

The great mass of the New Testament, in other words, has been transmitted to us with no, or next to no, variation; and even in the most corrupt form in which it has ever appeared, to use the oft-quoted words of Richard Bentley, "the real text of the sacred writers is competently exact; . . . nor is one article of faith or moral precept either perverted or lost . . . choose as awkwardly as you will, choose the worst by design, out of the whole lump of readings." If, then, we undertake the textual criticism of the New Testament under a sense of duty, we may bring 
it to a conclusion under the inspiration of hope. The autographic text of the New Testament is distinctly within the reach of criticism in so immensely the greater part of the volume, that we cannot despair of restoring to ourselves and the Chiurch of God, His Book, word for word, as He gave it by inspiration tc men.

The following pages are intended as a primary guide to students making their first acquaintance with the art of textual criticism as applied to the New Testament. Their purpose will be subserved if they enable them to make a beginning, and to enter into the study of the text-books on the sulject witl: ease and comfort to themselves. 


\section{CHAP'TER I.}

\section{THE MATTER OF CRITICISM.}

THE first duty of the student who is seeking the 1 true text of the New Testament is obviously to collect and examine the witnesses to that text. Whatever professes to be the Greek New Testament is a witness to its text. Thus we observe that copies of the Greek Testament are our primary witnesses to its text. The first duty of the textual critic is, therefore, to collect the copies of the Greek Testament, and, comparing them together, cull from them all their various readings. He will not only acquire in this way knowledge of the variations that actually exist, but also bring together, by noting the copies that support each reading, the testimony for each, and put himself in a position to arrive at an intelligent conclusion as to the best attested text. It is obvious that no external circumstances, such as the form of the volume in which it is preserved, or the mechanical process by which it is made, whether by printing or by hand-copying, will affect the witness-bearing of a copy to the text it professes to represent. Printed copies of the Greek Testament are per se as valid witnesses to its text as manuscripts; and had we no manuscripts we should not despair of attaining a 
good text from printed copies alone. Nevertheless, the universal consent by which printed copies are set aside and manuscripts alone used as witnesses rests on sound reason. The first printed Greek Testament was completed in 1514, and hence all printed copies are comparatively late copies, and therefore presumptively inferior as witnesses of the original text to the manuscript copies, almost all of which are older than the sixteenth century. Still more to the point: all printed copies have been made from the manuscript copies, and therefore, in the presence of the manuscripts themselves, are mere repeaters of their witness, and of no value at all as additional testimony to the original text. Wherever the printed copies agree with the manuscripts, they have been taken from them, and add nothing to their testimony-they are collusive witnesses; wherever they present readings that are found in no manuscript, this is due either to accidental error, and is therefore of no value as testimony, or to editorial emendation, and represents, therefore, not testimony to what the original New Testament contained, but opinion as to what it must have contained. In no case, therefore, are printed copies available as witnesses, and the manuscript copies alone are treated as such.

Alongside of the manuscripts as the primary witnesses to the New Testament text may be placed, as secondary witnesses, translations of the Greek Testament into other languages. Although a version does not reproduce the text, but only the sense which that text conveys, yet, so far as it is an accurate rendering, we can reason back from the sense conveyed to the 
text that conveys it. No doubt we could not reproduce the text of the New Testament from versions alone, even though we could gain from them the entire sense of the volume. No doubt, too, the ability of a version to witness on special points will depend on the genius of the language into which the Greek has been transmuted. For example, the Latin can seldom testify to the presence or absence of the article. But in conjunction with Greek manuscripts, and when regard is paid to the limitations of the various tongues in which they exist, the testimony of versions may reach even primary importance in the case of all variations that affect the sense. Especially in questions of insertion or omission of sections, clauses, or words, they may give no more uncertain voice than Greek manuscripts themselves.

For use as a witness to the text of the Greek Testament it is absolutely necessary that a version should have been made immediately from the Greek and not from some other version. In the latter case it is a direct witness only to the text of the version from which it was made, and only in case of the loss of that version can it be used as a mediate witness to the Greek text. Furthermore, it is desirable that a version shall have been made sufficiently early for its witness to be borne to the Greek text of a time from which few monuments of it have come down to us. Ordinarily a version is made from the Greek manuscripts in current use at the time, and if this time be so late that we have the manuscripts themselves, the version runs too great risk of delivering simply collusive testimony (like printed copies) to be of much use 
in criticism. The English version, for exanple, although taken immediately fiom the Greek by Tyndale in 1525, and repeatedly revised by the Greek since, is of inappreciable value as a witness to the Greek text, on account of the lateness of its origin. The use to which a version may be put in textual criticism depends still further on the exactness with which it renders the Greek; a slavishness of literal rendering which would greatly lessen its usefulness as a version would give it only additional value as a witness to the Greek text. For example, the Harclean Syriac version, which must have been a trial to the flesh of every Syrian reader who tried to make use of it, reveals its underlying Greek text as perhaps no other ancient version is able to do. Under such safeguards as these, the ancient, immediate versions of the Greek Testament may be ranged alongside of the manuscripts as co-witnesses to its text.

Still additional testimony can be obtained to the text of special passages of the Greek Testament by attending to the quotations made from the Greek Testament by those who have used it or written upon it. Whenever a reputable writer declares that his Greek Testament reads thus, and not thus, for as much of the text as it covers his assertion is equal in value as a witness, to a Greek manuscript of his day. And the ordinary quotations from the Greek Testament by early writers are, so far as they are accurately made, of real worth as testimony to the texts current in their time. As in the case of versions, patristic evidence will vary in value-with the age of the father who makes the quotation, with the accuracy 
with which he ordinarily quotes, and even with the character of the work in which the quotation occurs. For example, a citation in a polemic treatise, bent mayhap to fit the need, will be prima facie less to be depended on, in the minutice of the wording, than a lengthy quotation in a commentary copied out for the express purpose of explaining its very words. So far, however, as this patristic evidence is available at all, and can be depended on, it is direct evidence as distinguished from the indirect character of the evidence of translations, and cannot be neglected without serious loss.

The collection of the evidence for the text of the New Testament includes, thus, the gathering together of all the manuscripts of the Greek Testament, of all the ancient, immediate translations made from it, and of all citations taken from it by early writers; the comparing of all these together and noting of their divergences or "various readings"; and the attaching to each "various reading" the list of witnesses that support it. The labour required for such a task depends, of course, on the wealth of witnassing documents that exist and need examining, or "collating," as it is technically called. If, for instance, we were dealing with the first six books of the "Annals" of Tacitus, the task would be an easy one; there would be but a single manuscript to examine, no version, and before the fifteenth century but a single quotation. In the New Testament, on the other hand, the number of known manuscripts cannot fall below two thousand; at least a dozen early versions must be taken account of and the whole mass of patristic literature must be 
searched for quotations. In the "Annals" of Tacitus, again, as we have but a single manuscript and nothing to collate with it, we should have no various readings at all, while in the New Testament we must needs face, before the work of collation is more than half completed, not less than two hundred thousand; whence it is easy to see, we may remark in passing, that this great number of various readings is not due to greater corruption of the New Testament text than is ordinarily found in ancient writings, but to the immensely greater number of witnessing documents that has come down to us for it, over and above what has reached us for any other ancient work whatever. It is also immediately apparent, however, that no one man and no one generation could hope to bring to completion the task of collecting the various readings of the New Testament with the full evidence for each. As a matter of fact, this work has been performing now, by a succession of diligent and self-denying scholars, since the undertaking of Walton's Polyglot in 1657. Already in Mill's day $(1707)$ as many as 30,000 various readings had been collected; and from Bentley and Wetstein to Tischendorf, Tregelles, and Scrivener, the work has been prosecuted without intermission, until it has now reached relative completeness, and the time is ripe for the estimation of the great mass of evidence that has been gathered. It must not be inferred from this that all the known manuscripts of the New Testament have even yet been collated; only a small minority of the whole number have been accurately examined, much less entirely collated, and every year 
additions are made to the mass of facts already known. But now, at length, enough have been collated to give us knowledge of the general character of the whole, and to place the testimony of all the oldest and most valuable in detail before our eyes. The scholar of to-day, while beckoned on by the example of the great collators of the past to continue the work of gathering material as strength and opportunity may allow, yet enters into a great inheritance of work already done, and is able to undertake the work of textual criticism itself as distinguished from the collecting of material for that work.

The results of the collations that were made befcre the publication of those great works have been collected and spread orderly before the eye of the student in the critical editions of the Greek New Testament edited by Dr. Tregelles and Dr. Tischendorf. With the "digests of readings" given in these works the beginner may well content himself. $\mathrm{He}$ will discover later that such digests have not been framed and printed without some petty errors of detail creeping in, and will learn to correct these and add the results of more recent collations. But he will under. stand more and more fully every year that he prosecutes his studies, what monuments of diligence and painstaking care these digests are, and how indispensable they are for all future work. Every student who purposes to devote any considerable time to the study of this branch of sacred learning should procure at the outset either Dr. Tregelles' The Greek New Testament, edited from Ancient Authorities, with the Various Readings in full, etc. (London, 1857-1879, 
in 4 to parts); or else, and preferably, Dr. Tischendorf's Novum Testamentum Grace ad antiquissimos testes denuo recensuit, etc. Editio octava criticc maior (Leipzig, 1869-1872, 2 vols. 8vo). A "minor" edition of Tischendorf, described as "editio critica minor ex viii. maiore desumpta" (Leipzig, 1877, 1 vol. thick $12 \mathrm{mo}$ ), contains an excellent compressed digest, and will suffice for the needs of those who can ill afford the large edition, or who can put but little time on the study of this subject. One or another of these three editions is, however, little less than a necessary prerequisite for the profitable study of textual criticism.

The compression with which the evidence for the various readings is given in the digests makes the notes of a critical edition appear little less than insoluble enigmas to the uninitiated eye, and renders it necessary to give the beginner some hirits as to their use. Let us take a sample note at random. We open Tischendorf's eighth edition at Mark i. 11, and find

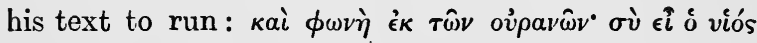

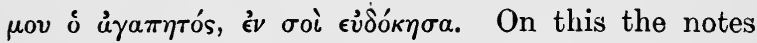
stand as follows :-

"11 $\phi \omega \nu \eta$ cum $\aleph^{*} \mathrm{D} \mathrm{ff}^{2 .}$ mt ... s Ln Ti add $\epsilon \gamma \epsilon \nu \epsilon \tau o$ cum NcABLP unc ${ }^{11}$ al fere omn itpl (sed b de crelo facta est) vg cop syrutr al ; item a venit vox, f vox venit ; $28.2^{\text {pe }}$ gl $^{1 \cdot} \eta \kappa o v \sigma \theta \eta$ post ovp. (:: Mt

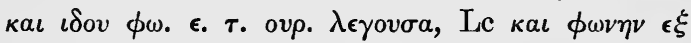
ovp. $\gamma \epsilon v \epsilon \sigma \theta \alpha \iota) \mid \epsilon \nu \sigma o \iota$ (Gb.) cum $\mathrm{BD}^{\mathrm{gr}} \mathrm{LP} \Delta 1.13$. 22. 33. 69 al plus ${ }^{25}$ a c ff ${ }^{2 \cdot}$ (et. $\mathrm{ff}^{1}$ ut $^{\text {vid }}$ ) $\mathrm{g}^{2 \cdot} \mathrm{l}$ vg cop $^{\text {schw }}$ syr $^{\text {sch }}$ etp text arm $^{20}$ æth go ... $s \in \omega$ cum AГI unc $^{8}$ al pl b d (in quem complacui) $\mathrm{g}^{1 \cdot}$ (f 


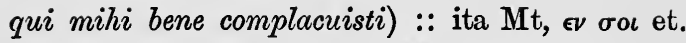

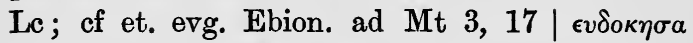

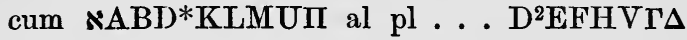

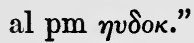

We observe first that the language of the notes is Latin, but that every word is abbreviated which can be abbreviated, and the compression goes so far as to omit even the point which usually stauds at the end of a contracted word. We note next that a vertical line, thus $\mid$, divides between notes on different words; so that there are three separate notes on verse 11 , - one

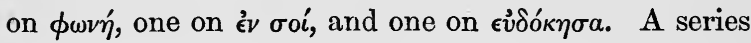
of points, thus ..., marks the transition from the evidence for one reading to that for a rival reading. Next we note that the testimony is cited by means of symbols, either letters or numerals, representing the witnessing documents, the full names of which would extend the note to unmanageable proportions, as well as present so poor a mark for the eye as to double the labour of using the digest. The abbreviations of Latin words as well as all symbols peculiar to this book are explained in a preliminary list prefixed to the volume. With this much of explanation we may manage to read the cypher before us thus:-

" $\phi \omega \nu \eta[$ i.e. without any verb, as the latter half of the note tells us, is read in the text above, in accordance] with [the testimony of the following witnesses, to wit-]." Then follow the symbols of the witnessing documents, two of which in this case (those represented by the two capital letters, $\left.N^{*} D\right)$ are Greek manuscripts; and the other two each a MS. of a Latin version. The break made by the row of points indi- 
cates the passage over to the other side of the evidence, where we read: " $s$ [a conventional symbol, indicating here the editions of the New Testament published by Robert Stephens in 1550 and the Elzevirs in 1624, together with those of Griesbach (1827) and Scholz (1830)], Ln. [i.e. Lachmann's edition, 1842], Ti. [i.e. Tischendorf's earlier edition, 1859, called his seventh]

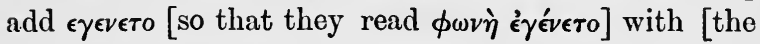
following witnesses, to wit-]". Then again follows the enumeration of the witnesses by symbols. In this case five Greek manuscripts are named, under the symbols, $\aleph^{\bullet}, \mathrm{A}, \mathrm{B}, \mathrm{L}, \mathrm{P}$, with the additional information that "eleven other uncials [i.e. Greek MSS. written throughout in large letters] and nearly all other" Greek MSS. join in this testimony. With the symbol "it $\mathrm{pl}^{\mathrm{pl}}$ the enumeration of the versions commences, this symbol representing the "Itala," or Old Latin version, while the pl tells us that the statement here made holds good of most (plerisque) of its MSS. in opposition to the one cited (under the symbol $\mathrm{fr}^{22}$ ) on the other side. The divergent reading of the Old Latin MS., $b$, is then particularly stated in parentheses, and the enumeration proceeds with the citation of the Vulgate Latin version (vg.), the Coptic version (cop.), both Syriac versions (syr ${ }^{\text {utr }}$ ) and the intimation that other versions yet $(\mathrm{al}=$ aliis $)$ might be added. Next, after a semicolon, more particular quotation is given of peculiar readings which yet appear to make for the insertion of $\epsilon$ $\epsilon$ $\epsilon \tau o$, viz., " Likewise [the Old Latin MS.] a [reads] venit vox, [the Old Latin MS.] f, vox venit." After another semicolon other peculiar readings are given, thus: "[Two Greek MSS. written in 
small letters and cited as] 28. $2^{\text {po }}$, [and one Old Latin

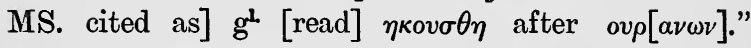
Finally, in parentheses, the parallel passages from Matthew and Luke are given as briefly as possible, and we find ourselves against the perpendicular line which tells us that we are at the end of this note.

The next note concerns the reading ' ${ }^{\nu} \nu \sigma o l$, and tells us :- “ $\epsilon \nu \sigma o \iota$ ([commended also by] Griesbach), [is read above in accordance] with [the testimony of the following uncial manuscripts of the Greek Testament, viz., those cited by the symbols] $\aleph, B, D^{\mathrm{er}}, \mathrm{L}, \mathrm{P}, \Delta$, [and the following, written in small letters, viz., those cited by the symbols] $1,13,22,33,69$, and more than 25 others, [as well as of the following MSS. of the Old Latin version, viz., those cited as] a, $\mathrm{c}, \mathrm{ff}^{2}$, (also [et. = etiam ], apparently $\mathrm{ff}^{\mathbf{L}}$, ) $\mathrm{g}^{2}, \mathrm{l}$, the Vulgate Latin version, the Coptic version according to Schwartze's edition, the Syriac version according to Schaaf's edition [of the Peshitto], the text of the Syrian version according to White's edition [of the Harclean], the Armenian version according to Zohrab's edition, the Ethiopic version, and the Gothic version." At this place we reach the points, and pass over to the reading and evidence on the contrary part:- "Stephens, 1550, Elzevir, 1624, Scholz and Griesbach's text [all this is included in the sign $S$ ] [read] $\epsilon \nu \omega$ with $A, \Gamma, \Pi$, and eight other uncial and most other Greek MSS., [as well as with the Old Latin MSS. cited as] b, d ([which latter reads] in quem complacui), $\mathrm{g}^{\mathbf{L}}$ (f [reads] qui mihi bene complacuisti)." The information is then added that the parallel in Matthew reads $\epsilon v \omega$, while in Luke $\epsilon \boldsymbol{v} \sigma o \iota$ is read, to which is added: "Compare 
also the Ebionite Gospel [as quoted in the note] at Matt. iii. 17," where, sure enough, we find a long quotation from this apocryphal book, taken from Epiphanius.

The third note is briefer, and only tells us:

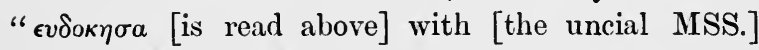

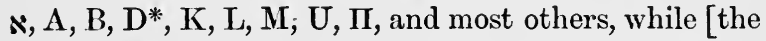
uncial MSS.] $\mathrm{D}^{2}, \mathrm{E}, \mathrm{F}, \mathrm{H}, \mathrm{V}, \mathrm{\Gamma}, \Delta$, and very many

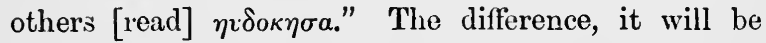
observed, turns on the presence or absence of the augment.

The reader has probably not waded through this explanation of these notes without learning something more than the mere knack of unravelling their contractions and extending their implications. He has learned, doubtless, that there are two classes of Greek manuscripts, the one written in large letters and cited by capital letters as symbols, and the other written in small letters and cited by numerals as symbols. Above all else, however, he is likely to have learned that digests of readings are useless to those who know nothing about the things digested. $\mathrm{He}$ has not read even these few notes without feeling that he must know something about these manuscripts and versions and fathers (for it is a mere chance that no father is quoted on Mark i. 11), if he is to deal with their testimony. We may assume, therefore, that he is the better prepared by a sight of the digest to go with us in our next step, and learn something about our three classes of witnesses. 


\section{Greer Manuscripts of the New Testanent.}

The most astonishing thing about the manuscripts of the New Testament is their great number: as has already been intimated, quite two thousand of them have been catalogued upon the lists, - a number altogether out of proportion to what antiquity has preserved for other ancient books. The oldest of them was written about the middle of the fourth century; the youngest after the New Testament had been put into print. The products of so many ages, they differ among themselves in numerous particulars : the material on which they are written, the character in which they are written, the divisions that have been introduced into the text or indicated on the margin, the punctuation they have received, and the like. The oldest copy that has survived to our day, it will be observed, was made quite two centuries or two centuries and a half after the latest book of the New Testament was given to the world. There can arise no question among them, therefore, as to the autographs of the sacred books. However we may account for it, the autographs disappeared very early; perhaps the brittleness of the papyrus ( 2 John 12) on which they were written and the constant use to which they were put, combined with the evil fortunes of a persecuted Church and a piety which knew nothing of the sacredness of relics, to destroy them very rapidly. At any rate, except in a rhetorical burst of a Tertullian, we hear nothing of them in the primitive Church, and an Irenæus and an Origen were, 
like us of to-day, forced to depend solely on the oldest and most accurate copies.

In attempting to classify this vast mass of material, the first and sharpest line that is drawn concerns itself with the contents of the manuscripts, and separates those which give a continuous text-of whatever extent-from those that contain only the Church lessons drawn from the New Testament. The latter are called "Lectionaries," and number several hundreds, dating from the eighth to the sixteenth and even seventeenth centuries; they form a subordinate class of manuscripts, which will engage our attention at a later point. The continuous manuscripts are much morc numerous, but differ greatly among themselves in the extent of their contents. Only a few contain the whole New 'Testament, and some are small fragments that preserve only a few verses or even words. Most of them, doubtless, never contained the entire New Testament, but were, when complete, manuscripts of one or more of the portions into which the bulkiness of a written copy and the costliness of hand-made volumes caused the New Testament to be divided in early times. This circumstance leads to the apportioning of our extant manuscripts into classes, according to the parts of the New Testament that they contain; and following the indications of the early custom, the New Testament is divided, for critical purposes, into four sections-viz. (1) the Gospels, (2) the Acts and the Catholic Epistles, (3) the Epistles of Paul, and (4) the Apocalypse. The manuscripts for each of these sections are counted separately, and symbols assigned to them inde- 
pendently. It hence happens that when a manuscript contains more than one section it may be represented by different symbols in its several parts, while conversely the same symbol may represent different manuscripts in the several sections. Thus, for example, D in the Gospels is Codex Bezæ, while D in Paul is Codex Claromontanus, a related but entirely different manuscript; B in the Gospels is the Great Codex Vaticanus, the oldest and most valuable of our manuscripts, while $\mathbf{B}$ in the Apocalypse is the late and inferior Codex Vaticanus 2066; on the other hand, $\Delta$ of the Gospels is the same codex as $\mathrm{G}$ in Paul; and 13 of the Acts is the same with 33 of the Gospels and 17 of Paul ; and 69 of the Gospels is the same as 31 of Acts, 37 of Paul, and 14 of the Apocalypse. On the other hand, $\mathbf{N}, \mathbf{A}$, and $\mathrm{C}$ represent the same coulices throughout the four parts, and 1, 3, 5, 6, etc., are the same codices in the Gospels, Acts and Paul. The list for each of the four parts is redacted, in a word, in entire independence of the others; and must be treated independently. The conveniences that arise from this arrangement are manifold; while very small inconvenience results, except when we wish to speak of a manuscript in a context that gives no hint of the portion of the New Testament to which it belongs. Usually it is easy to use its name in such cases; when this is inconvenient, a kind of shorthand method of distinguishing it has been suggested, which consists in placing a small numeral at the bottom (not at the top, liks an exponent, - this means something very different) of the symbol, designating it as the second, third, or fourth manuscript of that symbol in 
the lists, the parts being counted, of course, from the Gospels on. Thus, D without numeral means Codex Bezæ, which contains the Gospels and Acts; and $\mathrm{D}_{2}$ Codex Claromontanus, which contains the Epistles of Paul. In like manner $\mathbf{E}$ means Codex Basiliensis of the Gospels, while $\mathrm{E}_{2}$ means Codex Laudianus 35 of the Acts, and $\mathrm{E}_{3}$ Codex Sangermanensis of Paul. Or again, $B$ is the Great Codex Vaticanus, and includes the Gospels, Acts, and Paul, while $\mathrm{B}_{2}$ is Codex Vaticanus 2066, and contains the Apocalypse. Another method of somewhat more clumsily securing the same result is to place at the top of the symbol an abbreviated indication of the portion of the New Testament in which the manuscript bears this symbol, thus: $\mathrm{B}^{\text {apoc. }}, \mathrm{D}^{\text {erv. act. }}, \mathrm{D}^{\text {paul }}$, and the like. No such distinguishing marks are needed in citing the manuscripts in the direct business of textual criticism, for which purpose their classification and symbolising were invented: the passage that is under discussion determines the section, and the bare symbol is sufficient to identify each manuscript.

Another sharp division line that separates the manuscripts into great and well-marked classes concerns itself with the character or handwriting in which they are written. By this division the manuscripts are parted into two very unequal bodies, called respectively "Uncial MSS." and "Minuscule (or, more improperly and confusingly, "Cursive') MSS." The former includes all those manuscripts, less than a hundred in number, which are written throughout in that kind of half-capital character which is technically known as uncial; they are designated in the 
lists and cited in the digests by the capital letters of the Latin, Greek, and Hebrew alphabets as symbols: A, B, C, D, etc., $\Gamma, \Lambda$, $\Xi, \Pi, \Sigma$, etc., $\aleph$. The latter class includes all other manuscripts, about two thousand in number, all of which are written in a character that more closely resembles the small letters of our ordinarily printed Greek and hence is appropriately called minuscule (or more improperly, cursive); they are designated in the lists and cited in the digests chiefly by Arabic numerals as symbols: 1, 2, 3, 4, 527 , etc. The importance of this classification resides not so much in its great formal convenience as in the fact that it separates the manuscripts according to their age. No known uncial MS. of the continuous text was written later than the tenth century, and no known minuscule (cursive) was written earlier than the ninth; so that the tenth century forms a sharp division line between the two classes. The introduction of the minuscule hand in the ninth century is not only proved by the earliest dated books existing in that hand-viz., Codex 481 of the Gospels, dated 7th May, 835, the Bodleian Euclid, dated 888, and the Bodleian Plato, dated 895-but is oddly illustrated by Codex $\Lambda$ of the Gospels, which comes to us from the ninth century, and is written partly in uncials and partly in minuscules. Nevertheless, few specimens of the minuscule hand of the ninth century exist among manuscripts of the Greek Testament. In the tenth century they become numerous, and in the eleventh they have entirely displaced uncial codices for the continuous text; though the conservatism of ecclesiastical institutions is illustrated by the con- 
tinuance of the uncial hand in use for the lectionaries through the eleventh century, of which age even important dated copies exist. By this classification there are thus set apart from one another the few, old, uncial copies, and the many, late, minuscule copies, and a separate set of symbols assigned to each. Even in the brief digests we may see these two bodies of codices marshalled in separate regiments, as it were, and are enabled to estimate them accordingly at a glance.

The chronological effect of classifying codices by the handwriting employed in them is due to the fact that handwriting, like language and all else human, is subject to gradual change and undergoes historical development, so that its stages of growth mark progressive epochs. In the development of the Greek book-hand three strongly marked stages are to be distinguished,-the stages of Capitals, Uncials, and Minuscules. But contemporary with these book-hands there was also in use, running in parallel development, a current or cursive hand for the more familiar and rapidly written documents of business or private life. And it was this cursive hand that became the real parent of each new book-hand, so that from the cursive capitals grew up the uncial book-hand, and from the cursive uncials the minuscule book-hand. The development was always, thus, the resultant of the co-working of two forces, one pushing towards ease in writing, the other towards ease in reading,- the one securing fluency, the other legibility. Next after these, the most powerful force that affected the development of 
writing seems to have been change in the material on which the writing was wrought. The lapidary capitals, the angular shapes of which were peculiarly suitable to the art of stone-cutting, became graceful, light, curved uncials when written with a pointed reed on the friable substance of the papyrus-paper, which constituted the usual material of books in the centuries immediately preceding and following the commencement of our era. These semi-cursive, rapid and light lines were no sooner transferred to the hard, smooth surface of vellum than they acquired the firmness and regularity which makes the bookhand of our earliest vellum manuscripts (about the fourth century A.D.) the most beautiful known; although it began to degenerate almost as soon as formed, under the temptation which the smooth surface offered to broaden and coarsen the strokes. Once more, so soon as the uncial cursive of common life was transferred from the papyrus of business writings to the vellum of books, it acquired firmness and regularity, and became the beautiful minuscule of the ninth and tenth centuries, - only, however, to enter in its turn on a long course of gradual change and debasement. No Greek writing has come down to us in capitals; they are confined in extant books to titles; superscriptions, and the like. The earliest extant remains of Greek literature and of Greek private writing alike (second century B.c.) present us with truly uncial writing, but with an uncial which is as yet so largely cursive as to hint of a recent origin. The uncials reach their highest beauty, so far as our monuments allow us to trave them, about the fourth century A.D.; and 
the gradual changes which they undergo, the coarsening that came in in the sixth century, the oblong and oval shapes that were introduced together with a sloping writing in the seventh century, and the like, are among the most trustworthy guides of the palæographer in determining the age of a manuscript. In like manner the growth of the minuscule hand is traceable through four marked and many less striking changes that furnish landmarks to the student. The details must be left to works on palæography; and it will suffice for us to have indicated them thus briefly, while we insist only on the broad distinction between the uncials and minuscules as great classes,- the former embracing, in general, the Biblical manuscripts written from the fourth to the tenth century, and the latter those written from the tenth century until the printing-press put a stop to hand-copying altogether.

As has been already hinted, the very material on which a manuscript is written may become of importance as a criterion of its age. It is perhaps certain that the New Testament autographs were written on the paper made from the Egyptian papyrus (cf. 2 John 12), which appears to have been the ordinary literary vehicle of the time. This paper could be manufactured in small sheets only, which were glued together at the side edges into long ribbons, thus forming rolls, and then written upon with a reed pen in short columns running across the roll, a column to each of the original sheets. To "open" such a book was simply to roll up the long ribbon at one end, simultaneously allowing it to unroll at the other; 
thus a long succession of short, narrow columns, corresponding to our pages, would pass before the eye of the reader in a not inconvenient arrangement. This papyrus-book seems to have been in use pretty universally during the first ages of the Christian era, and papyrus continued to be used by Greek scribes as a writing material as late as the ninth century. No very early papyrus manuscripts of the New 'Testament have come down to us ; some meagre fragments of the fifth century containing a few words from 1 Corinthians (cited as Q), and a seventh (?) century fragment of Luke's Gospel, possibly from a lectionary, brought to light by Wessely in 1882, are about all that we have as yet knowledge of, although it is understood that there are more among the Fayûm papyri at Vienna. The columnal arrangement of our oldest New Testament manuscripts on vellum appears to be a reminiscence of the appearance of an open papyrus roll and a witness to a desire to retain on vellum the familiar appearance of a many-columned sheet of papyrus. Codex $\aleph$ has four columns to each page, so that at every opening it offers a view of eight narrow parallel colunins. Codex B has three columns to a page, and several manuscripts have two. When vellum took the place of papyrus as a literary vehicle, the stiffness of the new materiul, which lent itself ill to rolling, necessitated a change in the form of the book, which now became a "codex," or, in other words, assumed the form of bound leaves as in our ordinary bonks. Papyrus leaves are rarely found so bound, and always interleaved with vellum at intervals, to give stability to 


\section{THE' MATTER OF' CRITICISM.}

the whole. Cotton paper made its appearance in the Western world in the eighth century; the first specimen of a New Testament manuscript written on it is a lectionary of the ninth century. It did not, however, become a serious rival of parchment until it was itself largely displaced by rag or linen paper, which was introduced in perhaps the twelfth century, and came into general use in the fourteenth, although parchment was never entirely displaced until after the invention of printing. Occasionally (e.g. Codex Leicestrensis) parchment and paper both enter into the composition of a book.

Throughout the whole history of vellum books the practice more or less prevailed of supplying parchment for new books by washing out the writing from old sheets, which were thus made available for renewed use. So destructive of literary monuments did this occasionally become that it was necessary at the end of the seventh century, for instance, to forbid the destruction of perfect manuscripts of the Scriptures or the Fathers by a synodal decree. The passage of time brings out again, perhaps by a chemical action of the atmosphere, though often very faintly, the lines of the older writing in such twicewritten codices - muless, indeed, the erasure was performed by some such perfect method as rubbing down the softened surface of the vellum itself with pumicestone. Such codices are called " codices rescripti," or "palimpsests," and some of our most valuable texts, classical and Biblical alike, are of this kind. For' example, the precious Codex Ephraemi at Paris, so called because the top (later) writing contains the 
works of Ephrem the Syrian, is a palimpsest of a fifth-century New Testament (cited as C). So also Codex $\mathrm{Z}$ at Dublin consists of some very valuable sixth-century fragments of Matthew peeping out from beneath some patristic writings. $I^{b}, \Xi, R, W^{\text {b. e. f. }}$ are other New Testament examples. The deciphering of such erased writing is a difficult and painful task, even with the assistance of chemical mixtures for bringing out the faint lines.

The difficulty of consulting a manuscript New Testament in the earliest ages was largely increased by the total lack of all those aids to the eye which later editing has gradually invented, and introduced into or attached to the text. The earliest manuscripts, and no doubt the autographs, were written even without divisions between the words. The unbroken succession of letters ran from the beginning to the end of each line, and the division of these letters into words, clauses, sentences, and paragraphs, was left to the good sense of each individual reader. Each book of the New Testament, by this arrangement, stood as a single word, and, at each opening of the papyrus roll or vellum codex, a series of solid columns alone confronted the eye. The difficulty which an untrained eye would find in reading such a text must not be taken as a standard for the readers of that day, but it is obvious that reading was a severer task under such circumstances than it is now. Let the student exercise himself in dividing into its words and clauses the following passage, the line divisions of which are those of Codex Vaticanus (B) :- 


\begin{tabular}{|c|}
\hline APXHTOYEYAГTEAIOY \\
\hline$\overline{I Y X Y Y I O Y \overline{\theta Y} \kappa \Delta \theta \omega C \Gamma \epsilon}$ \\
\hline 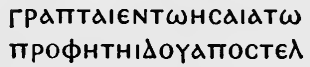 \\
\hline 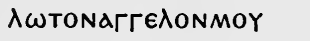 \\
\hline проптосштоҮсоҮос \\
\hline 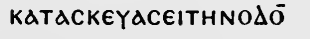 \\
\hline $\operatorname{COY} \phi \omega N H B O \omega N T O C$ \\
\hline
\end{tabular}

We have no means of discovering when editorial care began to be expended in inventing helps to easy reading and introducing them into these unbroken columns. No existing manuscript is wholly without such helps, although the oldest have them rarely and fitfully. Even our oldest manuscript, Codex Vaticanus (B), which comes to us from the early fourth century, occasionally marks a break in the sense by a point at the height of the top of the letter or by a little blank space, and begins a new paragraph now and then by allowing the first letter of the line to project a little beyond the edge of the column. But it has no capital letters, no divisions between the words, no further punctuation, no breathings, no accents. Our next oldest manuscript, Codex Sinaiticus ( $\times)$, which also is as old as the fourth century, allows the letter that begins the new paragraph to stand entirely outside the column, and, like B, has a single point irregularly for punctuation; but it, too, lacks all breathings, accents, further punctuation, and divisions between words. In Codex Alexandrinus (A), of the fifth century; capitals (that is, larger letters than those in the text) occur in the margin at the beginning of paragraphs. In Codex Claro- 
montanus $\left(\mathrm{D}_{2}\right)$, of the sixth century, although the text is continuous, the words are divided in the inscriptions and subscriptions of the several books. Breathings and accents do not occur until later; the latter probably not until the eighth century. Thus gradually the text took upon itself more and more of the helps to easy reading which are now in universal use, until the later minuscules were furnished almost as fully as modern printed copies.

The most interesting attempt of early times to provide a handy edition of the New Testament, account of which has come down to us, was that made by Euthalius, a deacon of Alexandria, who published an edition of the Epistles of Paul in A.D. 458, and, shortly afterwards, a similar edition of the Acts and Catholic Epistles. His editions furnished a complete system of prologues, prefaces, lists of quotations sacred and profane frund in the books, and catalogues of chapters and ecclesiastical lections. In addition to this, the lectior ${ }_{1}$ s and chapters were marked in the margin of the text itself, where also every fiftieth line (or oríxos) was indicated by its appropriate numeral. Whether he also broke up the text into short lines of varied length designed to aid in public reading-each line (called "colon" or " comma") forming a sense-clause -is more doubtful, but appears possible. At all events, it is important that we do not confuse the $\sigma \tau i \chi 0 \iota$, which Euthalius certainly accurately counted and numbered, with the cola or commata with which lie may also have busied himself. Just as the "em" of a modern printing office is a fixed affair and the 
unit of measurement for the work done by the

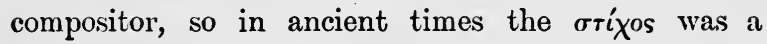
line of set length, according to the number of which included in any writing, in whatever line-lengths it was actually written, the length of the book was estimated and the pay of the scribe calculated. The actual length of the standard Greek oríxos appears to have been that of the average hexameter line; and it is apparent at once that accurately to estimate these and mark every fiftieth one on the margin of New Testament MSS. presented a means of referring to each passage which would be independent of the form of the particular manuscript. The name oríxos was often applied also to the comma ur. colon, which differed from the oríxos, technically so called, not only in having to do with the sense, but also in leing of varied length. It was to the writings of the orators and other books much used in public reading that the colon-writing was first applied. Thence it was taken over into the poetical books of the Old Testament, and Jerome proposed to introduce it into the prophets. Whether Euthalius introduced it. into the New Testament or adopted it into his edition of the New Testament books or not, it first appears ins extant New Testament codices not long after his time. The great examples of it are Codex Bezic (D) of the Gospels and Acts, and its companion, Codex Claromontanus $\left(\mathrm{D}_{2}\right)$ of the Pauline Epistles, as well as $\mathrm{H}_{3}$ of Paul. As these clause-lines varied much in length, the writing in such manuscripts is far from compact, and much vellum is wasted; hence, sometimes these "oríxcı" are divided from one another 
by a point, and the manuscript written solidly. Such a manuscript is $\mathrm{K}$ of the Gospels.

Euthalius is not to be accounted the inventor of the lessons or the chapters which he marked in his editions. He nowhere claims to be their author, and he records two separate schemes of chapter-division in the Acts. When the New Testament was first divided into chapters we have no data for determining. Clement of Alexandria already speaks of pericopes, Tertullian of capitula, and Dionysius of Alexandria of $\kappa \epsilon \phi a ́ \lambda a \iota a$. Our oldest manuscripts already bear them on their margins, and have inherited them from a past older than themselves. For example, the chapters in Codex Vaticanus (B) for Paul's Epistles are numbered consecutively throughout the book, arid although Hebrews stands immediately after 2 Thessalonians in the Codex, the numerals attached to the chapters prove that they were adopted from a manuscript in which Hebrews stood next after Galatians. Again, this same Codex (B) presents two separate systems of chapters for Paul and ths Acts and Catholic Epistles alike, which could scarcely be unless both had been older than it. The most important of the chapter-divisions in the Gospels is that which apparently became the commonly accepted one (found in A, C, N, R, Z, etc.), and which is called the

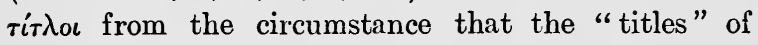
these chapters are gathered into tables at the beginning of each Gospel or written at the top or foot of

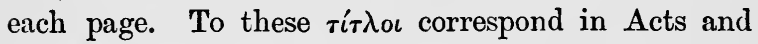
the Epistles the $\kappa \epsilon \phi a ́ \lambda a \iota a$ of Euthalius. A still more interesting division in the Gospels is that which 
goes under the name of the Eusebian (or Ammonian) sections and Eusebian canons, the object of which appears to have been harmonistic. Each Gospel was divided into shorter or longer numbered sections: 355 in Matthew, 233 in Mark, 342 in Luke, and 232 in John. Then ten tables or lists were formed called "canons," the first of which contained all the passages common to all four Gospels; the second, third and fourth those common to any given three; the tifth to the ninth inclusive those common to any two, and the tenth those peculiar to one. By attaching to the number of each section in the margin of the text the number of the list or "canon" to which it belonged, a very complete harmonistic system, or at least system of reference to parallel passages, resulted. Thus, opposite John xv. 20 was written $\stackrel{P \Lambda \Theta}{\Gamma}$ or $\begin{gathered}139 \\ 3\end{gathered}$ whence we learn that this is the 139th section of John, and belongs to the third canon; on turning to the canons, the third is found to contain passages common to John, Matthew, and Luke, and in it, opposite John 139 we find Matthew 90 and Luke 58. It is easy to turn to these sections in the text and read the parallel passages to John 139. Codex A of the fifth century is the oldest codex that preserves this system complete. C, D, and many others, have the sections, but not the canons. Sometimes the harmonistic information is entered on the margin of each page. No codex which has any part of this system at first hand can be older than Eusebius.

The early history of the lections drawn from the Greek Testament is very obscure. At an early period, 
however, it became the custom to mark the beginning and end of each in the margin of continuous copies of the Greek Testament, which were thus redacted for use in public service. This was one of the excellences of Euthalius' editions. The earliest MS. which possesses a table of the lessons prefixed to the text is probably Codex Cyprius (K), of the ninth century ; and the arrangement of such tables for Acts and the Epistles is apparently claimed to himself by Euthalius. Many Greek MSS. after the eighth and ninth centuries mark the beginning of the lections with the word $\dot{\alpha} \rho \chi \eta^{\prime}$ or $\underset{\alpha}{\alpha} \rho$ or $\dot{\alpha} \rho$, and the end with

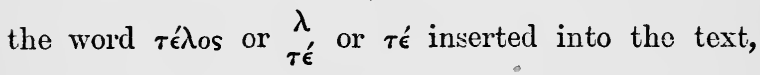
but written in coloured, commonly vermilion ink. It bccame the custom also to insert in the margin rubrics directing the substitution of words for the text as it stood, in the public reading. For example, in Luke x. 24 we read, "And behold a certain lawyer arose," but the margin directs us to read, "A certain lawyer came to Jesus, tempting him and saying : Master," etc. So at Luke x. 22 we are directed to read, "And turning to His disciples, He said." Naturally enough, from these MSS. many erroneous readings crept out of the margin into the text itself. - Codex 7 of the Gospels presents a very perfect specimen of a manuscript redacted for liturgical use.

A glance like this over the origin of the various divisions that have beeil introduced into the New Testament text can scarcely fail to impress tho 
student with the unauthoritative character of them all. Least of all can the ordinary divisions of our modern Bibles into chapters and verses be permitted to affect our free treatment of the text. No one of the ancient divisions found in the manuscripts passed over into modern Bibles. Our chapters were invented apparently by Stephen Langton ( $\$ 1228$ ), and were first applied to the Latin Vulgate, only thence finding their way gradually into the printed Greek Testament. Our verses were made by Robert Stephen "inter equitandum," on a journey from Paris to Geneva, and were first introduced into the Greek Testament published by him in 1551. The inspired text consists of the simple succession of letters, and must be separated into words and sections and paragraphs by each scholar for himself.

No attempt was made to give to the earlier MSS. any further beauty than that which resulted from the use of the best materials and the exquisitely neat and regular writing. The vellum of Codex Sinaiticus (N) is made from the finest antelope skin, and that of $\mathrm{B}, \mathrm{A}, \mathrm{D}_{\hat{i}}, \mathrm{~N}$ is not unworthy of comparison with it; while the regularity and beauty of the hand in which these manuscripts are written challenge the admiration of all beholders. Ornamental capitals and colophons were, however, soon introduced, and red ink was used for variety in them as well as in various rubrics and the like. The most sumptuous of the early manuscripts are the "purple manuscripts," the vellum of which is dyed purple or crimson and the text written upon it in silver and gold. Jerome scoffed at such "éditions de luxe," as possessing mor' 
external splendour than inner excellence. Sereral of the most valuable codices of the Old Latin version (as, e.g., those cited as b, f, e, i), as well as the famous Codex Argenteus of the Gothic version, belong to this class. The purple MSS. of the Greek Testament come mainly from the sixth century: such are $\mathbf{N}, \mathbf{\Sigma}, \Phi$. Of these $\Sigma$ (Codex Rossanensis) is especially noteworthy, inasmuch as it is adorned also with a collection of miniatures, and is the earliest New Testament manuscript so ornamented, and shares this honour with only one other Biblical manuscript, a purple codex of Genesis at Vienna. The art of dyeing MSS. was revived under Charlemagne and his successors, giving us a series of minuscule purples of the ninth and tenth centuries, such as the St. Petersburg codex, lately published by Belsheim, and the second purple codex discovered at Berat by the Abbé Batiffol.

With these preliminaries, we may proceed next to catalogue the Uncial Manuscripts that have come down to us. There have, at the present writing, been placed on the lists some eighty-nine of them all told, which are cited by the following symbols :-

N $\mathrm{A} B \mathrm{~L}^{\mathrm{Apoc}} \mathrm{C} \mathrm{D}^{\mathrm{Evr} . \text { Act. }} \mathrm{D}^{\text {Paul }} \mathrm{E} \mathrm{E}^{\text {Act. }} \mathrm{E}^{\text {Paul }} \mathrm{F} \mathrm{F}^{\text {Pau. }}$ $F^{\text {a. }}$ G $G^{\text {Act. }}\left[G^{\text {Paul }}=\Delta\right] G^{\text {b. }} H H^{\text {Act. }} H^{\text {Paul }}$ I.2.3.4.5.6.7. $I^{\mathrm{b}} \mathrm{K} \quad \mathrm{K}^{\text {Cath. Paul }} \mathrm{L} \mathrm{L}^{\text {Act. Cath. Paul }}$ $M M^{\text {Paul }} \mathrm{N} \quad \mathrm{N}^{\mathrm{a}} \mathrm{N}^{\text {Paul }} \mathrm{O} \mathrm{O}^{\text {2.b.c.d.e.f.g. }} \mathrm{O}^{\text {Paul }}$ $\mathrm{O}^{\text {b. Paul }} \mathrm{P} \mathrm{P}^{\text {Act. Cath. Paul. Apoc. }} \mathrm{Q} \mathrm{Q}^{\text {Paul }} \mathrm{R} \mathrm{R}^{\text {Paul }}$ ${ }^{\star} \mathrm{T} T T^{\text {b.c.d.e.f. }} \mathrm{T}^{\text {woi }} \mathrm{U} \mathrm{V} \mathrm{W}^{\text {a.b.c.d.e.f.g.h. }} \mathrm{X} \mathrm{Y} \mathrm{Z}$ $\Gamma \Delta\left[=G^{\text {Paul }}\right] \Theta^{\text {a b.c.d.e.f.g.h. }} \Lambda \Xi \Pi \Sigma \Phi=89$ separate copies. 
To these should be added another including some words from 1 Tim. vi. 2 and iii. 15, 16, described by Zahn in his Forschungen zur Geschichte des N.I'. Kanons, Theil iii., p. 277, bringing the total up to 90 .

These manuscripts are distributed among the various sections of the New Testament as follows:-

Uncial MSS. of the Gospels :-

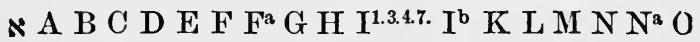

$$
\begin{aligned}
& \mathrm{O}^{\text {a.b.c.d.e.f.g. }} \mathrm{P} \text { Q R S T } \mathrm{T}^{\text {b.c.d.e.f. }} \mathrm{T}^{\mathrm{woi}} \mathrm{U} \mathrm{V}
\end{aligned}
$$

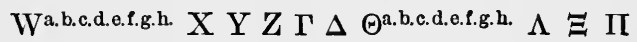

$$
\begin{aligned}
& \text { ऽ } \Phi=67 \text {. }
\end{aligned}
$$

Uncial MSS. of the Acts and Catholic Epistles:-

$$
\begin{aligned}
& \times \mathrm{A} \text { B C D E } \mathrm{F}_{2} \mathrm{~F}_{2} \mathrm{G}^{\mathrm{b}} \mathrm{H}_{2} \mathrm{I}^{2.5 .6} \mathrm{~K}_{2} \mathrm{~L}_{2} \mathrm{P}_{2}=16, \\
& \text { of which } \mathrm{K} \text { does not contain the Acts, and } \\
& \text { only } \times \mathrm{A} \mathrm{B} \mathrm{C} \mathrm{K} \mathrm{K}_{2} \mathrm{~L}_{2} \mathrm{P}_{2} \text { contain the Catholic } \\
& \text { Epistles. }
\end{aligned}
$$

Uncial MSS. of Paul's Epistles:-

$$
\begin{array}{rl}
* \mathrm{~A} & \mathrm{~B} \mathrm{C} \mathrm{D} \mathrm{D}_{2} \mathrm{E}_{3} \mathrm{~F}_{2} \mathrm{~F}^{\mathrm{a}} \mathrm{G}_{3} \mathrm{H}_{3} \mathrm{I}^{2} \mathrm{~K}_{2} \mathrm{~L}_{2} \mathrm{M}_{2} \mathrm{~N}_{2} \mathrm{O}_{2} \\
& \mathrm{O}^{\mathrm{b}}{ }_{2} \mathrm{P}_{2} \mathrm{Q}_{2} \mathrm{R}_{2}=20 \text {, to which Zahn's Codex } \\
& \text { is to be added, making } 21 .
\end{array}
$$

Uncial MSS. of the Apocalypse:-

$$
\sim \mathrm{A} \mathrm{B}_{2} \mathrm{C} \mathrm{P}_{2}=5 \text {. }
$$

They are distributed according to the centuries in which they were written as follows :-

Uncial MSS. of the fourth century :-

$\therefore \mathrm{B}=2$.

Uncial MSS. of the fifth century :-

A C I $I^{1.23 .} \mathrm{I}^{\mathrm{b}} \mathrm{Q} \mathrm{Q}_{2} \mathrm{~T}^{\mathrm{T}}{ }^{\mathrm{wol}}=10$. 
Uncial MSS. of the sixth century :-

$\mathrm{D} \mathrm{D}_{2} \mathrm{E}_{2} \mathrm{H}_{3} \mathrm{I}^{4.7 .} \mathrm{N} \mathrm{N}^{\mathrm{a}} \mathrm{O}_{2} \mathrm{O}_{2} \mathrm{O}^{\mathrm{c}} \mathrm{P} \mathrm{R} \mathrm{T}^{\mathrm{b}} \mathrm{T}^{\text {c.e. }} \mathrm{Z}$ $\Theta^{\text {c.e.f.g. }} \Sigma[\Phi$ and Zahn's Codex ?] $=24$.

Uncial MSS. of the seventh century :$\mathrm{F}^{\mathrm{a}} \mathrm{G}_{2} \mathrm{I}^{\text {5.6. }} \mathrm{O}^{\mathrm{d}} \mathrm{T}^{\mathrm{d}} \Theta^{\mathrm{a} . \mathrm{b} .} \mathrm{R}_{2}=9$.

Uncial MSS. of the eighth century :-

$$
\mathrm{B}_{2} \mathrm{E} \mathrm{L} \mathrm{W} \mathrm{W}^{\mathrm{a} b} \mathrm{Y} \Theta^{\mathrm{d}} \Xi=8 \text {. }
$$

Uncial MSS. of the ninth century :-

$$
\begin{gathered}
\mathrm{E}_{3} \mathrm{~F} \mathrm{~F}_{2} \mathrm{G}^{\mathrm{b}} \mathrm{G}_{3} \mathrm{H}_{2} \mathrm{~K} \mathrm{~K} \mathrm{~K}_{2} \mathrm{~L}_{2} \mathrm{M}_{2} \mathrm{~N}_{2} \mathrm{OO}^{\text {a.e.f.g. }} \mathrm{P}_{2} \\
\mathrm{~T}^{\mathrm{f}} \mathrm{V} \mathrm{W}^{\text {c.d.e.f.g.h. }} \mathrm{X} \Gamma \Delta \Lambda \Pi=31 .
\end{gathered}
$$

Uncial MSS. of the tenth century :$\mathrm{G} \mathrm{H} \mathrm{O} \mathrm{O}^{\mathrm{b}} \mathrm{S} U \mathrm{\Theta}^{\mathrm{a}}=6$.

Very many of these MSS. are the merest fragments. N alone contains the whole New Testament. B contains the whole up to the middle of Hebrews, and thence lacks part of Hebrews, the Pastoral Epistles, Philemon, and the Apocalypse. A contains all but a few chapters. C contains fragments of nearly every book. On the other hand, many manuscripts have received such marginal or other correction by the first or later hands as to give us practically manuscripts within manuscripts. These various hands are usually quoted by numerals, letters, or asterisks placed at the top of the letter symbolising the MS., though these must not be confounded with the compound symbols given in the list above (such as $1^{1.2 .3 .} \mathrm{I}^{\mathrm{b}} \mathrm{N}^{\mathrm{a}} \mathrm{O}^{\text {a.b.c. }}$ etc.), which represent separate fragments classed thus together under one symbol for convenienco' sake. All other signs attached to 
the top of the symbol besides those enumerated in the lists above, represent different hands which have been correcting the manuscript designated by the symbol. Thus $\mathrm{D}^{*} \mathrm{D}^{* *} \mathrm{D}^{* * *}$, or $\mathrm{D}^{*} \mathrm{D}^{2} \mathrm{D}^{3}$, or $D^{*} D^{b} D^{c}$ would be three ways (all of which are in use) of designating $\mathrm{D}$ as originally written $\left(\mathrm{D}^{*}\right)$, and the corrections of the second $\left(\mathrm{D}^{* *}, \mathrm{D}^{2}\right.$, or $\left.\mathrm{D}^{\mathrm{b}}\right)$ and third $\left(\mathrm{D}^{* * *}, \mathrm{D}^{3}\right.$, or $\left.\mathrm{D}^{\mathrm{c}}\right)$ hands. If no hand has corrected the reading the manuscript is cited simply as. $D$; where it is cited as $D^{*}$, this advertises to us that a correction may be looked for elsewhere in the digest. The correctors of our oldest manuscripts, such as B, «, C, are of importance. $\mathrm{B}^{2}$ is of the fourth century; $\mathrm{B}^{3}$ of the tenth or elevert.. $; \mathrm{C}^{2}$ of the sixth; and $\mathrm{C}^{3}$ of the ninth. $N$ has been corrected by very many hands, which are cited by Tischendorf by the following system: $\boldsymbol{N}^{\mathrm{a}}$ is of the fourth century; $\boldsymbol{N}^{\mathbf{b}}$ is of the sixth; four separate correctors of the seventh century are cited as $\aleph^{c}$, $\aleph^{c b}, \aleph^{c c}, \aleph^{c c *} ; \aleph^{\circ}$ is of the twelfth century. How manuscripts came to be furnished with such series of successive corrections may be readily understood if we will only bear in mind the different conditions under which a manuscript came into and continued in being from those governing a printed book. Not unfrequently the fortunate owner of a copy, on obtaining access to another, would compare the two more or less accurately throughout, and enter the differences; and thus (as has happened in the caso of 67 of Paul as compared with $67^{* *}$ ) has given himself on the margin a far better text than his copy contained in itself. 
It would be of interest to add here a brief technical description of each of the MSS. named by symbol above. The beginner may, however, dispense for the time with matter of this sort; and when he feels the need of it, it is better for him to seek it where it can be found in full. The best source of such information is the Prolegomena to Tischendorf's eighth edition, which have been prepared by Dr. Caspar René Gregory, and published by Hinrichs (in Latin) at Leipzig. The most comprehensive treatise of the sort in English is Dr. Scrivener's "Plain Introduction to the Criticism of the New Testament," third edition (Cambridge: Deighton, Bell, \& Co., 1883), in connection with which must be used the little pamphlet, called “Notes on Scrivener's 'Plain Introduction, etc." " chiefly from the memoranda of the late Professor Ezra Abbot, and published by Dr. Thayer (London: Ward, Lock, \& Co.). It will be sufficient here to give a compressed list of the uncial manuscripts.

\section{(1) Uncial MSS. of the Gospels.}

$\aleph$. Sinaiticus, nunc Petropolitanus. Sæc. IV. Contains the whole New Testament.

A. Alexandrinus Londinensis. Sæc. V. Contains the whole New Testament, except Matthew i. 1 to xxv. 6 ; John vi. 50 to viii. 52 ; and 2 Corinthians iv. 13 to xii. 7 .

B. Vaticanus Romæ. Sæc. IV. Contains the whole New Tesiament, except Hebrews ix. 14 to xiii. 25; 1 and 2 Timothy, Titus, Philemon, and the Apocalypse. 
C. Ephraemi Syri rescriptus Parisiensis. Sæc. V. Contains fragments of all the books, except 2 Thessalonians and 2 John.

D. Bezæ Cantabrigiensis. Sæc. VI. Contains the Gospels and Acts, with some small lacunæ.

E. Basiliensis. Sre. VIII. Contains the Gospels with lacunæ.

F. Boreeli Rheno-Traiectinus. Sæc. IX. Contains the Gospels with lacunæ.

Fa. Margo Octateuchi Coisliniani Parisiensis. Sæc. VII. Contains fragments of the Gospels, Acts, and Pauline Epistles.

G. Seidelii Londinensis. Srec. IX. or X. Contains the Gospels with lacunæ.

II. Seidelii Hamburgensis. Sæc. IX. or X. Contains the Gospels with lacune.

I'3.4.7. Petropolitani rescripti. Srec. V., V., VI., VI. Contain fragments of the Gospels.

$I^{b}$. Londinensis rescriptus. Sæc. V. Contains a fragment of John.

K. Cyprius Parisiensis. Sre. IX. Contains the whole of the Gospels.

L. Regius Parisiensis. Srec. VIII. Contains the Gospels with lacunæ.

M. Campianus Parisiensis. Srec. IX. Contains the whole of the Gospels.

N. Purpureus. Sre. VI. Contains fragments of the Gospels.

$N^{a}$. Cairensis. Sxc. VI. Contains fragments of Mark.

O. Moscuensis. Sxc. IX. Contains fragments of John. 
O.b.c.de.f.g. Guelferbytanus, Bodleianus, Veronensis, Turicensis, Sangallensis, Moscuensis, Parisiensis. Sæc. IX., X., VI., VII., IX., IX., IX. Contain the hymns of Luke i. and ii.

P. Guelferbytanus rescriptus. Sæc. VI. Contains fragments of the Gospels.

Q. Guelferbytanus rescriptus. Sæc. V. Contains fragments of Luke and John.

R. Nitriensis, nunc Londinensis, rescriptus. Sæc. VI. Contains fragments of Luke.

S. Vaticanus Romæ. Sæc. X. Contains the Gospels. T. Borgianus Romæ. Sæc. V. Contains fragments of Luke and John.

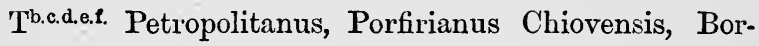
gianus Romæ, Cantabrigiensis, Mellsiæ Horneri. Sæc. VI., VI., VII., VI., IX. Contain small fragments of the Gospels.

Twoi. Woidii. Sæc. V. Contains fragments of Luko and John.

U. Marcianus Venetus. Sæc. IX. or X. Contains the Gospels.

V. Moscuensis. Sæc. IX. Contains the Gospels up to John vii. 39 , with some lacunæ.

Wa.b.c.d.e.f.g.h. Parisiensis, Neapolitanus Borbonicus, Sangallensis, Cantabrigiensis, Oxoniensis et Atho., Oxoniensis, Londinensis, Oxoniensis. Sæc. VIII., VIII., IX., IX., IX., IX., IX., IX. Contain fragments of the Gospels.

X. Monacensis. Sæc. IX. or X. Contains fragments of the Gospels.

Y. Barberinus Romæ. Sæc. VIII. Contains a frag. ment of John. 
Z. Dublinensis rescriptus. Sæc. VI. Contains fragments of Matthew.

I. Tischendorfianus IV. Sxc. IX. or X. Contains the Gospels with lacunr.

$\Delta$. Sangallensis. Sre. IX. or X. Contains the Gospels, except John xix. 17-35.

$\Theta^{a}$. Tischendorfianus Lipsiensis. Src. VII. Contains a fragment of Matthew.

Qb.c.de.f.g.h. Petropolitani et Porfiriani Chiovenses. Sæc. VII., VI., VII. or VIII., VI., VI., VI., IX. or X. Contain fragments of the Gospels.

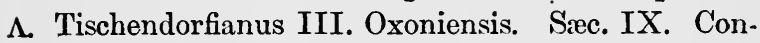
tains Luke and John.

E. Zacynthius Iondinensis. Sac. VIII. Contains fragments of Iuke.

II. Petropolitanus. Srec. IX. Contains the Gospels with lacunæ.

¿. Rossanensis Purpureus. Srec. VI. Contains Matthew and Mark, except Mark xvi. 14-20.

Ф. Beratinus Purpureus. Srec. VI (?). Contains tho Gospels of Matthew and Mark with lacunæ.

(2) Uncial MSS. of the Acts and Catholic Epistles.

N A CD. See under these same symbols for the Gospels.

E. Laudianus Oxoniensis. Sæc. VI. Contains Acts with lacunæ.

$F^{d}$. See under the same symbol for the Gospels.

G. Petropolitanus. Srec. VII. Contains a fragment of Acts.

Gb. Vaticanus Romæ. Sæc. IX (?). Contains fragments of Acts. 
H. Mutinensis. Sæc. IX. Contains Acts with lacuna

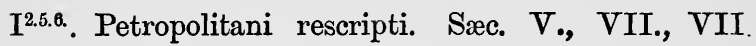
Contain fragments of Acts.

K. Moscuensis. Sæc. IX. Contains Catholic Epistles and Pauline Epistles, with lacunæ in the latter. L. Angelicus Romæ. Sæc. IX. Acts with lacunæ, Catholic Epistles entire, and Paul's Epistles up to Hebrews xiii. 10.

P. Porfirianus Chiovensis. Sæc. IX. Contains Acts, Catholic Epistles, Paul's Epistles, and the Apocalypse, with lacunæ.

(3) Uncial MSS. of the Epistles of Paul.

N A B C. See under the same symbols of the Gospels.

D. Claromontanus Parisiensis. Sæc. VI. Contains the Epistles of Paul.

E. Sangermanensis, nunc Petropolitanus. Sæc. IX. Contains Paul with lacunæ.

F. Augiensis Cantabrigiensis. Sæc. IX. Contains Paul with lacunæ, except Hebrews.

$F^{a}$. See under this symbol in the Gospels.

G. Bœrnerianus Dresdensis. Sæc. IX. Contains Paul with lacunæ, except Hebrews.

H. Parisiensis, Moscuensis, et al. Sæc. VI. Contains fragments of Paul.

I2. Petropolitanus. Sæc. V. Contains fragments of 1 Corinthians and Titus.

K. See under this symbol of Acts and Catholic Epistles.

L. See under this symbol of Acts and Catholic Epistles. 
M. Londinensis et Hamburgensis. Sæc. IX. Contains fragments of 1 and 2 Corinthians and Hebrews.

N. Petropolitanus. Sæc. IX. Contains fragments of Galatians and Hebrews.

O. Petropolitanus. Sæc. VI. Contains a fragment of 2 Corinthians.

$\mathrm{O}^{\mathrm{b}}$. Moscuensis. Sæc. VI. Contains a fragment of Ephesians.

P. See under the same symbol of Acts and Catholic Epistles.

Q. Porfirianus Chiovensis Papyraceus. Sæc. V. Contains fragments of 1 Corinthians.

R. Cryptoferracensis. Sæc. VII. Contains a fragment of 2 Corinthians.

[S ?]. Parisiensis. Sæc. IV.-VI. Contains fragments of 1 Timothy.

(4) Uncial MSS. of the Apocalypse.

N A C. See under the same symbols for the Gospels. B. Vaticanus Romæ. Sæc. VIII. Contains the Apocalypse.

P. See under the same symbol for the Acts and Catholic Epistles.

It ought to be noted that $\mathrm{Wg}^{\mathrm{g}}$ above is given the symbol $\Upsilon$ by Dr. Scrivener; that the symbol $\Phi$ is used by Dr. Scrivener to designate a codex which has been since found to contain no part of the New Testament, and by Gebhardt to designate the reconstructed common parent of the minuscules 13, 69, 
124, 346 ; that $\mathrm{T}^{\mathrm{f}}$ is Dr. Scrivener's Evangelistarium 299 ; that B of the Apoc. is cited by Dr. Tregelles by the symbols $\mathrm{L}$ and $\mathrm{Q}$; and that the symbols $\mathrm{G}_{\mathrm{a}}$, $\mathrm{O}^{\text {a.c.d. }}$ of Tregelles' Supplement represent the codices cited here as $\mathrm{G}_{2}, \mathrm{O}_{2}, \mathrm{R}_{2}, \mathrm{~N}_{2}$, respectively.

The Minuscule MSS. of the New Testament, while far more numerous than the uncials, are later, and therefore, as a class, of less importance. About thirty of them contain the whole New Testament, and many contain more than one section of it. They range in date from the ninth to the sixteenth century inclusive, and present several well-marked types of writing, on the ground of which they are separated by palæographers into at least four classes. They differ in the general character of the text which they exhibit less widely than the extent of time which they cover might lead us to expect. Only about one hundred and fifty of them have as yet been fully cellated, although many more have been partially collated, and enough of this work has been done to give us a general knowledge of them as a class. They are cited for critical purposes, for the most part, by Arabic numerals. Full lists of them, with the information concerning each that has been thus far made public, may be found in the third edition of Dr. Scrivener's "Plain Introduction." The second volume of Dr. Gregory's Prolegomena to Tischendorf, which is to contain an account of the minuscules, is not yet published, but is expected to greatly increase both the extent and the accuracy of our knowledge. 
The following are some of the most interesting of the minuscules :-

(1) Miniscule Codices of the Gospels.

1-118-131-209. Basiliensis, Oxoniensis, Vaticanus, and Venetus. Sxc. X. (?), XIII., XI., XI. or XII. Four closely related codices, the joint authority of which preserves for us an ancient common original.

13-69-124-346. Parisiensis, Leicestrensis, Vindobonensis, and Mediolanus. Sæc. XII., XIV., XII., XII. Four codices which Professors Ferrar and Abbot have shown to be descended from a single not very remote common original. 22. Colbertinus Parisiensis. Sæc. XI.

28. Colbertinus Parisiensis. Srec. XI.

33. Colbertinus Parisiensis. Srec. XI. (= Acts 13, Paul 17).

59. Cantabrigiensis. Sæc. XII. 66. Londinensis. Sæc. XII.

81. Petropolitanus. Sæc. IX. Cited by Tischendorf as $2^{\text {pe }}$.

102. Cantabrigiensis. Sæc. XIV. (= Acts $102\left[\mathrm{k}^{\mathrm{scr}}\right]$, Paul $\left.27\left[\mathrm{k}^{\mathrm{scr}}\right]\right)$. Cited by Tischendorf as $\mathrm{w}^{\text {scr }}$. 157. Urbino-Vaticanus. Sre. XII. 201. Londinensis. Sæc. XIV. (= Acts 91, Paul 104, Apoc. $\left.\mathrm{b}^{\text {scr }}\right)$. Cited sometimes as $\mathrm{m}^{\text {scr }}$ in tho Gospels, and $\mathrm{p}^{\mathrm{scr}}$ in Acts and Paul.

238. Moscuensis. Sæc. XI. 346. Mediolanus. Sxc. XII. 604. Londinensis. Sæc. XI. or XII. 
(2) Minuscule MSS. of the Acts and Catholic Epistles.

13. The same as 33 of the Gospels.

27. Londinensis. Sæc. XV. (= Paul 33).

29. Genevensis. Sæc. XI. or XII. (= Paul 35).

31. Leicestrensis. Sæc. XIV. (= Gospels 69, Paul 37, Apoc. 14).

36. Oxoniensis. Sre. XIII.

40. Alexandrino-Vaticanus. Sæc. XI. (= Paul 46, Apoc. 12).

44. (= Scrivener's 221). Sæc. XII. (= Paul 265).

61. Londinensis. Sæc. XI. Cited also as $10^{\text {ti }}$ and $p^{\text {ser. }}$.

68. Upsal. Sæc. XI. (= Paul 73).

69. Guelferbytanus. Sæc. XIV. (= Paul 74, Apoc. 30).

102. Same as 102 of the Gospels. Cited sometimes as $\mathbf{k}^{\text {ser }}$.

110. Londinensis. Sæc. XII. (= Paul 252). Cited by Tischendorf as $\mathrm{a}^{\text {scr }}$, and Scrivener's 182.

112. Londinensis. Sæc. XV. (= Paul 254). Cited by Tischendorf as $\mathrm{c}^{\text {scr }}$, and Scrivener's 184.

137. Mediolanus. Sæc. XI. (= Paul 176).

(3) Minuscule MSS. of Paul's Epistles.

5. Parisiensis. Sæc. XIl. (= Gospels 5, Acts 5).

6. Parisiensis. Sæc. XI. (= Gospels 6, Acts 6)

17. Same as Gospels 33.

23. Parisiensis. Sæc. XI.

27. Same as Gospels 102 . Cited sometimes as $\mathrm{k}^{\text {ser }}$.

31. Londinensis. Sæc. XI. (= Acts 25, Apo 7! 
37. See under Acts 31.

39. Oxoniensis. Sre. XI. or XII. (= Acts 33).

46. See under Acts 40.

47. Oxoniensis. Sæc. XI. or XII.

67. Vindobonensis. Sæc. XII. (= Acts 66, Apoc. 34). The corrector of this MS., marked $67^{* *}$, is very valuable.

73. See under Acts 68.

80. Vaticanus. Sæc. XI. (= Acts 73).

137. Parisiensis. Sæc. XIII. (= Gospels 263, Acts 117, Apoc. 54).

221. Cantabrigiensis. Sxe. XII. (= Gospəls 447, Acts 111). Cited as $o^{\text {ser }}$ by Tischendorf.

(4) Minuscule MSS. of the Apocalypse.

1. Reuchlini. Srec. XII. The only one used by Erasmus, 1516.

7. See under Paul 31.

14. See under Acts 31.

38. Vaticanus. Sæc. XIII.

47. Dresdensis. Sæc. XI. (= Gospels 241, Acts 140, Paul 120).

51. Parisiensis. Sxc. XIV. (= Gospels 18, Acts 113, Paul 132).

82. Monacensis. Sæc. XI. (= Gospels 179, Paul 128).

95. Parham. Sæc. XII. or XIII. Cited sometimes as $\mathrm{g}^{\mathrm{ser}}$.

The Lectionaries are rightly assigned a secondary place among the MSS. of the New Testament, both because they do not give the continuous text and 
occasionally change the text they do give arbitrarily, to fit it for detached reading, and because they are comparatively late in date. The earliest lectionaries hitherto. known date from the seventh and eighth centuries, although the papyrus fragment which Wessely published in 1882 may come from a century earlier. Lectionaries may be either uncial or minuscule, and uncial writing occurs among them a century later than in manuscripts of the continuous text. No line of division is drawn among them on the ground of handwriting, however, but all are classed together, and cited by Arabic numerals, like minuscule copies of the continuous text. They are divided into two classes on the ground of contents, called Evangeliaria or Evangelistaria (which contain lessons from the Gospels), and Praxapostoli, or sometimes Lectionaria (which contain lessons from the Acts and the Epistles). Dr. Scrivener, in the third edition of his "Plain Introduction," brings the catalogue of the former up to 414, and that of the latter up to 127. A number of them are, however,

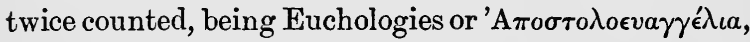

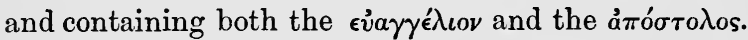
Upwards of eighty of the lectionaries on our lists are written in uncial letters. Lectionaries have hitherto been less used by critics than could be desired. It is not to be hoped, doubtless, that very much material of the first value can be obtained from documents so late, and representing a system of lessons which itself cannot be traced farther back than the latter part of the fourth century. But the results of the little work already expended on 
them are, within the limits of legitimate hope, very encouraging.

\section{Versions of tire New Testament.}

The number and variety of early versions of the New Testament are a matter of wonder second only to the number of Greek MSS. that have come down to us. Wherever Christianity penetrated, the evangelists carried the Divine word in their hands, and gave it to the people in their own tongues; and although the languages in which these early versions were written have now in every case become obsolete, the versions remain to us, sometimes still in use in public worship, sometimes extant only in long-forgotten and fragmentary codices, as witnesses to the popular character of early Christianity, as well as to the text of the New Testament that was read and honoured in the primitive ages of the Church. The value of the testimony of the versions is much enhanced by the fact that several of them were made at an age far earlier than our most ancient MSS. of the Greek text. The Syriac, Latin, and Coptic speaking peoples all had translations of the New Testament in the second century, and fragments at least of these versions are still extant. The Abyssinians and Goths received the New Testament in their own tongues at about the time when our oldest remaining Greek MSS. were penned; at about the same time the older Syriac and Latin versions were revised to suit them to enlarged use and conform them to the texts most esteemed at the time. But little later the Armenians obtained a national Bible, and other 
Syriac revisions or translations were made. The result is that textual science can make use of some dozen ancient versions which are superior, or but little inferior, in point of age, to our best and oldest Greek MSS.

Some of the drawbacks to the use of versions in textual criticism have been mentioned on a previous page: the greatest difficulty yet remains. Before the testimony of a version can be confidently alleged, its own text must be settled, and we must be careful lest we quote, not the testimony of the version itself, but that of some scribe's error as he copied one of its MSS. It is a fact, however, that the text of none of the early versions has as yet been satisfactorily restored; and hence the use of versions hitherto in textual criticism is liable to as much doubt as may result from this circumstance. That this is not as fatal to all successful use of the early versions as it might seem at first sight, will be evident when we consider that the same scribal errors are not likely to occur in the two lines of transmission-that, namely, of the Greek MSS. themselves, and that of MSS. written, say for example, in Syriac. Consequently when MSS. and versions are used together they may correct, to a measurable degree, each other's errors. Nevertheless, the versions were liable, throughout their whole transmission, not only to change and error in the line of their own development, but also to constant correction by contemporary Greek MSS. Often successful appeal may be made from the later or printed text of the versions to their earlier and better MSS. 
It is only a partial escape, however, that we can make from this difficulty, by quoting the various MSS. of a version in the criticism of the Greek text, as it has become the custom to do with the Latin versions. So far as these MSS. vary from one another because of revision by the Greek, each is, no doubt, a witness for a Greek text; but this may be a Greek text of the date of the MS. itself, or of the date of any of its ancestors, back to the very origin of the version. The MSS. of the versions ought primarily to be quoted only for the texts of the versions themselves; and only when their original texts have been reconstructed, and the history of their transmission has been traced out, can their readings and the readings of the various MSS. which profess to represent them be adduced with perfect confidence in the criticism of the Greek text. That the history of the versions has not been wrought out fully in any case, and that a really critical edition of any of them is yet to frame, are circumstances which are not indeed fatal, but are very serious drawbacks to the use of versions in criticism, and little less than an open disgrace to the Biblical science of the day.

A few word: need to be added on the character and, so far as it has been recovered, the history of the chief versions.

(1) Two Latin versions have long been in use in criticism, distinguished by the names of the "Old Latin" (quite commonly but improperly called also the "Itala"), and the "Vulgate," for which Tischendorf uses the abbreviations "It." and "Vg." 
These versions are not, however, two in the sense that they are independent of each other : the Vulgate, so called because it has long been the Latin version in common and ecclesiastical use, was rather a revision of the already existing Latin version, often very slightly altered, and was made by the great Biblical scholar Jerome at the end of the fourth century. The habit of distinguishing sharply between the Vulgate and the Old Latin, while necessary so far, obscures the fact that the text of the Vulgate differs from that of certain of the MSS. cited under the category "Old Latin" far less than the "Old Latin" MSS. differ among themselves. This great diversity among the Old Latin MSS. has necessitated their detailed quotation in the digests of readings for the Greek Testament, and may be observed on almost every page where their witness is borne at all. The MSS. of the Old Latin are designated in the digests by the small letters of the alphabet: thus, a (Codex Vercellensis of the fourth century), b (Codex Veronensis of the fourth or fifth century), c (Codex Colbertinus of the eleventh or twelfth century), $d$ (the Latin part of Codex Bezæ, D, of the sixth century), e (Codex Palatinus of the fourth or fifth century), and the like. There are about thirty-eight separate codices of this class known, of which some twentyfour belong to the Gospels (some such as $a_{2}$.n.o.p.r.s., containing only small fragments), seven to the Acts, four to the Catholic Epistles, nine to Paul, and three to the Apocalypse. The MSS. of the Vulgate are cited by short abbreviations of their names,-thus, am (Codex Amiatinus, of the sixth to ninth century), 
fuld or fu (Codex Fuldensis, of the sixth century), tol (Codex Toletanus, of the eighth century), for (Codex Forojuliensis, of the sixth century), harl (Corlex Harleianus of the seventh century), etc.

Under such circumstances, the tracing of the history of the Latin versions and the formation of critical texts of them has proved so difficult as hitherto to be impossible. This much only has been certain. A Latin version existed as early as the second century. It was already old and established in the use of the people when Tertullian wrote, at the end of the second century, and must, therefore, have been made, in who!e or part, as early as the middle of that century. The complexion of this early version, current in North Africa, is easily observed from the quotations from it made by Tertullian, so far as his quotations from the Latin can be disentangled from those that he took directly from the Greek, and especially from the quotations made from it by Cyprian, who appears to have used it only. The extant MSS. embodying this same type of text can safely be assigned to the African Old Latin. Whether this African New Testament lay at the root of all the Old Latin MISS., or not, has been a disputed question. On the one hand it has been urged that the diversity of the texts is, on this supposition, remarkable. On the other, that their manifold variety, as well as the testimony of Jerome and Augustine alike to the existence in their day of "tot exemplaria penè quot codices," or (as Augustine plirases it) "Latinorum interpretum infinita varietas," is best explained by the great licence of individual. 
correction of a common basis, so that the root was one though the branches were so diverse. In this "interpretum numerositas," Augustine commends a text which he calls the "Itala" as preferable to the others, inasmuch as it was "verborum tenacior cum perspicuitate sententiæ"; and this name has hence been applied to the Old Latin as a whole (against the example of Augustine, who so names a specified type of the Old Latin), or else to some special form of it, more frequently of late to what appears a revision that was current, chiefly in North Italy, in the fourth century. It was under the spur of this confusion of texts that Jerome (about 383) undertook his revision, which won its way at length into the position of a vulgate about the end of the sixth century.

More recent investigations have shed new light on several dark points in this history, and we are now able to trace, at least tentatively, the outlines of the development of the Latin versions in such a way as to give the testimony of its different MSS. a more defined place in textual criticism. It is still uncertain whether one or two parent stocks lie at the base of the Old Latin MSS., but the Old Latin testimony is very distinctly that of two strongly marked types. Their divergence has been obscured by the immense amount of mixture that has taken place between the two as represented even in the earliest codices, as well as by the great licence of individual alteration which has affected all lines of descent. These two versions may be called the African and the European. The former is represented by the fifth- 
century Codex Bobiensis (k), at a later stage of development by the beautiful fourth or fifth century Codex Palatinus (e), and at a still later stage by the Speculum Augustini (m), in the Gospels. To it also belong the palimpsest fragments of the Acts and Apocalypse cited as $\mathrm{h}$, and of course the quotations of Tertullian (when not taken from the Greek), Cyprian, as well as Optatus, and (for the Apocalypse) Primasius. The European is represented by the great mass of the codices, the oldest of which are $a, b, d, f$. The African text is as old as the second century; the age of the European is less certain, but some of its MSS. belong to the fourth century, and the version itself must be as old as the opening of the fourth century or end of the third at the latest. There is good evidence to show that the European Latin was made the object of various revisions during the course of the fourth century, the final product of which may be called the Italian Latin all the more appropriately that it seems to be this text that was preferred by Augustine, if we may judge from the quotations in many of his works. To the unrevised European Latin may be assigned, in the Gospels, Codices a, b, c, ff, h, i, r, and some other fragmentary or mixed texts, and in the Acts g. To the Italian revision belong $\mathrm{f}, \mathrm{q}$, in the Gospels, $\mathrm{r}, \mathrm{r}_{2}, \mathrm{r}_{3}$ in Paul, $q$ in the Catholic Epistles, and perhaps $g$ in the Apocalypse. Jerome's further revision seems to be based on the Italian revision, and in the Gospels on a text very closely related to that of Codex $f$, which, in parts at least, received only a very surface revision.

Instead of two Latin versions, wo thus appear to 
have the testimony of no less than three or four to take account of in textual criticisus: one of the second century-the African; one of the end of the third or beginning of the fourth-the European; a somewhat later revision of the European-the Italian ; and finally, the revision of the Italian which Jerome carried through at the end of the fourth century-the Vulgate.

By attending to the distribution of the codices among the various forms of the Old Latin, as indicated above, some light is thrown on the testimony as drawn out in detail in our digests. We can, not infrequently, separate already the testimony of the several forms, and allow weight to the groups accordingly. A critical edition of even the Vulgate is, however, still a desideratum. The revision of the current texts undertaken by Alcuin in the eighth century, and that ordered by the Council of Trent, had this as their object. But the work has been badly done, and the Clementine Vulgate of 1592 is anything but a critical text.

(2) The early history of the Syriac versions is even more obscure than that of the Latin, but from a different cause. Here we have an almost entire lack of material. The Peshitto version (or as its name imports, the "simple" version) well deserves the title of the Syriac vulgate, since it was the common translation in use among all the Syrian sects throughout the whole of the flourishing epoch of Syrian history, and continues to-day the ecclesiastical version of their heirs. So admirably has its text been guarded, that it remains substantially the same in 
the later MSS. as it stands in the oldest MS. of the Peshitto that has survived to our time (the Codex Additionalis 14459 of the British Museum, fifth century), or even as it is extracted in the quotations of Ephrem of the fourth century. This venerable and most admirable version bears, however, traces of having received the form which it has so long preserved with such well-justified tenacity through a revision which may be dated at some time between A.D. 250 and 350. Accordingly, the considerable fragments of a version of the Gospels which were recovered by Dr. Cureton from one of the MSS. brought by Archdeacon Tattam from the Nitrian desert in 1842, have been recognised by most scholars to contain an older form of the Peshitto. The venerable codex, written about the middle of the fifth century, which contains these fragments is now in the British Museum, while the version itself which it contains is clearly not independent of the Peshitto, and almost equally clearly older than it, and is assigned by most scholars to the second century. Its great age has been oddly confirmed by the discovery of Tatian's "Diatessaron" (a Gospel-harmony of the second century), which is found to be based on this version. How much of the New Testament was included in this oldest Syriac (which is appropriately called from its discoverer, the "Curetonian Syriac") cannot be confidently determined. Fragments of the Gospels only have as yet come to light. The Peshitio, if we confine this name to the form the version took after its late third or early fourth century revision, has never contained the four smaller Catholic Epistles 
(2 Peter, 2 and 3 John, and Jude) or the Apocalypse, it is uncertain whether by inheritance or as a result of a revision of the cancn contemporary with the revision of the text.

A somewhat different reading of the earliest stages of the history of the Syriac versions has been lately commended to scholars by the very careful studies of Baethgen. The dependence of the Peshitto on the Curetonian may be said to be demonstrated by him; but he supposes the Curetonian to be based upon Tatian instead of the source from which he drew, and assigns it to about A.D. 250, while the Peshitto revision is dated by him about the middle of the fourth century. We venture to leave the question of the relation of the Curetonian to Tatian undecided, as not of essential importance for our present purpose. Another Syriac version, not altogether independent of the Peshitto, was made in the early sixth century (A.D. 508) by the Chorepiscopus Polycarp, under the patronage of Philoxenus, Bishop of Mabug or Hierapolis. This version has left very few traces of itself in its original form, though the Gospels of it may have bean recently recovered in a MS. brought to notice by Prof. Isaac H. Hall, and the property of the Beirût Syrian Protestant College. It was subjected to a thorough revision by Thomas of Harkel in 616 , who added to its margin readings from several Greek MSS. belonging to an Alexandrian library, and which prove to be valuable. In this form it has come down to us in numerous MSS. It contains all the New Testament except the Apocalypse, and as its characteristic feature is ex- 
cessive literality, it is everywhere useful as a witness to its underlying Greek text. It goes without saying that its margin presents additional evidence, and is to be taken account of as fully as the text itself.

Yet another Syriac version, and one which may be independent of the Peshitto, has been partially preserved for us-chiefly in some lesson-books. It is assigned by Tischendorf to the fifth century. Its dialect is very peculiar; and as it has been supposed to represent a region lying contiguous to Palestine, the name of Jerusalem Syriac has been given to the version. Besides the lessons from the Gospels, only a few verses from the Acts are known.

The Syrian versions thus include: one from the second century-the Curetonian; a revision of this from the late third or early fourth century-the Peshitto; one from the opening of the sixth century, with its revision early in the seventh-the PhiloxenoHarclean; and one which is doubtingly assigned to the fifth century-the Jerusalem. In Tischendorf's digests these versions are cited as follows: syr $^{\mathrm{cu}}=$ the Curetonian; $\mathrm{syr}^{\mathrm{hr}}=$ the Jerusalem $; \mathrm{syr}^{\mathrm{sch}}=$ the Peshitto according to Schaaf's edition; $\operatorname{syr}^{\mathrm{p}}=$ the Harclean according to the edition of White; syr ${ }^{\text {utr }}$ $=$ both of these last two. Other critics make use of other abbreviations which will be found explained in their editions.

(3) From the early Egyptian Church two independent versions have come down to us, both of which appear to have been made, in part at least, in the second century, and both of which contained the whole New Testament, although treating the Apoca- 
lypse as a sort of appendix to the volume. This last circumstance may hint to us the time when these versions were finished-i.e., in the middle of the third century, when the Apocalypse was brought into dispute in Egypt, as we learn from Dionysius; or it may be the result of speculation taking effect upon an already completed version. Of these two versions, that which was made for use in Lower Egypt appears more faithfully to follow the details of the Greek, and may be a few years the older; it is called, variously, the Memphitic, the Bahiric, or, confusingly appropriating the name that is broad enough to embrace both versions, the Coptic. Tischendorf cites it by the abbreviation "cop." The version that was current in Upper Egypt is known as the Thebaic or Sahidic (cited by Tischendorf by the abbreviation "sah."), and is perhaps more faithful to Egyptian idiom than its sister; only fragments of it have been as yet recovered. Some of the lacunæ in the Thebaic version may be supplied by using a third Coptic version, about 330 verses of which from John and Paul are known, and which is not taken directly from the Greek, but is an adaptation of the Thebaic to another dialect, from which the version itself is known as the Bashmuric or Fayumic (cited by Tschenrlorf by the abbreviation "bash.").

(4) The early history of the Abyssinian Church is very obscure; but its version, the Ethiopic, was certainly made directly from the Greek, and dates probably from the fourth century, although its earliest extant MSS. appear to be as late as the fifteenth century. This version is smooth and flowing, and 
yet faithful, and contains the whole New Testament. From the same age with the Ethiopic comes the Gothic version, made in the middle of the fourth century by the great apostle of the Goths, Ulfilas. IVe possess the Gospels and Paul's Epistles (except Hebrews) with lacunæe, in codices that carry us back as far as the sixth century. The Armenian version, which contains the whole New Testament, was translated from the Greek about A.D. 433, under the patronage of Sahak, the patriarch, and apparently, in part at least, by the hand of Miesrob, the inventor of the Armenian alphabet. The printed editions are good, but not critically satisfactory, and it is necessary frequently to appeal from them to the MSS. To these the Slavonic version, made in the ninth century, may perhaps be added.

If we arrange this list of versions according to age, we cbtain the following series of versions which may be used in textual criticism of the Greek text:-

Versions of the early or middle second century, two, - the African Latin and the Curetonian Syriac.

Versions of the end of the second century, two,-the Memphitic and Thebaic.

Versions of the late third or early fourth century, two,- the Peshitto Syriac and European Latin.

Versions of the middle or late fourth century, four, - the Gothic, the Italian Latin, the Vulgate Latin, and the Ethiopic.

Versions of the fifth century, two,-the Armenian and the Jerusalem Syriac.

Versions of the sixth century, one,- the Philoxenian Syriac. 
Versions of the seventh century, one,- - the Harclean Syriac.

Versions of the ninth century, one,-the Slavonic.

\section{Early Quotations from the New Testament.}

The copiousness of the material to be derived from the quotations of early writers is liable to both overand under-estimation. The whole tone of the writing of the early Christian authors is Scriptural; but it is none the less often very difficult to make use of their allusions in the criticism of the text. Many verses, and some of these such as present important critical problems, are scarcely quoted at all by them. Others are frequently quoted, and in an immense variety of forms. Probably nearly the whole teaching of the New Testament, in one form or another, could be recovered from the writings of the fathers; but this would be too much to say of its text. In addition to the obvious hindrances to their use in textual criticism which have been already pointed out, two require to have especial emphasis laid upon them: the looseness with which the fathers usually quote, and the evil fortune which has attended the transmission of their works to our own day.

A physical cause lies at the bottom of much of the looseness of patristic quotation. There were no handy reference Bibles in those days, no concordances, no indices; and books were dear, and not at all times within reach. For brief quotations memory was necessarily relied on ; and thus the habit of depending on memory fixed itself. Even very long quotations can often be but little trusted in their details, and 
in general it is unsafe to draw from a father a reading which is not supported by some MS. or version, except in those comparatively rare coses in which he tells us that such or such a reading actually stood in codices within his knowledge. And at the very best, it must be carefully borne in mind, that when the reading of a father has been settled, and it is deter. mined that he has actually drawn it from a Greek MS., its value is no more than it was as it stood in the MS. No matter how strongly a father asserts it to be the true reading, or the reading of the best and oldest MSS., it is after all but a MS. reading-of one or more codices according to the evidence in hand, and the value of the further assertions of the father will depend on our estimate of his ability and opportunities to form a critical opinion.

Time has dealt very sorely with patristic writings in general, and with the citations from Scripture contained in them in particular. Scribes and editors have vied with one another in conforming their quotations to the texts current in later times, and not infrequently the text that actually stands written is in conflict with the use made of it in the context. Above all other evidence, the evidence of the fathers needs sifting and critical reconstruction before it can be confidently used. Let us add that the remains of the earliest fathers that survive to our day are the merest fragments of the literature of their age, and in some very important instances have reached us only in Latin or Syriac translations of their original Greek. In this last case a new problen faces the critic: Ilas the translator rendered the Scriptural 
quotations that stood before him in the text, or requoted them from his own version? In the former case the value of the quotations ranks with that of versions of the New Testament; in the latter they are primarily witnesses to a version, and only secondarily, through that version to the testimony of which they add nothing, witnesses to the Greek text. Yet, which process the translator has followed can be settled in each individual instance only by a critical inquiry. In general, it is a safe rule to suspect all quotations in a translation from a Greek father which conform to the national version of the translator.

Of course, Greek fathers alone are direct witnesses to the Greek text. To these are to be added those Latin and Syriac writers who can be proved to have made use of the Greek text. So far as their quotations from the Greek can be sifted out from their quotations from their own versions, these are testimonies that will rank independently alongside of versions, while the rest will be testimonies only to the versions used by them, and through them indirectly to the Greek. The quotations of Latin and Syriac fathers in general are, of course, of this latter sort. Ante-Nicene Greek remains are not very copious. Only for the seventy-five years embraced between A.D. 175 and 250, when we have Irenæus, Hippolytus, Clement of Alexandria, and especially Origen, are we supplied with any abundance of testimony. Methodius later in the third century, and Eusebius early in the fourth, furnish very valuable material ; while Cyril of Alexandria is the most noteworthy writer for critical 
use that the fifth century gires us. The commentaries of the early Church may justly be expected to afford very important material, but unfortunately the commentaries that hare been preserved from the first four hundred years of early Christianity are not numerous. We have Origen's commentaries: on a good part of Matthew partly in the Greek and partiy only in a condensed Latin translation; on a small portion of Luke in Latin; on much of John in the Greek; on Romans in Latin; and on some parts of 1 Corinthians, Ephesians, and some other books. Then we have Theodore of Mopsuestia's commentaries on the lesser Epistles of Paul in a Latin translation, and Chrysostom's homilies on Matthew, John, Acts, and Paul in the Greek. The next century gives us Theodoret on Paul, and Cyril of Alexandria on the Gospels and Paul. And numerous fragments from several authors are preserved in C'utence. The value of such Latin commentaries as that of Primasius on the Apocalypse, or such Syriac ones as that of Ephrem on the Gospels, is wholly with reference to the respective versions on which they are based; from the former nearly the whole of the African Apocalypse has been recovered, and from the latter a considerable knowledge of Tatian's " Diatessaron."

The number of ecclesiastical writers that are catalogued for critical purposes considerably exceeds one hundred. From all of these occasional citations are drawn, but very few of them have been thoroughly put under contribution to critical science. Griesbach pretty thoroughly explored the pages of Origen, and Tregelles did much for Eusebius, and Dean Burgon 
has enlarged our knowledge of patristic citations in many directions. But much yet remains to be done, both in extracting their readings from the writings of the fathers and in testing the readings that now stand in the editions or MSS. by the context, before we can flatter ourselves that the work is much more than well begun. The fathers are cited by abbreviations of their names, and the Latin and Greek evidence is very much jumbled together in the digests. The following brief list of the names that are best worth our attention in the digests is borrowed from Dr. Westcott. The more important fathers are marked by small capitals ; Latin fathers by italics :-

Justinus M., c. 103-168.

IREN $A U S$, c. $120-190$.

Irenai Interpretes [c. 180? or 300 ?].

TERTULLIANUS (Marcion), c. $160-240$.

Clenens Alex., +c. 220.

ORIGENES, 186-253.

Hippolytus.

CYPRIANUS, + 258.

Dionysius Alex., $¥ 26 \tilde{\text {. }}$

Petrus Alex., + 313 .

Methodius, + c. 311 .

Eusebius Casar., $264-$ 340.

Athanasius, 296-373.

Cyrillus Hierosol., 315-38t.

LCCIFER, + 370 .

Ephraem Syrus [Tatianus], +378 .

BASILIUS MAGN US, 329-379.

IIIERONYMUS, 340-420,
Ambrosius, 340-397. Ambrostaster, c. 360 .

Victorinus, c. 360 .

Chrysostomus, 347-407.

Didymus, +396 .

Epiphanius, +402 .

Rufinus, c. $345-410$.

AUgustinus, 354-430.

Theodorus Mops., +429 .

Cyrillus Alex., † 444 .

HILARIUS, + 368 .

Theodoretus, 393-458.

Eutbalius, c. 450 .

Cassiodorus, c. 468-566.

Victor Antiochenus.

Theophylactus [c. 1077].

Andreas(Apoc.), c. 635-700.

Primasius (Apoc.) [c. 550].

Johannes Damascenus, + c.

756.

Ecumenius, c. 950 .

Eutbymius, c. 1100 , 
The student is now in a position to understand better than formerly the notes which we quoted from Tischendorf's digest. Let us take another example, however, and ask: Shall we read in John vii. 8, "I go not up to this feast," or "I go not yet up to this feast"? Tischendorf states the evidence thus :-

ovк cum $\aleph \mathrm{DKMI} 17 * * 389 \mathrm{p}^{\mathrm{scr}}$ a bceff ${ }^{2} \cdot \mathrm{l}^{2}$. vg cop syr ${ }^{\mathrm{cu}}$ arm æeth. Porph ap Hier ${ }^{2.747}$ vallars Epiph $^{447} \mathrm{Chr}^{8.328} \mathrm{Cyr}^{4.401} \ldots . . S(=\mathrm{Gb} \mathrm{Sz}) \mathrm{Ln}$

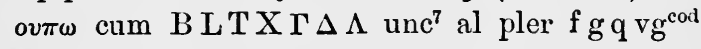
aliq (ap. Ln) go sah $\operatorname{syr}^{\text {sch }}$ etp $\left(\right.$ et $^{\text {nig græc }}$ ) et ${ }^{\text {hr }}$ (Syriace nunc non) Bas Eth 283.

A glance enables the reader to perceive that " not" is read by the uncial copies $N, D, K, M, \Pi$; by the minuscules $17 * *, 389, \mathrm{p}^{\mathrm{ser}}$; by the Old Latin copies $\mathrm{a}, \mathrm{b}, \mathrm{c}, \mathrm{e}, \mathrm{ff}^{2 \cdot}, \mathrm{l}^{2}$, which include both those of the African and those of the European type; by the Vulgate Latin, the Coptic (i.e. the Memphitic), the Curetonian Syriac, the Armenian, and the Ethiopic versions; and by Porphyry as cited by Jerome, Epiphanius, Chrysostom, and Cyril, at the places in their works indicated by the small numerals. On the other side, ovm $\omega$ is read by the editions included under the symbol ऽ-i.e., by Stephens and Elzevir, but not by Griesbach and Scholz (for that is the meaning of "= Gb. Sz."), and also by Lachmann in accordance with the testimony of the uncial copies $\mathrm{B}, \mathrm{L}, \mathrm{T}, \mathrm{X}, \Gamma, \Delta, \Lambda$, and seven others; of most other (i.e. minuscule) MSS.; of the Old Latin codices f, g, q (i.e. the Italian Latin); of MSS. of the Vulgate Latin cited by Lachmann; of the Gothic and Sahidic (= Thebaic) 
versions; of Schaaf's edition of the Syriac (Peshitto), White's edition of the Syriac (Harclean), as well in the Greek margin as in the text, and the Jerusalem Syriac; and of Basil at the place indicated by the numerals.

The student may not yet be in position to decide between the readings with any confidence; but he can, at least, understand now the testimony. He can do more: he can classify it at a glance into its various sorts,-uncials, minuscules, versions, fathers. And he can even analyse it according to age, thus :-

For ovk there are-

Uncial MSS. of the fourth century, one: $\mathbf{\wedge}$.

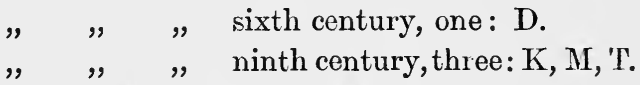

Minuscule MSS., three : $17^{* *}, 389, \mathrm{p}^{\text {scr }}$.

Versions of the second century, two (three): Memph., Syr ${ }^{\text {cu }}$ (Afr. Lat.). " " " fourth century, three: Europ. Lat., Vg., Æth.

Fathers of the late third century, one: Porphyry.
$" \quad$,
fourth century, two: Epiphanius,
Chrysostom.
" $\quad$ fifth century, one: Cyril of Alex- andria.

For $0 v \pi \omega$ there are:-

Uncial MSS. of the fourth century, one: B.

$\quad " \quad, \quad, \quad$ fifth century, one : T.
eighth century, two : I
$\quad$ (and E).


Uncial MSS. of the ninth century, six : $\mathrm{X}, \Gamma, \Delta, \mathrm{L}$ (and F, V).

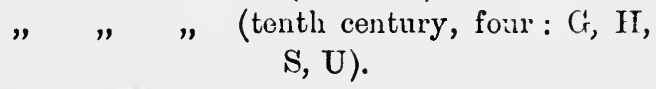

Minuscule MSS., almost all.

Versions of the second century, one: Thebaic.

" " fourth century, four: It. Lat., $\mathrm{Vg}^{\text {cod. aiiq. }}$, Go., Syr ${ }^{\text {sch }}$.

" " fifth century, one: Jerusalem Syriac.

" $\quad$ seventh century, one: Syr.p etms gress.

Fathers of the fourth century, one: Basil.

Such an analysis carries us an appreciable distance towards a decision as to the relative value of the support given to each reading. Yet it falls short of a decision. If numbers of witnesses are to rule, "not yet" must receive the palm; if age is to rule, the division is pretty even between the two; if weight and value of the witnesses is to rule,- - the student is not yet in position to have an opinion. Whence we may learn that it behoves us next to turn from the matter of criticism to its methods-that is, to put this query to ourselves: "How are we to proceed in order to reach a really grounded decision as to tho weight of evidence for each of these two readings?" 


\section{CHAPTER 11.}

TILE METHODS OF CRITICISM.

$T^{\mathrm{T}}$ has been already pointed out that there are but 1 two kinds of evidence to which we can appeal in prosecuting the work of criticising a text,--external and internal evidence. All methods of criticism are, therefore, but various ways of using these kinds of evidence; and when we undertake to investigate the methods of criticism, we simply inquire how we are to proceed in order to reach firm conclusions as to the text by means of internal and external evidence. We have been busied thus far in merely gathering the external testimony, and the reader is doubtless in a position to appreciate how little the mere collection of the testimony has advanced us in deciding on the text. It is our business now to consider how we may attain a grounded decision as to the true text.

\section{Internal Evidence of Readings.}

The most rudimentary method of dealing with the variations that emerge in the collection of the external testimony would be to use the external evidence only to advertise to us the fact of variation and to furnish us with the readings between which choice is to ke made, and then to settle the claims 
of the rival readings on internal grounds. Most crudely performed, this would be to select, out of the readings actually transinitted, that one which seemed to us to make the best sense in the connection, or to account most easily for the origin of the others. It requires no argument to point out the illegitimacy of thus setting aside the external evidence unheard; or the danger of thus staking everything upon our insight into the exact intention of the author or the springs of action that moved men through a millennium and a half of copying, if this insight be exercised extemporaneously, as it were, and without a very severe previous study of the authors and their times and the scribes and their habits. Nevertheless, though all may not be lightly ventured upon its untrained dictum, internal evidence of readings, when carefully investigated, constitutes a most valuable method of criticism, the aid of which we cannot dispense with. It will repay us, therefore, to consider its methods of procedure in some detail.

As has been already intimated, "internal evidence of readings" includes two separate and independent processes. In interrogating any reading as to the evidence that it bears to its own originality, we may make our inquiries with reference to the author, or with reference to the scribes who have transmitted what he wrote; and we may make them in either case absolutely, or relatively to other transmitted readings. We may ask, absolutely, What is the probability that this is the reading that the author would have placed just here? or, relatively, What probability commends this reading, above any of the 
others that have come down to us, as the reading which the author wrote here? Or we may ask what is the probability that this is the reading which the scribes began with, either absolutely-i.e., in the form, Does this reading suggest an earlier one, out of which it was made by the scribes? or relatively to the other transmitted readings-that is, in the form, What is the probability that the other readings have grown out of this one? When dealing absolutely with each reading, we are seeking directly the autographic text. When dealing relatively with each, we are seeking in the first instance only the earliest transmitted text, and leaving it to a further inquiry to determine whether or not this is the autographic text. In either case we are making useof two separate methods of inquiry; one of which deals with the probability that the author wrote this: reading, and the other with the probability that the scribes began with it. The one is appropriately. called Intrinsic Evidence, and the other Transcriptional Evidence.

\section{Intrinsic Evidence.}

By intrinsic evidence is meant the testimony which each reading delivers, by its very nature, to its fitness to stand in the text. It is elicited by actually trying the reading in question in the passage and testing its appropriateness by the contextual argument, the rhetorical flow of the language, the known style and habits of speech and thought of the author, aud the general language and thought-circle of the times and society in which he lived. The danger 
that attends the use of the method grows out of our tendency to read our own standpoint into our author, instead of reading ourselves back into his. It is easy to become an improver instead of remaining a simple editor; and it is often very difficult not to make an author speak our thoughts, if not even our language. It cannot, however, be too strongly insisted upon that any attempt to estimate intrinsic probubilities by the rule of what appears to us to be the best reading is simply an attempt to corrupt the text and train it to festoon the trellises of our own desires. All trustworthy appeal to intrinsic evidence is a delicate historical process by which the critic, having steeped himself in the times of the writer and having assimilated himself to his thought and style, thinks his thoughts and estimates the value and fitness of words with his scales. The reading which would be intrinsically certain in $\mathrm{Mr}$. Carlyle might be intrinsically ridiculous in $\mathrm{Mr}$. Ruskin. The reading that we should commend in Lucian might be unthinkable in Epictetus; that which would be appropriate in Lucretius might be impossible in John. The preparation for a just use of this method of criticism consists, therefore, in a serious and sympathetic study of the author in hand; and without this, all appeal to it is but opening the floodgates to the most abounding error.

Above all other processes of criticism this method requires in its user a fine candour and an incorruptible mental honesty which are content to read from the authors with which they deal only what those authors have put into their words, and which can 
distinguish between what Paul, for instance, says, and what we could wish he had said. Despite what we may have antecedently thought, some writers are ungrammatical, somo are obscure, some are illogical, some are inconsequent, some are frightfully infelicit. ous. And the business of the textual critic is not to correct their grammar, and brighten their obscurities, and perfect their logic, and chasten their style, but to restore their text exactly as they intended to write it, whatever there may be in it to offend our taste or contradict our opinions. Intrinsic evidence in the hands of some critics means nothing else than a ruthless elimination of everything exceptional or even distinctive in an author's style. When $\mathrm{Mr}$. Margoliouth lays it down as a canon for criticising the Attic tragedians that "anything which is difficult or awkward is corrupt," we more than doubt the validity of his methods; and when Mr.McClellan, dealing with the New Testament, states as the "golden canon," that "no reading can possibly be original which contradicts the context of the passage or the tenor of the writing," we recognise the justice of the statement, but desiderate some safeguard that the test shall be applied from the point of sight of the author, and not of the nineteenth-century reader, in whose logical infallibility there may be less reason to believe than in that of the writer who is criticised.

Delicate as the process of intrinsic evidence thus becomes, however, it is yet not only a valuable but also an indispensable agent of criticism, and its verdicts sometimes reach a practical certainty. Whenever it is the expression of careful and sympathetic 
study of an author's thought and style it demands our serious attention, and if, when so used, it distinctly and directly opposes a reading, it may attain a real finality. Cases of this kind, where intrinsic evidenco sets itself immovably against a reading, must be very sharply distinguished from those in which it only adjudges one of several readings to be on the whole preferable to the others. In the former case its verdict has an absoluteness which is wholly lacking to the merely relative result reached in the latter. If the other readings, in this case, any or all of them, would have seemed unexceptionable in the absence of the preferred reading, the preference thrown upon this by intrinsic evidence can carry us but a little way towards settling the text, and raises but a faint presumption against any other form of evidence.

The variation in Matt. vi. 1 may perhaps serve as an illustration of the force of intrinsic evidence when thus simply passing on the comparative appropriateness of two readings. The Authorised English Version reads, "Do not your alms before men," which the Reviscrs change to "Do not your righteousness before men." Which doas intrinsic evidence commend? Unquestionably the latter. Throughout this context our Lord is giving instruction concerning righteousness; and having commanded His disciples in the previous chapter (v. 20,sq.) to sce to it that their righteousness exceeded that of the scribes and Pharisees, and illustrated the command by instancing the laws against murder, adultery, false swearing, and the like, he proceeds now (vi. 1) to guard against an ostentatious righteousness, and, just as before, illus. 
trates His command by instancing certain details,here, almsgiving $(2-4)$, prayer (3-15), and fasting $(16-18)$. To read "righteousness" here is thus far more consonant with the context, and even brings out a connection with the preceding part of the discourse which with the reading "alms" is in danger of bєing overlooked. "Righteousness," moreover, ccmes with a Hebraistic flavour straight from the Old Testament, both in the structure of the phrase, " to do righteousness," and in its use as a genus of which "alms" is a species, and thus is especially suitable in the Hebraistic Matthew. We cannot fail to feel that such considerations create a very substantial corroboration of the testimony of those MSS. which contain "righteousness" here. Nevertheless, if " alms" were strongly pressed upon us by external cridence, this intrinsic evidence would not avail to sct it aside. For although intrinsic evidence decidedly prefers " righteousness" here, it does not distinctly refuse "alms" ; apart from the other reading "alms" would be easily accepted by it, and, hence, if it is otherwise strongly supported, we can receive it as the original reading. Another example of like character is furnished by Luke $\mathrm{xv} .21$, where the variation concerns the insertion or omission of the repetition from verse 19 of the words "Make me as one of thy hired servants." Intrinsic evidence casts its vote for omission. That the son does not carry out his intention of asking to be made a servant after his father had hasted to claim him as a wellbeloved son, is a fine trait; and we hesitate to believe that such true psychology, and such a beautiful turn 
of composition, have entered the narrative only by a slip from the bungling hand of a sleepy scribe. But after all, may it not have done so? If no copy had omitted the words, we should scarcely have thought of doing so; and hence, even here, intrinsic evidence raises a probability only and does not attain certainty. In a word, intrinsic considerations, in all such cases, give evidence, and oft-times very strong evidence, but scarcely such decisive evidence as can withstand the pressure of a strong probability brought from another quarter.

The evidence is more decisive in such a case as that of Acts xii. 25, where to read that Paul and Barnabas returned "to Jerusalem," seems flat in the face of the context, although some relief may be got from an unnatural construction. It is to be observed, howover, that even this result is negative, and in rejecting $\epsilon$ 'is 'I $\epsilon \rho \sigma \sigma \alpha \lambda \eta^{\prime} \mu$ here, intrinsic evidence does not nccessarily cornmend thereby either of its rivals ' $\dot{\xi} \xi$ or ämó: it contents itself with simply refusing the reading offered to it. This may be illustrated further by the variation at $\Lambda$ cts xi. 20 . Intrinsic evidence utterly refuses to have anything here except a reading that gives the sense of $\tilde{\epsilon} \lambda \lambda_{\eta}$ ras ; but again this is negative, and does not amount to a demand for just this word. All that we learn from it is that the author of the book placed here some word which contrasted with the "Jews" of v. 19, and which recorded an advance on the previous practice of the Church, and prepared for distinguishing the Christians from the Jews (xi. 26), and for sending missions to the Gentiles (xiii.) It tells us with great positive- 
ness, therefore, that Greek-speaking Jews were not meant here, but veritable Gentiles. It is perhaps a mistake to spring too rashly to the conclusion, however, that this is equivalent to commending

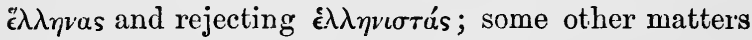

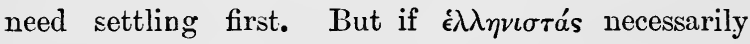
means "Greek-speaking Jews," then this evidence does decisively reject it. And if " ${ }^{\prime} \lambda \lambda \eta v a s$ be otherwise well commended, intrinsic evidence accepts it gladly as furnishing just the thought it desires.

These examples illustrate the nature and the limitations of this method of criticism. It cannot be used idly, and it is very easy to abuse. But when exercised with care, and guided by a sympathetic insight into the literary character of the author under treatment, it is capable of much, and indispensable to the critic. It is chary of giving a positive verdict with too great decision; but it may be safely asserted that no conclusion to which it does not give at least its consent can be accepted as final in any case of textual criticism.

\section{Transcriptional Evidence.}

By transcriptional evidence is meant the testimony which each reading bears to its own origination. It is elicited by comparing together the whole series of claimants to a place in the text, in any given passage, with a view to discovering in what order they must have arisen-that is, which one of them, on the assumption of its originality, will best account for the origin of all the rest, or to what reading the whole body of extant readings points, as their source and fountain. The danger to which this method is 
exposed resides in our liability to come to conclusions on the ground of tendencies to error which we may observe in ourselves, rather than on the ground of the actual tendencies that led astray the scribe; who have transmitted ancient bosks to us. Our only safeguard against this danger is to make preparation for using this method by a thorough study of the character of scribes' work, and of the errors to which they were liabls as exhibited in the actual errors which they have marle. A few hours of careful scrutiny of a series of acknowledged errors actually occurıing in our codices will do more towards fitting us for the excrcise of this nice process than any length of time spent in à priori reasoning. Above all, it must be remembered that in criticising - say, for instance, the text of the New Testament-we are dealing with a writing which has had not one but many scribes successively engaged upon it, and that, therefore, we are to deal with a comp'ex of tendencies which may have been engaged in progressively corrupting a text, and that in even exactly opposite directions. The greatest difficulty of the process is found in experience to reside less, however, in inability to arrange any given series of readings in an order which may wall have been, on known tendencies of scribes, the order of their origination, than in inability to decide which of several orders, in which they seem equally capable of being arranged, is the actual order of their origination. Just because the tendencies to error ran through a very wide range and pulled in divergent directions, it often seems equally easy to account for each rival reading as a 
corruption of some other; and the acute cditor is seldom at a loss to defend the reading which he prefers, by pointing out some way in which the rival readings may have grown out of it. The only remedy against this ever-present danger is a more careful study of the MSS. themselves, and a more rigid exclusion of all undue subjectivity from our judgments. What is difficult is not impossible; and, as experience grows, it is usually discovered that we can with ever-increasing confidence select from a body of readings the one which actually did stand at the root of all the others. Wherever this can be done, transcriptional evidence may be able to deliver a very decided verdict.

A circumstance which appears, at first sight, sufficiently odd, operates to give us especial confidence in the union of transcriptional and intrinsic evidence in the same finding. Just because intrinsic evidence asks after the best reading and transcriptional evidence after the reading that has been altered by the scribes, they are frequently found, at first examination, in apparent conflict. An obviously satisfactory reading is not especially apt to be changed by a scribe; it is often the play of his mind about a reading that puzzles him in one way or another, that distracts his attention from or intrudes his conjecture into his writing. When we ask which is the best reading, therefore, we often select the one which appeared also to the scribe to be the best, and which, when we ask after the original reading, just on this account appears to be a scribe's correction of a less cbviously good or easy reading. Rarely, this contra- 
diction between the two forms of internal evidence is ineradicable. Commonly, howerer, it is only the signal to us that we have carelessly performed our work in the one process or the other, and thus directs us to a further study, and finally to a complete reconciliation of the divergent findings. The reading that seemed to us intrinsically unlikely comes often on deeper study to seem intrinsically certain; or else the reading which seemed at first certainly derivative, comes to be seen to be without doubt original. Whenever these two so easily opposing forms of evidence can be shown to unite heartily and certainly in favour of one reading, they raise a presumption for it that will not yield to any other kind of evidence whatever. But, for precisely the same reason, whenever they seem hopelessiy set in oppcsition to one another, we may with the greatest justice suspect the conclusions at which we have arrived by the one or the other,-perhaps by both.

The very essence of a preparation to engage in criticism by the aid of transcriptional evidence is experience of actual scribes' work. Nothing can quite take the place of familiarity with MSS. themselves. Where this is impossible, facsimiles may form a partial substitute; and even the information given in the digests may be turned to excellent account by the diligent student. Some primary hints of how various readings have arisen in the text, which may serve as a basis for further and more direct :studies, are all that it is possible to set down here.

Considered from the point of view of their effect con the text, various readings are either additions, 
omissions, or substitutions. But such a classification is of small use to the student of transcriptional evidence. What he desires to know is how various readings originate, that he may have some means cf investigating the origin of the readings that come before him. From this point of view, all readings may be broadly classified as intentional and unintentional corruptions. Every change brought into the text is the result either of a conscious and intentional alteration made by the scribe, or of an unintentional and unconscious slip into which he has fallen. Taking the mass of various readings together, a very inconsiderable proportion of them can be attributed to intentional changes, and any detailed classification of them is so far arbitrary that many readings may be equally easily accounted for on two or more hypotheses, and hence may be assigned indifferently to either of two or more classes. With this explanation a rough classification of the sources of error may be ventured, as follows :-

I. Intentional corruptions :

1. Linguistic and rhetorical corrections.

2. Historical corrections.

3. Harmonistic corrections.

4. Doctrinal corruptions.

5. Liturgical corruptions.

II. Unintentional corruptions :

1. Errors of the eye.

2. Errors of the memory.

3. Errors of the judgment.

4. Errors of the pen.

5. Errors of the speech. 
Most of the corruptions which may be fairly classed as intentional fall under the head of linguistic and rhetorical corrections, and were introduced, we may believe, almost always in good faith and under the impression that an error had previously crept into the text and needed correcting. Sometimes they were the work of the scribe himself, sometimes of the official corrector (somewhat analogous to the modern proof-reader) under whose eye the completed MS. passed before it left the "publishing house." Examples may be found in the correction of dialectic forms, such as the rejection of the second aorist termination in $a$, and the substitution of the more common forms-e.g., $\ddot{\eta} \lambda \theta_{0} \mu \epsilon \mathrm{l}, \grave{\eta} \lambda \theta_{\epsilon \tau \epsilon}, \ddot{\eta} \lambda \theta_{o \nu}$ for $\ddot{\eta} \lambda \theta \alpha \mu \epsilon \nu$, $\ddot{\eta} \lambda \theta \alpha \tau \epsilon, \grave{\eta} \lambda \theta \alpha \nu$; the euphonic changes which transform

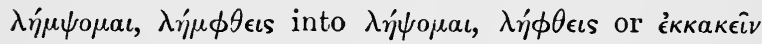

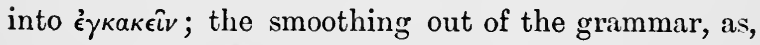
e.g., when in Matt. xv. $32 \dot{\eta} \mu \mu^{\prime} \rho \alpha \iota \tau \rho \epsilon \hat{\text { s }}$ is changed

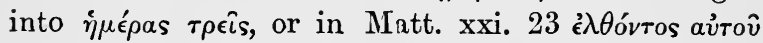

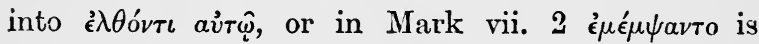
inserted and thereby a difficult sentence rendered easy. Here, too, may be ranged such corrections as the change of the participles $\kappa \rho \dot{u} \xi \alpha s$ and $\sigma \pi \alpha \rho \alpha \dot{\xi} \alpha$ s in Mark ix. 26 into $\kappa \rho \alpha \dot{\xi} \alpha \nu$ and $\sigma \pi \alpha \rho a ́ \xi \alpha \nu$ in order to make them agree grammatically with their neuter noun $\pi v \epsilon \hat{v} \mu \alpha$. Examples of corrections for clearing up historical difficulties may be found in the change of "Isaiah the prophet" into "the prophets" in Mark i. 2 ; of "sixth" into "third" in John xix. 14, and the like. Harmonistic corruptions, though not confined to the Gospels (compare, for example, Acts ix, 5, 6 with xxvi. 14, 15), are, of course, most 
frequent there, and form, whether consciously introduced or unconsciously, one of the most fertile sources of corruption. Familiar examples may be found in the assimilation of the Lord's Prayer as recorded by Luke to the fuller form as recorded by Matthew, and the insertion of "unto repentance" in Matt. ix. 13 from Luke v. 32. Something very similar has often happened to the quotations from the Old Testament, which are enlarged from the Old Testament context or more closely conformed to the LXX. wording. Examples may be found in the

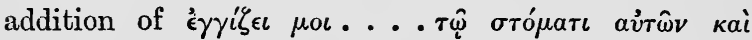
out of Isa. xxix. 13 into Matt. xv. 8, and of ov $\psi \varepsilon v \delta o \mu a \rho \tau v \rho \eta ́ \sigma \epsilon \iota s$ in Rom. xiii. 9. On the other hand, it is doubtful if any doctrinal corruptions can be pointed to with complete confidence. Even the Trinitarian passage in 1 John v. 7 and part of 8 may have innocently got into the text. The most likely instances are the several passages in which fasting is coupled with prayer in some texts-as, e.g., in' [Matt. xvii. 21], Mark ix. 29, Acts x. 30, 1 Cor. vii. 5 ; but even these are doubtful. Liturgical corruptions, on the other hand, are common enotigh, but can seldom be assigned to intention except in the service-books, where they deceive nobody, or in certain MSS. redacted for use as service-books, which have been fitted for public reading by such changes as inserting "And turning to His disciples He said," at Tuke x. 22 (the beginning of a lesson), or of "But the Lord said," at Luke viii. 31, or the change of "His parents" into "Joseph and Mary," at Iuke ii. 41, and the like. 
So long, however, as we are dealing with corruptions which may with some plausibility be classed as intentional, we are on the confines of the subject. The fecund causes of the abounding error that has crept into the text lie rather in the natural weakness of flesh, limiting the powers of exact attention. From each of the sources of error which have been tabulated above as unintentional have sprung many kinds of corruption. Under errors of the eye, for instance, are to be classed all those mistakes, of whatever kind, which have arisen through a simple misreading of the MS. that lay before the copyist to be copied. The ancient mode of writing in continuous lines, and the similarity that existed between some of the letters, facilitated such errors. A considerable body of omissions have arisen from what is called " homœoteleuton " or "like-ending." When two succeeding clauses or words end alike, the last is apt to be omitted in copying; the copyist, having written out the first, glances back at the MS. for the next clause, and, his eye catching the like-ending of the second clause, he mistakes this for what he has just written, and so passes on to the following words, thus omitting the second clause altogether. The same result of ten happens when the same sequence of letters occurs twice near together, and when two consecutivo clauses begin alike instead of ending alike-a case which differs in name rather than in fact from the one just described. An example of "homœoteleuton" may be found at 1 John ii. 23, where the whole clause, "He that confesseth the Son, hath the Father also," is omitted 
in some codices because both it and the preceding

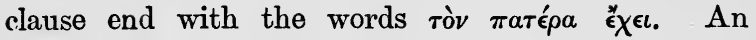
instance in which only a few letters are involved is the omission of $\delta$ 'I $\eta$ rov̂s in Matt. ix. 28, which is apparently due to the custom of writing 'I $\eta \sigma o v$ s in

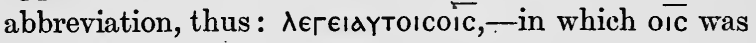
easily mistaken for the preceding orc. Other examples are the omission of the whole verse, Luke xviii. 39, in a few codices, and of a clause in John vi. 39 by $\mathrm{C}$.

Another error of the eye arises from mistaking similar letters for one another, such as, e.g., the confusion of (one way or the other) $\epsilon ı$ and $H$ (Luke xvi. 20, $\epsilon \iota \lambda \kappa \omega \mu \epsilon \nu o s-\eta \lambda \kappa \omega \mu \epsilon \nu \circ$; 2 Cor. xii. $1, \delta \eta-\delta \epsilon \iota)$; $\pi$ and $\mathrm{Tl}$ (John vii. 31, $\mu \eta \pi \lambda \epsilon \iota \nu \nu \alpha-\mu \eta \tau \iota \pi \lambda \epsilon \iota \nu \nu)$;

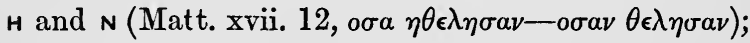
$\theta$ and o (Luke vii. 13, $\epsilon \sigma \pi \lambda \alpha \gamma \chi \nu \iota \sigma \theta \eta-\epsilon \sigma \pi \lambda \alpha \gamma \chi \nu \iota \sigma o \nu)$; $\boldsymbol{Y}$ and $\mathrm{B}(\Delta \alpha \beta \iota \delta-\Delta \alpha v i \delta)$, and the like. Possibly the famous reading $\Theta_{\epsilon}$ s in 1 Tim. iii. 16 may have arisen as an error of the eye whereby oc was mistaken for the abbreviation $\overline{\Theta c}$, which differs from it only by two light lines; although it may have equally well arisen as a strengthening correction or a mere blunder of a scribe, who mechanically added the lines which he had so frequently attached to this pair of symbols. The misreading of abbreviations was also a fertile source of error, and may be classed with errors of the eye. One of the most frequent instances results in the insertion of : 'I $\eta \sigma o v s$ after av่тoîs, by first doubling the orc, and then mistaking it for the abbreviated oic. In like manner we have Kalp $\hat{\varphi}$ in Rom. xii. 11, probably through a misreading 


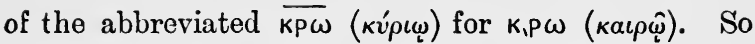

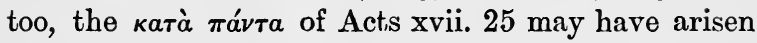

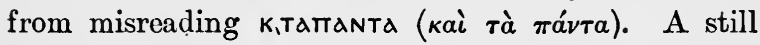
more striking instance is found at Acts xiii. 23, where the abbreviation cPaIN (or cWTHPaIN) has been misread as if it were cPIaN (or CWTHPIaN), and thus $\sigma \omega \tau \hat{\eta} \rho a^{\prime}$ 'I $\eta \sigma o v v$ transmuted into $\sigma \omega \tau \eta \rho i a \nu$. Still another class of errors of the eye arises from the wandering eye taking up and inserting into the text a word or part of a word from a neighbouring line or a neighbouring column. Perhaps the form 'A $\sigma a ́ \phi$ in Matt. i. 7 has so come into the text from the influence of the 'I $\omega \sigma \alpha \phi a$, which stands immediately beneath it. Even whole lines may be omitted or exchanged by a similar slip, and this may be the true account to give of the varied relative position of the clauses in 1 Cor. i. 2. Another error of the eye of somewhat similar kind produces an assimilation of neighbouring tcrminations-as, for example, in Rev. i. 1, where

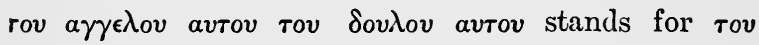

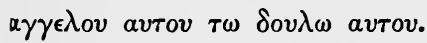

As errors of memory we should class all that brood which seem to have arisen from the copyist holding a clause or sequence of letters in his somewhat treacherous memory between the glance at the MS. to be copied and his writing down what he saw there. Hence the numerous petty changes in the order of words; the substitution of synonyms, as $\epsilon i \pi \epsilon \nu$ for $\check{\epsilon} \phi \eta$ in Matt. xxii. 37, '́ $\kappa$ for a.mó, and the reverse (cf. Acts xii. 25), $\dot{\jmath} \mu \mu a ́ \tau \omega \nu$ for $\dot{\phi} \phi \theta a \lambda \mu \hat{\omega} \nu$ in Matt. ix. 29, and the like; permutation of tenses, as, e.g., $\beta a \pi \tau i \sigma \alpha \nu \tau \epsilon s$

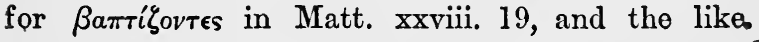


Here, too, belong many of the harmonistic corruptions, and the conformation of quotations from the Old Testament to the LXX. text, the scribe allowing his memory unconsciously to affect his writing.

As errors of the judgment may be classed many misreadings of abbreviations, as also the adoption of marginal glosses into the text, by which much of the most striking corruption which has ever entered the text has been produced. As the margin was used for both corrections and glosses, it must have been often next to impossible for the scribe to decide what to do with a marginal note. Apparently he solved his doubt generally by putting the note into the text. Doubtless this is the account to give of the abundant interpolation that deforms the text of such codices as those cited by the symbol D. More interesting examples are afforded by such explanatory notes as " who walk not according to the flesh but according to the spirit," inserted at Rom. viii. 1, to define "those in Christ Jesus" of the text; or as the account of how it happened that the waters of Bethsaida were healing, inserted at John v. 3, 4. Even more important instances are the pericope of the adulteress inserted at John vii. 53, sq., and the last twelve verses of Mark, both of which appear to be scraps of early writings inserted from the margin, where they had been first written with an illustrative or supplementary purpose. What a sleepy or stupid scribe could do in this direction is illustrated by such

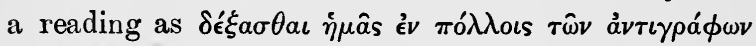

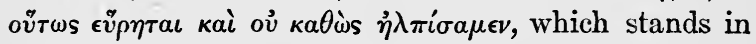
a minuscule copy at 2 Cor. viii. 4,5 . 
Under errors of the pen we class all that great body of variations which seem to be due to a simple careless miswriting of what lay rightly enough in the mind of the scribe at the time, such as, e.g., transpositions, repetitions, petty omissions of letters, and the like. It is impossible to draw any sharp line of demarcation between this class and errors of the cye or memory, and many readings combine more than one slip in their origin. For instance, when in Matt. ix. 15 we read otanap $\theta$ H in Codex D insteul of otaNaTAPOH, we recognise that there has becn confusion of $N$ and $\pi$, and then homœoteleuton at work in omitting $\Delta \pi$ after $\triangle \mathrm{N}$; but the result is simply the omission of two letters. So, in 1 Cor. vii. 34 , when $\mathrm{D}, \mathrm{E}$, omit the second $\kappa$ ai in the sequenco of letters мємєрістаıкаıн, we scarcely know whether to call it simple incuria, or to explain it by homœoteleuton of the ral and kal. On the other hand, when $\mathfrak{N}$ writes eis rà åyıa twice in Heb. ix. 12, or I3

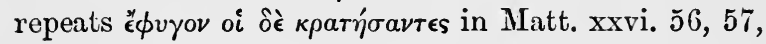
we have before us a simple blunder; and the like is found in every codex. Matters of this kind call for remark only when the slip of the scribe creates a difference in sense which may mislead the reader-as, e.g., when E, M, etc., transform é $\lambda \alpha \beta o v$ in Mark xiv. 65 by a simple transposition of letters into $\dot{\epsilon} \beta \alpha \lambda o v$, and $H$ corrects this into $\epsilon^{*} \beta a \lambda \lambda o v$; or when $H$, by a careless repetition, inserts an article into the

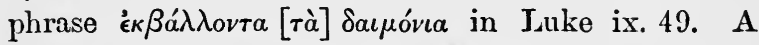
more difficult case occurs at Matt. xxvi. 39, where $\aleph \mathrm{A}, \mathrm{C}, \mathrm{D}$, etc., read חросє $\lambda \theta \omega \mathrm{N}$, but $\mathrm{B}, \mathrm{M}, \Pi$, etc., $\pi p \circ \in \lambda \theta \omega N$; either the former is a careless insertion, 
or the latter a careless omission of c, helped by the neighbourhood of the other round letters $o$ and $\epsilon$.

Finally, by errors of speech we mean all those which have grown out of the habitual forms of speech (in grammar, lexicography, or pronunciation) to which the scribe was accustomed, and which therefore he tended to write. His purism obtruded itself in correcting dialectic forms or Hebraistic turns of speech into accordance with his classical standard. Examples of this have been given under another caption. Sometimes, on the other hand, the idiom would be too elegant for his appreciation, and he would unconsciously conform it to his habitual speech. An instance may be seen in Acts xvi. 3, where

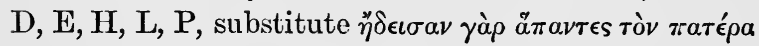

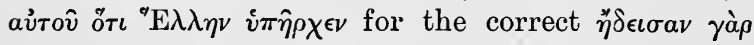

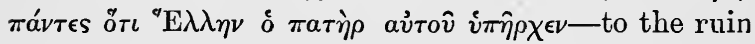
of the proper emphasis. The most considerable body of corruptions of this sort, however, grows out of what is technically called "Itacism," that is, out of that confusion of vowels and diphthongs which was prevalent in pronunciation and could not fail to affect here and there the spelling. It consequently happens that $\iota$ is continually getting written for $\epsilon \iota$ and vice vers $\hat{a}$, and $\alpha \iota$ and $\epsilon ; \eta, \iota$, and $\epsilon \iota ; \eta$, o $\iota$ and $v$; o and $\omega ; \eta$ and $\epsilon$ are confused in the spelling. For determining the age of these confusions of sounds in the speech of the people, we are dependent on epigraphical material, and on its testimony they must be carried back to a very remote antiquity. The confusion of $\epsilon \iota$ and $\iota$, for instance, occurs even in an Attic inscription earlier than 300 B.c., and was already prevalent in other regions 


\section{THE METHODS OF CRITICISM. 103}

bofore that. From the end of the third century it was prevalent everywhere, while in the second century A.D. the distinction between the two was a crux orthographica. At the same time it must be remembered that a standard spelling was current, and carefully written MSS. tried to conform to it; so that we are not surprised to learn that the MSS. differ much among themselves in the amount and in the classes of itacism that have found their way into their pages. For instance, among the papyrus fragments of Homer, those usually cited as $\mathrm{N}$ and $\mathrm{\Sigma}$ are very free from itacism, while $\Omega$ (of the first century B.c.) is full of it. Among New Testament MSS. $\times$ shows a marked preference for the spelling in $\iota$, and $B$ for the spelling in $\epsilon$. Allowance for such particular characteristics must be made in passing judg. ment on readings ; but it must also be borne in mind that all the codices of the New 'Testament were copied at a time when itacistic spelling was current, and hence are more or less untrustworthy when the point is to distinguish between the vowels thus confused. The most common confusions are those between $\epsilon \iota$ and $\iota, \omega$ and $o$, $a \iota$ and $\epsilon$; and after these those between $\eta$ and the two pairs $\iota$ and $\epsilon \iota$, and o The effect of the first may be illustrated by the readings $\epsilon \succsim \delta \epsilon \tau \epsilon$ and $\check{\imath} \delta \epsilon \tau \epsilon$ in Phil. i. 30 , or the

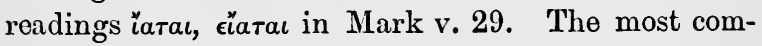
mon effect of the confusion between $o$ and $\omega$ is to confound the indicative and subjunctive moods; the

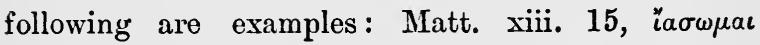

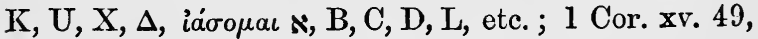
$\phi о \rho \varepsilon ́ \sigma \omega \mu \epsilon \nu \aleph, ~ A, C, D$, etc., форє́́ $\sigma o \mu \epsilon \nu$ B, 46 ; 2 Cor. vii. 1, 


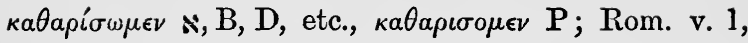

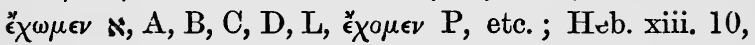

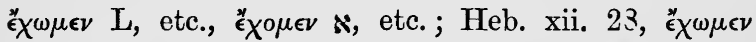
$\mathrm{A}, \mathrm{C}, \mathrm{D}, \mathrm{L}, \stackrel{\mathrm{\epsilon}}{\chi} \propto \mu \in \nu \wedge, \mathrm{K}, \mathrm{P}$, etc. There is nu MS. of the New Testament that does not at times confuse $o$ and $\omega$; consequently, the testimony of every MS. is liable to suspicion on this point, and our decision turns largely on intrinsic evidence. The confusion of $\epsilon$ and aı may produce or remove infinitives-as, e.g., Luke xiv. 17, єै $\rho \chi \epsilon \sigma \theta \epsilon 13,346$ Latt.,

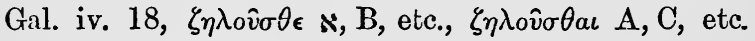
Occasionally also it transforms a word into another-

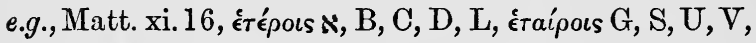
etc. In $i \mu \epsilon \nu$ and $\eta \mu \eta \nu$ Acts xi. 11, $\epsilon$ and $\eta$ are confused.

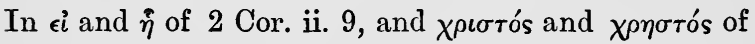
1 Peter ii. 3 , we have instances of the triad $\eta, \epsilon \iota, \iota$. The frequent confusion of the pronouns $\dot{\eta} \mu \epsilon \hat{s}$ and $\dot{v} \mu \in \hat{i}$ s in their various cases is an example of $\eta, o, v$. Even $\alpha$ and $\epsilon$ seem occasionally to pass into one another-

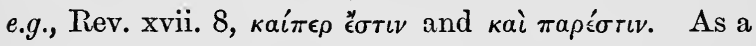
connected specimen of itacistic writing we add a part of the closing prayer of a certain John of Constantinople, who wrote a psalter now at Cues : $\sigma o \sigma o v \mu \epsilon$

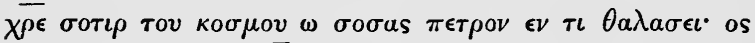
$\epsilon \kappa \iota v o v \mu \epsilon \delta_{\iota \alpha \sigma o \sigma o v}$ o $\bar{\theta}_{S} \kappa a \iota \epsilon \lambda \epsilon \iota \sigma o v \mu a \iota$. Let the student exercise his ingenuity in restoring this to the ordinary spelling of a Greek, which will translate: "Save me, O Christ, Saviour of the world, who didst save Peter in the sea; like him save me entirely, $O$ God, and have mercy on me." This was written in the ninth or tenth century.

These instances are probably enongh to illustrate 


\section{THE METHODS OF CRITICISM. 105}

the way in which, even by the most honest copying, the text of any document may become corrupt; and to serve as examples of the kind of facts with which the student must have a personal familiarity in order to be prepared to trace back a reading to its source in a scribe's error, or to classify a body of readings according to their origination. It is important for him next to obtain an intimate knowledge of the habits, so to speak, of the important individual MSS. in order to check by familiarity with the habits of the one scribe the conclusions that are reached from a study of tho general habits of all scribes. A fact in point has been already mentioned: $\wedge$ tends to write $\iota$ everywhere for $\epsilon \iota$, and B to write $\epsilon \iota$ everywhere for $\iota$, and a knowledge of this fact is a help in determining readings involving $\epsilon \iota$ and $\iota$, for which these codices are sponsors. That A loves synonyms, or in other words the scribe that wrote this codex had an active mind that worked as he copied, and so felt the sense of what he wrote more than most scribes, is an important fact to know when we are deciding on the probability of a synonymous reading that A supports. That the scribe of $N$ was a rapid penman, proud apparently of his handwriting; and that B's scribe was on the contrary a careful, plodding fellow, who copied the text before him with only such petty slips as such a writer would fall into,-brief omissions, doubling of short words, repetitions of letters and such stupidities,- - these and such facts enable us to pass ready judgment on variations which might otherwise somewhat puzzle us.

Above all, however, it is necessiry to remember 
that every attempt to account for the errors that occur in our MSS. is an attempt to bring the accidental under rule, and every effort to classify them according to their sources is only an effort to group the effects of human carelessness; so that much must remain over of which we can only speak as instances of incuria. It may be useful to the student to look at a brief list of slips of the scribe of $\kappa$, gleaned from the digest of the Epistle to the Hebrews, and to consider how many of them can be assigned to the several classes mentioned above :-

Incuria of $\boldsymbol{\kappa}$ in Hebrews.

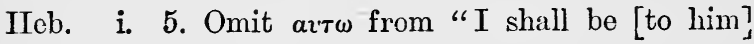
for a father."

99

9

,

:

,

9

9

,9

9

,

9)

,

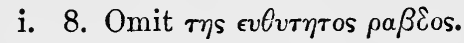

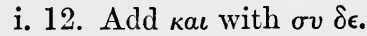

ii. 18. Omit $\pi \epsilon \iota \rho a \sigma \theta \epsilon \iota s$.

iv. 9. Omit the whole verso.

iv. 11. Omit $\tau \iota s$.

viii. 3. Omit кal.

viii. 10. Mov for $\mu$.

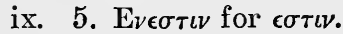

ix. 12. Eıs $\tau a$ a $\gamma \iota \alpha$ written twice.

x. 7. Omit $\eta \kappa \omega$.

x. 11. Order changed to $\lambda \epsilon \iota \tau$. $\kappa u \theta . \eta \mu \epsilon \rho$.

x. 26. T $\eta \varsigma \epsilon \pi \iota \gamma \nu^{\prime} \omega \sigma \iota \alpha \nu$ for $\tau \eta \nu \epsilon \pi \iota \gamma \nu \omega \sigma \iota \nu$.

х. 32. A $\mu \alpha \rho \tau \iota a s$ for $\eta \mu \epsilon \rho a s$.

$\mathrm{x} .3 \mathrm{~b}$. Change of order to $\chi \rho \epsilon \iota \alpha \nu \in \chi \epsilon \tau \epsilon$.

x. 39. Eıs $\alpha \pi \omega \lambda_{\iota} a s$ for $\epsilon \iota s a \pi \omega \lambda \epsilon \iota \alpha \nu$.

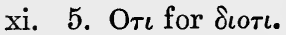

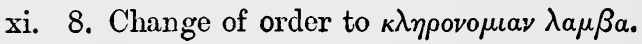


IIeb. xi. 9. Omit $\tau \eta s$ after $\epsilon \pi \alpha \gamma \gamma \epsilon \lambda \iota u s$.

", xi. 20. Omit Iбаaк.

" xi. 31. Insert $\epsilon \pi \iota \lambda \epsilon \gamma \circ \mu \epsilon \nu \eta$ before $\pi$ \% $\nu \eta \eta$.

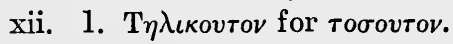

xii. 10. O $\mu \epsilon \nu$ for $o \iota \mu \epsilon \nu$.

xiii. 2. T $\eta \nu \phi \iota \lambda \circ \xi \epsilon \nu \iota v$ for $\tau \eta s \phi \iota \lambda \circ \xi \bullet$

xiii. 12. Omit $\epsilon \pi a \theta \epsilon \nu$.

ง9

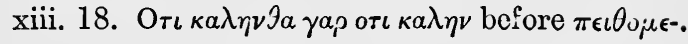

xiii. 22. Omit $\gamma a \rho$.

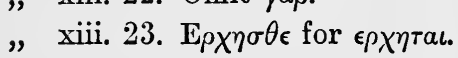

There are in this list instances of errors of the eye (homœoteleuton, the wandering eye catching a neighbouring word, confusion of similar letters), of the memory, of the judgment, of the pen, and of the speech,-and others also. It looks as if the scribe were taking a sly nap when he was writing the tenth chapter, and as if he either nodded again or was interrupted by an unthinking chatterer at xiii. 18, where, at least, we find a very odd case of repetition.

Efforts hive been made to generalise upon the phenomena of the various readings, and so to furnish "canons of criticism" for the guidance of the student. Transcriptional evidence cannot, however, be reduced to stiff rules of prccedure. All "canons of criticism" are only general averages, and operate like a probability based on a calculation of chances. A "chance" is always open that this particular instance is one of the exceptions. But, although to use them as strict rules to square our conclusions by were but to invite error, general rules are re:y useful, as succinctly embodying the results of broad observation. 
If we use them only as general gu:des, and expect to find exceptions to them continually turning up, the following three rules are valuable:-

1. The more difficult reading is to be preferred: founded on the observed tendency of scribes to render the sense smooth by correction or unconscious tinkering.

2. The shorter reading is to be preferred: founded on the observed habit of scribes to enlarge rather than shorten the text.

3 . The more characteristic reading is to be preferred: founded on the observed tendency of scribes to reduce all they touch to their own level, and so gradually eliminate everything especially characteristic of an author.

Not co-ordinate with these, but above them and inclusive of them, stands the one great rule that embodies the soul of transcriptional evidence: that reading is to be preferred from which the origin of all the others can most safely be derived. Knowledge of the habits of scribes and of the phenomena of MSS. is needed to interpret this rule. Commonsense is here even more than usually needed. But given the knowledge and common-sense, this one rule adequately furnishes the worker in this department of evidence.

That much could be done towards settling the text of any work by the use of intrinsic and transcriptional evidence alone, which would be generally recognised as sound, is certain. But it is equally clear that a special danger attends processes that are so nice and 
delicate, of the intrusion of those wishes that are fathers to thoughts; and in criticising the tex $\mathrm{t}$ of a book that stands in such close relation to our dearest beliefs as the New Testament, this danger reaches its maximum. This does not render the method of internal evidence of readings invalid; nor does it exonerate critics from the duty of using it,-with strict honesty and a severe exclusion of improper subjectivity. But it throws sufficient doubt on individual judgment in attaining some of its results, to render it desirable to test its conclusions by some less easily warped method of investigation. We gladly remember, then, that besides "internal evidence of readings" we have "external evidence of readings" to depend on, and proceed to inquire after the methods of using it.

\section{External Evidence of Readings.}

(a) Comparative Criticism and Internal Evidense of Documents.

The crudest method $1 \mathrm{~h}$ it could be adopted to decide between readings on the ground of external evidence would be simply to count the witnesses for each reading and follow the greatest number. It requires little consideration to perceive the illegitimacy of such a method. The great practical difficulty stands in the way of adopting the principle that the majority shall rule, that we cannot certify ourselves that we have the majority. For this, we must first collate every known copy, and even then the doubt would hang over us that mayhap the majority of copies 
are yet unknown: have not, indeed, the majority actually perished? If we should adopt a simple majority principle, therefore, we could never reach certainty; we could never be sure that the copies as yet unknown, or hopelessly lost, might not alter the balance; and we should be betraying the text into the hands of the chance that has preserved one MS. and lost another. A greater theoretical difficulty lies behind. Who can assure us that the many are the good? The majority of MSS. are late MSS.; and if it be the original text that we are seeking, is it likely that the many MSS. of the eleventh century will better help us to it than the few of the fourth? Dare we overmatch the multitude of years by the multitude of copies, - our two codices of the fourth century by the mixed hordes that throng on us from the fourteenth? If corruption be largely due to the fortunes of hand-copying, it will of necessity be progressive, and the MSS. of the earlier centuries may be rightfully presumed to be purer and better than those of the later. We may even expect to find in them the parents of the very later codices which now would crowd them out of the witness-stand. If so, to follow mere numbers is to betray the text into the hands of the later corruption.

Shall we, then, say that not the most MSS. but the oldest shall rule? This certainly would be a far better canon. But it is met again, on the threshold of practical use, by a double difficulty,-theoretical and practical. After all, it is not the mere number of years that is behind any MS. that measures its distance from the autograph, but the number of 
copyings. A MS. of the fourth century may have been copied from another but little older than itself, and this again from another but a little older than it, and so on through a very long genealogy; whereas a MS. of the eleventh century muy have been copied from one of the third, and it from the autograph. It is not, then, the age of the document, but the age of the text in it, that is the true measure of antiquity; and who shall certify us that many of our later documents may not preserve earlier texts than our earliest MSS. themselves ?-or, indeed, that all our later documents may not be of purer descent than our few old codices? With the frankest acceptance of the principle that the age of a document is presumptive evidence of the age of the text, it is clear that we can reach little certainty in criticism by simply agreeing to allow weight to documents in proportion to their age. And here the practical difficulty enters the problem: how much greater weight shall we allow to greater age? Certainly two fourth-century documents cannot reduce all tenth-century documents to no value at all, simply by reason of their greater age : but how nice the question as to the exact increment of weight that must be added for each century of additional life! Professor Birks set himself once to investigate this question; and his conclusion was "that on the hypothesis most favourable to the early MSS., and specially to the Vatican [B], its weight is exactly that of two MSS. of the fifteenth century, while the Sinaitic [ $[\times]$ weighs only one-third more than an average MS. of the eleventh century." Mr. Monro was at pains to point out certain errors in 
Professor Birks' calculations which appear to vitiate his conclusions. But for the purposes of actual criticism were they not valueless even if correct? How is it possible to calculate the value of each document relatively to all the others on the ground of age alone? Let us confess it: to admit that the older a MS. is the more valuable it is likely to be, carries us but an infinitesimal way towards the actual work of criticism, and it is entirely impossible to apportion their values to codices by their ages. Though we may feel that a MS. of the fourth century ought to be a better and safer witness than one or two, or a hundred, or a thousand for that matter, of the fifteenth, we cannot certify ourselves of this with regard to any given MS.; and we certainly cannot arrange all our MSS. in a table of relative weights as resulting from their relative ages, and then use this table as a touchstone for our critical problems. It is a plain fact that MSS. need not and do not always vary in weight directly according to age.

A great step forward is taken when we propose to allow MSS. weight, not according to their age, but according to the age of the text which they contain. To Tregelles must be ascribed the honour of introducing this method of procedure, which he appropriately called "Comparative Criticism." It is a truly scientific method, and leads us for the first time to safe results. Briefly stated, it proceeds as follows. The earlier versions and citations are carefully ransacked, and a list of readings is drawn from these dated sources which can be confidently declared to be ancient. Each MS. is then tested, in turn, by this list. If a MS. con- 
tains a considerable proportion of these readings, or of readings which on grounds of transcriptional probability are older than even these, it is demonstrated to contain an old text. If, on the other hand, a MS. fails to contain these readings, and presents instead variants which according to transcriptional probability appear to have grown out of them, or which can be proved from dated citations to have been current at a later time, its text may be assumed to be late. From an examination of the Mis. thus proved to exhibit an early text, we may next obtain a very clear general notion of what the earlier text is, and this will serve us as a more extended test of the age of texts contained in MSS., and we may confidently divide them into two great classes-the early and the late.

Here, it is plain, our feet rest on firm ground. What may be done towards settling the text by this method may be observed in the text which Dr. Tregelles actually framed, and which stands to-day as his suitable and honourable monument. But a little consideration will satisfy us that, as an engine of criticism, this method is far from perfect. It will furnish us with a text that is demonstrably ancient, and this, as a step towards the true text, is a very important gain. It is something to reach a text that is certainly older than the fourth century, - that was current in the third or second century. But this can be assumed to be the autographic text only if we can demonstrate that the text current in the second or third century was an absolutely pure text. So far from this, however, there is reason to believo 
that the very grossest errors that have ever deformed the text had entered it already in the second century. By this method, therefore, we may deal successfully with all cases of variation in which the older and later texts stand opposed as bodies, and thus may sift out a vast rabble of late corruptions; but we stand, with it only to help us, helpless before all cases in which the oldest witnesses themselves differ. This result might have been anticipated. If our touchstone only reveals to us texts that are ancient, we cannot hope to obtain for our result anything but an ancient text. What we wish, however, is not merely an ancient but the true text.

Yet another process has been developed for our aid in this perplexity. It has been pointed out that the way is open to the estimation of MSS., not by the age of the parchment on which they are written, nor yet by the age of the text which they contain, but by the actual excellence of the text which they contain. This is another great advance. For we are now invited to assign weight to MSS. according to their real value. The process by which this method undertakes to ascertain the relative value of the different MSS. is appropriately called "Internal Evidence of Documents," and proceeds by interrogating each MS. as to its own value, by testing it by the only kinds ir evidence available - namely, intrinsic and transcriptional evidence. A rude example of what is intended by this will, perhaps, be its best explanation. Let us suppose two copies of a will or deed to be laid before us, and it to be our task to determine which is the better-ie., the more correct. 
What would be the common-sense procedure? Beyond doubt, we should begin by noting every point in which they differed; and then, taking this list of various readings, we should ask, in the case of each reading, which appeared to be the original. We should have two ways of determining this: in each case we should ask, Which reading is it probable, considering the context, style, and the like, the author wrote? and, Which reading, considering the known habits of the scribes, the accidents to which they are liable, and the like, is it probable that the scribe had before him in order to produce the other? When these two modes of inquiry resulted in the same answer, the reading would be determined by a high degree of probability. Now, after having thus passed through the whole list of various readings, we could count up what proportion of them had been determined in favour of one MS. and what proportion in favour of the other. This would furnish us with a fair general estimate of the comparative value of the two copies. If, for instance, the two differed in a hundred places, and the two varieties of internal evidence of readings united in commending the readings of one in ninety of these, and those of the other in only ten, we should have no difficulty in greatly preferring the former to the latter copy. Nay, it would not be strange if we now revised our decision in some of the other ten cases, and allowed our demonstrably better copy to determine their readings on documentary grounds. No doubt such a method offers us only probable results; but it is scarcely open to doubt but that, so far as they go, they are sounc? 
results, and in favourable cases the probability may reach moral certainty. It is equally plain that the method is not essentially affected if the documents we have to compare are a dozen instead of two, or even a hundred or a thousand; nor yet if our two varieties of evidence fail to give us clear or united testimony in a number of the readings. It would still remain true that the relative value of the MSS. could be ascertained by determining the proportionate number of their special readings which internal evidence will commend. After its own relative value has been assigned to each MS. of a work by this method, we may proceed to its textual criticism on documentary grounds, allowing each MS. the weight thus indicated. This is not reasoning in a circle. By one process, tentatively applied, we attain a general notion of the value of each MS. When a considerable number of readings have been used in this work, errors in their estimation check one another, and our general result is sound. It is quite consistent next to treat all these readings as still undecided: this is but to recognise that tentative results as to the details are provisional. We may, therefore, justly call in the MSS. according to the relative values which have been assigned them by our tentative results en masse to decide now on each reading in detail.

Precisely this process has been applied to the MSS. of the New Testament. And we are asked to determine the relative weight of the witnesses for each disputed reading by allowing to them the weights assigned them by this method of testing. It would 
be idle to dispute the validity of the process. It is transparently just and scientific. It is equally impossible to doubt that it will enable us to come to conclusions on which we can depend. Especially when taken in connection with the former method, which marshals MSS. according to the age of the texts they exhibit, this method, which marshals them according to the tested value of their texts, will lead us to very important conclusions, both in the way of testing the results obtained by the former method, and in carrying them some steps farther. The mere fact that the results of this method accord with those obtained by the former, so far as they were legitimate, gives us confidence in using it. It may be in one sense an accident that our oldest MSS. should be shown by comparative criticism to contain the most ancient text, although an accident in the line of the pre-existing presumption. But it cannot be by mere accident that the text obtained as the most ancient should in the main accord with that obtained as the best. And it is reasonable to be led by this accordant result of two independent methods to put confidence in the further results obtained by one of them which in the nature of the case cannot be tested by the other. We are justified, therefore, in using internal evidence of documents to decide for us the readings in which the older text is itself divided.

As already intimated, Dr. Tregelles' text may bo taken as the type of the results attainable by comparative criticism. He was accustomed to divide the MSS. into classes, thus: (a) Uncial MSS. of the most ancient class,-i.e., those earlier than the seventh 
century; (b) Later uncial MSS. of special importance ; (c) Certain important MSS. in minuscule letters; (d) The later uncials. He aimed at citing the testimony of all the uncial MSS., those of the minuscules the text of which was ancient, all versions down to the seventh century, and the fathers down to and including Eusebius. In class $(b)$ he included $\mathrm{L}, \mathrm{X}, \mathrm{Y}$, $\Delta, \Theta, \Xi$, of the Gospels, $\mathrm{P}$ of Acts and the Catholic Epistles, and F, G, of Paul. In class (c) he included 1, 33, 69 of the Gospels, 13, 31, 61 of Acts and the Catholic Epistles, 17, 37, 47 of Paul, and 38 of the Apocalypse. To these might well be added, now, the minuscules cited in the lists of minuscules given in the proper place above. The other classes $(a),(d)$, may be gathered from the lists of uncial MSS. given above. When tested by internal evidence of documents, the MSS. arrange themselves in a not dissimilar classification. As is practically universally confessed, B is by this means shown to be the lest single MS., and $\boldsymbol{x}$ stands next to it. Naturally enough the documents most like $\mathrm{B}$ are given the next place. But the general character of such codices as $\mathrm{D}, \mathrm{D}_{2}, \mathrm{G}_{3}, \mathrm{~F}_{2}$, is not very high, when tested by internal evidence of documents, although their text is certainly very old, as comparative criticism satisfactorily proves. Among the versions, the palm falls to the Memphitic and Thebaic.

A various reading that occurs in Matt. vi. 4 may serve us as an example of the working of these processes. Shall we read in this verse simply, "And thy Father that seeth in secret shall reward thee"? or shall we add the word "openly" at the 


\section{TILE METIIODS OF CRITICISM. 119}

close? Tischendorf states the evidence thus:-omit

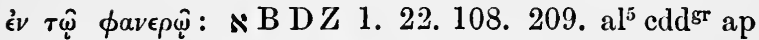
Aug (nulta exx. Latina sic . . . . . reddet tibi palam ..... in Grocis quce priora sunt non invenimus palam) $\mathrm{ff}^{1} \mathrm{k}$, vg fr sax cop syr ${ }^{\mathrm{cu}}$ (Or 4, 256, cdd : non liquet quo spectet), Cyp Aug Hier Chrom al;

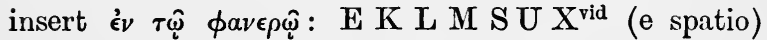
$\mathrm{abcf} \mathrm{g}^{1} \mathrm{hq}$ syr $^{\text {sch }}$ et ${ }^{\mathrm{p}}$ go arm æth al Const Chr Op al. In order to interpret the evidence by comparative criticism, we may arrange the matter as follows :-

Uncials prior to the serenth century.

Good later uncials.

Good minuscules.

Later uncials.

Second century versions.

Fourth century versions.

Fifth century versions. Seventh century versions.

Fathers before Eusebius. Fathers of the fourth century.

Fathers of the fifth century.

\section{Omit.}

N, B, D, Z, cdd ap Aug.

1. 22. [33]. 209.

Afr. Lat., Syr. $\mathrm{Cu}$, Copt.

Vulg. Lat.

\section{Cyp.}

[Ang.] Hier.

Chrom.
Insert.

L $\mathrm{X}^{\text {vid e spatio. }}$ rel. all.

Europ. Lat., Ital. Iat., Syr.sch. Go. Ath. Arm. Sylp.

Chrys. Constt. 
We observe that the addition "openly" does not 'occur in any known Greek MS. before the eighth century, or in any version or patristic citation before the fourth century. Some good later uncials, L of the eighth century, and apparently also $\mathrm{X}$ of the ninth, witness for it, but the better minuscules, again, omit it. No second-century version contains it, but all later ones do, with the sole exception of the Latin Vulgate. Its absence from this and from Jerome's quotations is probably to be explained by Augustine's precise statement that many Latin copies of his day contained it, but none of the earlier Greek copies,which in itself is a very strong testimony to the superior antiquity of the omission. On this evidence

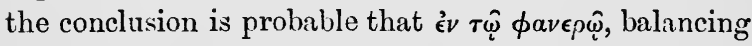
the previous $\dot{\epsilon} v \tau \hat{\varphi} \kappa \rho v \pi \tau \hat{\varphi}$, was first introduced into the Greek text late in the third or early in the fourth century. When we now withdraw our attention from the question of antiquity, and consider the witnesses according to their values, as determined by "internal evidence of documents," we discover that the kest witnesses array. themselves for omission. On this ground, too, therefore, we decide to omit the words.

Practically much the same division of evidence is met with in the more important matter of the insertion or omission of the doxology to the Lord's Prayer (Matt. vi. 13). There is, however, this important difference : the doxology appears in witnesses as early as the second century. For its omission are quoted: $\aleph, \mathrm{B}, \mathrm{D}, \mathrm{Z}, 1,17,118,130,209$; scholia in the margin of many copies that contain it; a, b, c, $\mathrm{ff}^{1}, \mathrm{~g}^{2}, \mathrm{l}$, 
vg., cop. ; Or., Nyss., Crs., Cyr ${ }^{\text {hr. }}$, Max., Cyp., Tert., etc. For its insertion : E, G, K, L, M, S, U, V, $\Delta, \mathbf{I}, \mathbf{\Sigma}, \Phi$, very many others, $f, g^{1},[k] q$, syı ${ }^{\text {utr }}$, et ${ }^{\text {cu }}$, et ${ }^{\text {hr }}$, xth., arm., go. [sah], [Teaching of the Twelve Apostles,] Constt., Chrys., and later fathers generally. The MS. evidence does not differ markedly from the distribution observed in Matt. vi. 4. But among the versions a doxology is found in the second century Curetonian Syriac and the Sahidic (- Thebaic); and in the fathers, in the early second century "Teaching of the Apostles." There is no question, therefore, but that a doxology is found attached to the Lord's Prayer as early as the very opening of that century. Nevertheless, the oldest MS. in which it is found dates no higher than the sixth century $(\Sigma)$. Even with comparitive criticism alone beneath our feet, we are not helpless here; for when we observe that the doxology appears in the recond century in as many differing forms as there are documents that contin it, that it occurs in no MS. before the sixth century, and in no commentator on the Lord's Prayer before Chrysostom at the end of the fourth century, conclusions as to its late origin present themselves with some force, and we can suspect that it entered the Greek Testament about the end of the third or opening of the fourth century. When we call in "internal evidence of documents," we see that the best old documents are ranged for omission, and our conclusion is strengthened accordingly.

The reading in John vii. 8 , the evidence in the case of which was analysed a few pages back, is distinctly more difficult to deal with. The two oldest 
and best MSS. are here set in opposition to one another; the second-century versions are divided as three to one, but the best and the worst agree against the second best, and the most stand witb the second MS. against the best. This is typical of the division of the evidence throughout. How, then, can we decide the matter on grounds either of the antiquity of the witnesses or of their excellence? Cases of just this complexity meet us on nearly every page of the New Testament. What are we to do with them?

These examples have been designed to illustrate both the strength and the limitations of the method of criticism which we are expounding. That much can be accomplished by it is clear. That it is scientific and sound, so far as it will carry us, is equally certain. But it is also true that it is helpless whenever the old or the good documents are pretty evenly divided; and that when, as in the New Testament, we have many documents to deal with, it does not always carry with it that practical certainty which we desiderate. The reason of both shortcomings is that its decisions rest everywhere, at botiom, on an arithmetical balance. Let us try to explain.

By this method of criticism, when all the old MSS. stand opposite the later, and when all the good MSS. stand opposite the bad, we have no difficulty in deciding the reading. But they will not always so arrange themselves; perpetually some of the older are on the side of the later, some of the better on the side of the worse. What are we to do in such cases? Even if we are confident that $\aleph, B, A, C, D$, 
when coinbined, may stand against the world, how do we judge the group to be weakened by the defection of $\mathrm{A}$ ? or of $\mathrm{C} l$ or of $\mathrm{B}$ ? or of $\mathrm{N}, \mathrm{B}$ ? or of $\mathrm{A}, \mathrm{C}, \mathrm{D}$ ? or of any two or any three or any four of them? These are puzzling questions. But until they are answered this method of criticism is helpless before the immense variety of divided testimony which meets the critic in every part of his work. Clearly, in such cases everything depends at bottom on our knowing not only that $\aleph, \mathrm{B}, \mathrm{C}, \mathrm{D}$, present an old, and $\mathrm{E}, \mathrm{S}, \mathrm{U}, \mathrm{V}$, a late text; or that $\aleph, \mathrm{B}, \mathrm{C}$, present a good and most minuscules a bad text; but also, very accurately indeed, the exact proportional excellence and consequent weight of each MS.: how much better precisely $\mathrm{B}$ is than $\mathrm{N}$, and $\mathrm{N}$ is than $\mathrm{C}$, and $\mathrm{C}$ is than V or 10 or 19. How else can we estimate the effect of each defection? Often decision on the bearing of documentary evidence will absolutely depend on an exact knowledge of the precise value of each MS., and a consequent ability to estimate the weight each brings to a group with its presence, or takes from it by its absence. Obviously this means (at our present stage) nothing less than ability to speak of MSS. in terms of numerical formula, and tho whole matter of documentary evidence becomes an arithmetical balance. If, assuming an ordinary minuscule of the fourteenth century to rank as 1 in weight, we lknow that $B$ ranks as 2000, and $N$ as 1800 , and $C$ as 1600 , and so on, we can accurately estimate the value of each group and by a simple sum in arithmetic settle the text. But unless we know this or something equivalent to it, 
the bearing of the documentary evidence is constantly escaping us. We cannot tell what effect on the

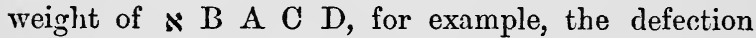
of $\mathrm{B}$ will have; we cannot tell whether $\wedge \mathrm{B} \mathrm{D} \mathrm{Z}$ may not be enough to carry our suffrages, and $\mathrm{B} D$ not enough; whether E K L M S U X may not be too weak to follow, but $\mathrm{E} \mathrm{G} \mathrm{K} \mathrm{L} \mathrm{M} \mathrm{S} \mathrm{U} \mathrm{V} \Delta \Pi \Sigma \Phi$ too strong not to follow. Manage it by whatsoever method we please, and conceal the fact from others or ourselves by any way of speaking of it that we may, the whole process of criticism which deals with MSS. as separate units amounts to nothing less, at bottom, than an attempt to settle readings by an open or veiled arithmetical balance. We are not now arguing whether such a method be not fundamentally wrong; but only that it cannot be carried successfully through any case where the testimony is well divided unless the arithmetical balance be accurately estimated. And it is clearly apparent that such a balance is not accurately estimated, and, indeed, cannot be. But by as much as it is not, by so much is our criticism but little removed in all nice problems from guesswork.

Let us try to realise in thought still further, what is implied in the very attempt to decide readings by such a balance. No less than this: the possibility of overwhelming all early and good testimony by the sheer numbers of late and bad testimony. Does not the very principle of an arithmetical balance yield the point that the early and good may be overborne by the late and bad, if only the latter be numerous enough? So, in pretending to estimate and weigh 


\section{TIIE METIIODS OF CRITICISM. 125}

witnesses, we fall into the trap of merely counting them. What we want is a method which will allow later testimony to overrule earlier, only if it be good enough to do so. But this method and all methods of a mere balance of individual documents inevitably puts itself in the position that the best and oldest may be overborne, if only we can produce a sufficient number of later documents. Sxy that $B$ is made equal to two thousand thirteenth-century copies, and ten or a hundred thousand nineteenth-century copies, it would be in the power of an enterprising printer to produce enough very debased copies to overbear its testimony. The procedure would be transparently ridiculous, no doubt; but this only proves that we need some method of criticism which is not capable of such a reductio ad absurdum, - which does not proceed on an assumption which can only arbitrarily protect us from such a conclusion. Something else is needed beyond knowledge of the general relative age of the texts that dccuments contain, or the general relative goodness of them, or anything that concerns single documents, before we can reach very secure results.

That those who have made use of "comparative criticism" have avoided the "weakness of an arithmetical balance in dealing with all that class of readings in which the older text differs from the later is no doubt true. But they have done it by confessedly or practically ignoring all later testimony. In this they have built better than their theory gave them ground for, and they have given us a text, consequently, better than their theory would 
legitimately defend. It has not unjustly been made their reproach that because they had discovered that the better testimony was to be found in a certain body of witnesses, they arbitrarily treated all the rest as if they had no testimony to offer at all. And in all that class of variations in which the older documents differ among themselves, these great critics have continually fallen a prey to the imperfection of their method, and their results have depended less on a scientific procedure than on a certain personal quality which we may call "critical tact," and which is but another name for a keen appreciation of the bearing of internal evidence of readings. The discovery of a single MS. ( ( ) revolutionised Tischendorf's text. Tregelles, always more cautious and consistent, was yet repeatedly led into the most patent errors. Every one who has attempted to decide on the weight of documentary groups on any large scale has necessarily been made to feel very keenly that very much of criticism which depends on such methods, wherever internal evidence of readings is not really decisive, is little removed from arbitrary decision or guesswork. From all which it is clear that some method which will enable us to deal with MSS. in groups and classes rather than as individuals is absolutely necessary before we can determine more than the outlines of the text with confidence.

\section{(b) Internal Evidence of Groups.}

A method of procedure which will relieve us from these difficulties has been pointed out under the 
appropriate name of "internal evidence of groups." Internal evidence of readings is the evidence of its own value which each reading supplies when subjected to the tests of intrinsic and transcriptional probability. Internal evidence of documents, as we have just seen, is the evidence of its own value which each document furnishes; and is obtained by noting what proportion of the characteristic readings of a document approve themselves as probably genuine under the twofold test of intrinsic and transcriptional evidence. This process can be carried, with equal ease, a step higher, and be applied to any given group of documents, and thus become internal evidence of groups. Nothing prevents our collecting all the readings supported by any group of documents in which we may be for the time interested, and then trying the list in each of its items in turn by transcriptional and intrinsic evidence. If the majority of its characteristic readings, when thus tested, approve themselves, the group is a good group; if the majority are condemned, it is a bad group; and the proportion between those approved and those condemned will furnish an accurate criterion of the actual value of the group. When two or more groups are successively subjected to this testing, the proportional result obtained in each case supplies data for determining their relative values.

Thus we may at will obtain, by this process, grounded decision as to the weight of any given group, and so determine the actual composite value of any combination of documents. If, for instance, 
we are studying the reading in John vii. 8, which we have already had before us, we may take the group $\times$ D K M П 17** $389 \mathrm{p}^{\text {scr }}$, and trace it throughout the Gospels, collecting all the readings which it supports into a list. Next we may test this list of readings by transcriptional and intrinsic evidence, and thus attain a very good, and certainly a well-grounded notion of the value of this group. It only remains, now, to return to the reading in hand, and allow the group there the weight which we are thus led to assign to it. We no longer try to estimate the weight of the group by the sum of the weights of its component parts; we no longer need to raise question as to the relative values of the separate MSS., and the effect of the defection of this one or that; we treat the group as a unit, and estimate its value as a whole. Instead of speculating as to the difference between $\approx \mathrm{D} \mathrm{K} \mathrm{M} \mathrm{II}$ $17 * * 389 \mathrm{p}^{\text {scr }}$ and B $\times$ D K M П 17** $389 \mathrm{p}^{\mathrm{scr}}$, or trying to calculate it by adding the weight of $\mathrm{B}$ to the weight of the former group, we simply go with this process to the places where these groups occur, collect the readings actually supported by each, and try each separately by the only kinds of evidence applicable, and so find for each in turn what its actual value is. The result is oddly portentous for all attempts to estimate readings by arithmetical balances. As a mere matter of fact, wherever א D K M П 17** $389 \mathrm{p}^{\mathrm{scr}}$, or its essential elements, occur, it is usually in support of an obviously wrong reading; and wherever $\mathrm{B}$ is added, this greater group usually supports an obriously right reading. In 
other words, the former is a bad and the latter a grood group.

Two practical limitations, in the use of internal evidence of groups, need statement at the outset. In estimating the value of any group, we must confine ourselves within the limits of the section of the New Testament in which the reading we are to study occurs, and, in the first instance at least, within the strict limits of the group we are investigating. There is every reason to believe that our great MSS. which contain, or once contained, the whole New Testament, wore made up directly or remotely of copies of different codices in the several parts of the New Testament; and; indeed, that in the early days of the Chureh each section was usually written in a volume apart. The result would naturally be that the Epistles of Paul, say, for instance, in Codex B, would have a very different history, could it be discovered, from that of the Gospels in the same codex. As a matter of fact, also, the result of the actual test gives a different value to the same apparent group in the several sections. Very divergent weights are assigned by it to $A$ in tho Gospels and in the rest of the New Testament. In the Gospel of Mark B $\Delta$ is excellent, but $B G$ in Paul is very suspicious. Experience thus teaches us that the value of the separate groups must be studied apart for each great section of the New Testament. The same experience teaches that it is not safe to confound two groups which lock alike. No man knows whether $B \times D L$ has the same value as, or more or less value than, $B \leqslant I$, 
until he has actually tested the matter empirically. We may afterwards learn from actual trial the limits within which each group may vary without essentially altering its weight, but we must be chary of assumption in this matter. Take the group D E F G in Paul. If we add $N$ to it its value is unaffected. Or if we add $B$ to it, it is essentially the same. If, however, we add both $\boldsymbol{N}$ and B, the group immediately changes from bad to good.

The immense advance that is made, by the introduction of this method, on all criticism that depends on estimating the values of groups from the values of the members that compose them, is apparent at a glance. All the difficulties and dangers of an arithmetical balance are escaped at a single step. We now estimate the weight of any group which supports a given reading, not by the age of the MSS. which compose it, nor by the age of the texts which these MSS. contain, nor by the value of the separate MSS., bu' by the tested value of the group itself. Each group stands before us as a unit; each is first tested as a unit, and then used as a unit. The full importance of thus escaping the arithmetical balance will not be appreciated, however, until we realise that the union of two codices will not necessarily, and indeed is sure not to, be the same in weight as the sum of their values. For example, $\times B$ is not the same as $\aleph+B$; and any system which proceeds openly or practically by an arithmetical balance is sure, therefore, to lead to error, which cannot be legitimately escaped until we learn tọ deal with groups in some way or other as units of testimony. Internal evi- 
dence of groups assigns to $\mathrm{B}$ no weight as a composition of $N$ and $B$, but recognises it as a third thing (just as blue plus yellow make the third thing, green), and seeks to discover its own value as it betrays it from the readings it supports; it thus accords it only the weight which it makes goorl its claim to.

The soundness of this method of work is bound up inseparably with that of internal evidence of documents, from which it differs rather in name than in fact. It does for groups of documents just what the former process does for single documents. It makes no assumptions as to how documents come to be grouped; it accepts as a fact that here is a circumscribed group supporting a series of readings, and then asks what kind of readings, good or bad, does this group support? It thus estimates the value of a witness by the character of what he witnesses to, - by his habits of truthfulness or the contrary elsewhere,-and gives him credit accordingly. No less obvious than that the application of this method will give us secure results is it, however, that it will entail a great deal of labour. It is far easier to guess at the weight of a group, or to leave it unguessed and fall back on internal evidence of readings as our sole dependence, than laboriously to test the weight of a group. The beginner may well be somewhat appalled at the prospect of painfully tracing every chance combination of documents through the crowded digests of a Tischendorf or a Tregelles, and even after this labour is completed, of feeling that the most trying task is still before him, - the careful testing of each one of the readings thus 
obtained by internal evidence, with a view to deter mining the value of the witnessing group. Yet, the result is worth the labour: royal roads have not a good reputation for safety, and the very thorns in this path have their useful lessons to teach. And it is right to point out that the number of groups needing testing is found in practice far fewtr than would à priori be thought likely. The New Testament MSS. do not arrange themselves in every conceivable grouping, and the student will not proceed far in this work without discovering that the number of varying groups that actually occur is comparatively small, and further, that these may be reduced to yet fewer by attending only to the essential core of each, - a core that can only be empirically discovered, but which yet, after a while, can be with certainty abstracted.

In a matter of this kind no one can afford to accept implicitly the results of other investigators and simply apply them to special cases. It is strongly recommended that every student actually study for himself the value of some few selected groups at the very outset, and that he be prepared to test all results of others in the same line of work, and to make trial of any group that puzzles him in any special reading. At the same time, the beginner may be allowed to stand on the shoulders of the masters of the science, and perceive the bearing of evidence through their eyes. Dr. Hort, in particular, has worked out the values of the chief groups throughout the New Testament, and his results may be safely accepted as sound. The most interesting 
of these results is the very high character given to the compound B $\mathbf{k}$, which approves itself as nearly always right, whether it stands alone, or with whatever further body of documents; and that throughout the New Testament. Next to B s, B conjoined with some other primary document, such as B L, B C, B T, and the like, whether alone or with other support, forms the most weighty series of groups, and this, again, throughout the New Testament. The only outstanding exception to this last generalisation is formed by B G in Paul's Epistles, whether alone or with other documents short of the whole body of primary uncials, which is usually condemned by internal evidence. B D in Paul is a good group, although B D G is bad, and although it hardly attains the very high excellence of the like group $B$ D in the Gospels and Acts, whether alone or in combination with other documents. On the other hand, $\times D$ is everywhere, and in every combination (if $\mathrm{B}$ be absent), very suspicious. Even with secondary witnesses only adjoined to it, $B$ stands the test excellently; and if clear slips of its scribe be excluded, even when wholly alone, $\mathbf{B}$ attains great excellence and stands forth as plainly the best single codex known. On the other hand, compounds of $\times$ with other documents ( $B$ being absent) are usually not strongly commended, and compounds of documents excluding both $s$ and $\mathbf{B}$ are commonly condemned by internal evidence. In the Apocalypse $\wedge$ falls to " low level, and $\mathrm{A}$ rises to the height of the best siagle MS., while $\mathrm{AC}$ is the best binary group, and is usually to be trusted, whether it stands alone or 
in combination with other documents. A very special discredit is thrown on D G in Paul's Epistles, whether it stands alone or in any combination, provided only that both $\mathbf{B}$ and $N$ are not adjoined to it.

These generalisations, all of which the student would do well to test by actual trial, already put us in a position to deal with most readings. For instance, in John vii. 8 internal evidence of groups clearly commends ov้ $\pi \omega$; for the good group B L T etc. supports it, while the bad group $N D$ etc. supports its opponent. So too in Matt. vi. 4 the group that omits $\dot{\epsilon} v \boldsymbol{\hat { \omega }} \phi \alpha \nu \epsilon \hat{\omega}-$-viz., $\mathrm{B} \times \mathrm{D} Z$-is seen, at a glance, to be one of the strongest possible. The same is true of the group that omits the doxology in the Lord's Prayer. In a word, internal evidence. of groups puts an engine of criticism into our hands which cuts the knots that seemed incapable of being unloosed by the older methods, and enables us to reach assured convictions as to the bearing of the external evidence, where before we stood helpless.

If in any case Dr. Hort's generalisations do not seem easily or safely applicable, or the results of their application bring us to a conclusion which seems difficult to square with internal evidence of readings, it is the duty of the inquirer to subject the special group before him to a renewed and independent testing. But even with the most easily studied and safely interpreted groups, it must be remembered always that we reach general and probable results only, and not invariable and unmistakable ones. The character assigned thus to 'groups of MSS., like the character assigned to individual MSS. by internal 
evidence of documents, is general character, and is quite consistent with the best groups being sometimes in error. The rules of procedure derived from internal evidence of groups are, therefore, not without exceptions. This may be illustrated by such a reading as that found in Matt. xxvii. 49. Here $\aleph, \mathrm{B}, \mathrm{C}, \mathrm{L}, \mathrm{U}, \mathrm{r}$, five minuscules, some mixed Latin MSS., a copy of the Jerusalem Syriac, the Athiopic version, and Chrysostom, with perhaps some other fathers, insert the sentence, "But another, taking a spear, pierced His side, and there came forth water and blood," to the confusion of the narrative. The intrinsic evidence seems immovable against the insertion; the transcriptional evidence seems to judge it an assimilation to John xix. 34 , clumsily done. But if the internal evidence is thus united against the insertion, we can scarcely insist on inserting it on account of the testimony of internal evidence of groups. Though this group is about as strong a one as can occur, yet internal evidence of groups gives us only the comparative weights of groups when considered throughout all their readings; it does not give us an exceptionless rule to apply mechanically. We learn from it what amount of correctness $N \mathrm{~B} \mathrm{C} \mathrm{I} \mathrm{U} \Gamma$ is apt to exhibit, not what amount it must have in every reading. The way is open for us to find some exceptions to the general excellence of the group, and hence to find an exception here.

If, however, the estimation of the value of the various groups which is attained by internal evidence of groups allows for exceptions, and attains on!y a 
probable force, it becomes immediately important to check its results by some other independent method of criticism, which will enable us to determine which are the readings in which the exceptions are found. That an independent method lies within our reach may be hinted by our use of internal evidence of groups itself. We shall not proceed far in using this method before we realise what has been already remarked: that the number of groups that actually occur in the digests is far short of the calculable number of possible combinations of the documents. We shall observe a certain persistency in some MSS. in getting together, and a certain persistency in keeping apart manifested by others. Nor will accident account for this. It is, no doubt, possible that two or more MSS. may occasionally unite in a reading by accident. But how rarely and in what a narrowly limited class of readings this can occur, a very little reflection will assure us. Only in such obvious corrections or in such unavoidable corruptions as two scribes might independently stumble upon, can codices agree accidentally. The improbability of many MSS. falling independently into an identical corruption of even this kind, and the still greater improbability of a plurality of MSS. falling independently into a considerable series of identical corruptions, is too immense to be apprehended. MSS. which fall frequently together can owe their frequent conjunction to nothing else than common inheritance. This is, indeed, the principle on which all textual criticism proceeds. We seek the original text of the New Testament in the extant MSS., because we judge that where these 
MSS. agree, this agreement car be accounted for in no other way than by common inheritance from the ancestor of all. The same principle is, of course, valid for any given group of MSS. short of all : their union in a body of readings common to them, and more or less confined to them, is proof that they are preserving in these readings parts of a MS. which, for these parts, lay at the root of all the MSS. in the group. When we gather together the readings of any given group of codices, we are gathering, therefore, a body of readings from a lost MS., the common parent in these readings of all the codices of this group. And when we test this list of readings by internal evidence of groups, we are only in appearance performing a process different from internal evidence of documents; we are testing a lost document, a body of the readings of which we have recovered, instead of an extant document all of the readings of which are before us. Internal evidence of groups is, therefore, simply internal evidence of documents applied to lost documents, a list of the readings of which has come down to us, and nothing more. 'This is why we have said that its validity i.s bound up with the validity of internal evidence of documents, and must stand or fall with it.

From this point of view we may understand why we find it in practice of the utmost importance to confine the examples of the use of any given group which we are testing, strictly within the bounds of the group that stands before us. Every MS. added to the group may carry us another step back for the common parent of the (now enlarged) group. If 
B C D in Paul, for instance, is being tested, we must exclude all readings supported by $\leqslant \mathrm{BCD}$, because we do not know whether the common ancestor of $\aleph$ B C D may not be another MS. from the common ancestor of $\mathrm{B} \mathrm{C} \mathrm{D}$, and thus we may be confusing two MSS. in our investigation and therefore obtaining results inapplicable to either. No doubt everything in $\aleph$ B C D must have been in the MS. which stood at the head of the subgroup B C D; otherwise it could not have been inherited by $\mathrm{B}$ and $\mathrm{C}$ and $\mathrm{D}$. And if our purpose were to recover as much as possible of the common ancestor of $\mathrm{B} \mathrm{C} \mathrm{D,} \mathrm{we} \mathrm{should} \mathrm{have} \mathrm{to} \mathrm{collect} \mathrm{all}$ readings found in these three MSS., no matter what others were added to them. But since our purpose is to test the value of this reconstructed MS., our first duty is to select from the whole mass of its readings those in which it differs from the opposing group, just as, in internal evidence of documents, we confined our attention to the list of various readings. To pay attention to all the readings of any MS. or group of MSS. gives us no basis of comparative judgment, since the readings common to both documents or groups cannot discriminate between them. Consequently, for internal evidence of groups the labour is lost which is spent on collecting readings which we cannot use, for the sake of sifting them out again. And it is worse than lost. Suppose we are testing the value of $B$. Is it valid to take account of the readings for which $B \times$ witness? Certainly not, in order to obtain a value to assign to $\mathrm{B}$ when it stands alone. And simply for this reason. 
$\mathrm{B} N$ is not $\mathrm{B}$, but the common ancestor of $\mathrm{B}$ and $\mathrm{N}$; and the value of this common ancestor of the two cannot be assigned to either separately without leading to extensive error. No doubt $B$ has preserved in all cases where $B$ and $N$ stand together the reading of the common ancestor of them both. But this does not prove that it has preserved it also where $B$ and $\aleph$ differ : $\boldsymbol{N}$ may have, then, preserved it and B lost it; and this is the case that we are now investigating. To confuse passages in which $B \times$ stand together with those in which $B$ stands alone, is to lend to $B$ everywhere the weight that belongs to it only when preserving the reading of the common ancestor of it and $\mathrm{N}$,-is practically to deny that any corruption has entered $B$ in all the course of descent from the common ancestor of it and $\boldsymbol{N}$ down to the writing of the MS. itself. Conversely, to attempt to estimate $B \times$ from the known value of $\mathbf{B}$ (as is done by all methods of criticism that treat the MSS. separately only) is to attribute to the common ancestor of $\mathbf{B} \times$ all the change that has entered through the many possible copyings which have taken place in the descent from it to $B$.

How empirical the foundations of this method of investigation are may be estimated from the fact that although, as just explained, the addition of a MS. to a group may make every difference in its value, on the other hand experience shows that it may make no difference at all. This, too, is due to the fact that MSS. agree together not by accident but by inheritance. Suppose the new MS. added is a near kinsman of those already tested, the descendant of the same 
common immediate ancestor or of one of the codices already in the group. Evidently, in such a case, its presence or absence will make no difference in the results of our testing process. For instance, we know that $F$ of Paul is a copy of $G_{3}$. Now, if we are investigating the value of $\mathbf{D ~ G}$ of Paul, it is obvious that it is all one whether we allow $\mathbf{F}$ to join them or not. With or without $\mathrm{F}$ it is the same common exemplar that lies at the base of the group. It follows as a rule of procedure that we must take nothing for granted in using this process, but try all things, and learn the effect of each addition only by actual testing.

The practice of internal evidence of groups is thus wholly independent of any genealogical considerations. It proceeds, and must proceed, in utter ignorance of all genealogies. It tests the composite value of every combination of documents that faces it; and it is all one to it whether this combination is one which chance has thrown together or which inheritance has compacted, whether it unites in a common ancestor at once or only in the autograph itself. All it knows is, Here are documents united. All it asks is, Do they form a good or a bad combination? Yet behind internal evidence of groups the student will see genealogies clamouring for recognition. He notes the peculiarities of the groupings,--some groups frequently occurring, others, apparently equally possible, never occurring at all. $\mathrm{He}$ notes the verdicts of internal evidence of groups,-some groups uniformly condemned, others, apparently just like them, almost as uniformly commended. Why is it that D, the African 


\section{THE METHODS OF CRITICISM. 141}

Iatin, and the Curetonian Syriac, stand so often to. gether? Why is it that B D is so generally good, and $\times \mathrm{D}$ so generally bad? The student would be something other than human if he did not wish to know the cause of all this. And the hope lies close that all may be explained and a new and powerful engine of criticism be put into our hands by the investigation of the genealogical affiliations of the MSS. which are suggested by these facts. The results of internal evidence of groups suggest not only the study of genealogies, but also certain genealogical facts on which that study may be begun. Every one must suspect that MSS. that are frequently in company are close of kin. Every one must suspect that the groups which support little else but corruptions are composed of the remaining representatives of a corrupt stock. Everybody must perceive that if such hints are capable of being followed out, and the New Testament documents arranged in accordance with their affiliations, we shall have a means of reaching the true text which will promise more than all other methods combined.

\section{(c) Genealogical Evidence.}

These hints have been followed out with the result of developing another method of criticism, which may be appropriately called "The Genealogical Method." This method proceeds by examining minutely all the documents representing a text, with a view to tracing out the resemblances between them and so classifying them in smaller and larger groups according to likeness. It assumes only the self-evident principlo 
that community in readings argues community of origin, and that, therefore, a classification of documents according to their resemblances is a classification of them according to origin. If this be true of all MSS. taken together, so that we can group all New Testament MSS., for instance, together as MSS. of the New Testament by virtue of their community in the general text of the New Testament, it is, of course, true of the minor resemblances also, and we can equally safely group the MSS. into numerous subgroups, each characterised by their special readings, and each, therefore, forming a family sprung from a common more proximate origin. Community in erroneous readings is as sure a test of relationship as community in correct ones : the point is not the kinds of readings that are involved, but the communion in them. Each MS. on becoming parent of others impresses its actual characteristics on its progeny, whether these characteristics be excellences or depravities; and we may, therefore, select from the mass of MSS. the progeny of each parent, by selecting those MSS. possessing the same characterising peculiarities. The labour involved in this method of criticism, again, is no doubt very great. Every document has to be examined minutely, and compared with every other one. Those most alike are to be put together into small groups of close kinsmen; these small groups are then to be compared, and those closest to one another put together as constituting a higher and more inclusive group; these higher groups are then in like manner to be compared and grouped into yet higher groups; and so on, until 
we reach a point at which they all unite in one great group, inclusive of all the extant MSS. of the work, with the oldest transmitted text as theil common source. The result of the labour is, however, here too, worth the expenditure. Its effect is to arrange all the witnesses in the form of a genealogical tree, and so to enable us to see at a glance the relative originality of the witness of each,-to sift out those combinations of documents which must represent only a lately originated corruption, and to trace out the combinations which will take us back to the original of all.

All this will most easily be made clear by a concrete example. Mr. Robinson Ellis finds that the MSS. of Catullus so class themselves as to admit of a genealogical arrangement which, with a little compression, we may represent thus:-

AUTOGRAPH.

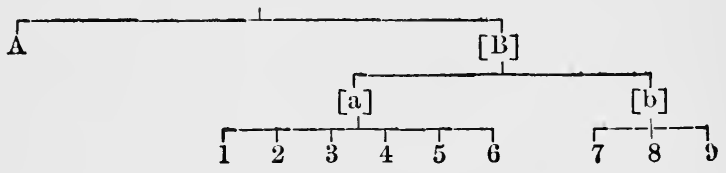

In this special instance, $\mathrm{B}, \mathrm{a}$, and $\mathrm{b}$, are lost; but let us suppose for the moment that all the MSS. marked on the plan are still in our hands. We should, then, have thirteen MSS.:-A, B, a, b, $1,2,3,4,5,6,7,8,9$. Should each of these be allowed the same weight? Clearly $\mathbf{B}$ and 9, say for instance, stand in very different relations to the autograph, and, when the two differ, it would be 
manifestly unfair to allow to 9 equal weight with $B$. We can even go further: there is nothing legitimately in 9 which was not already in $\mathrm{B}$, and if 9 differs from $B$, it does so only by error, and is worthless. There is absolutely nothing legitimately in any of the codices $1-6$ which is not already in $a$, or in the codices 7-9 which is not already in $b$, or in the whole array $a, b, 1-9$, which is not already in B. If, then, B is extant, all its descendants are useless to us; when they agree with $B$ they are mere repeaters of testimony already in hand, and when they differ from $B$ they are introducers of new error, and in both cases they must be absolutely neglected as useless and confusing. That $\mathrm{B}$ has two children $(a, b)$ and nine grandchildren $(1-9)$ standing by its side, while $\mathrm{A}$ stands alone, is at best an accident; and it is clearly unfair, on account of this accident in copying or in the preservation of copies, to allow $B$ twelve repeating rotes to A's single voice. It is obvious rather that the whole group $\mathrm{B}$ a $\mathrm{b} 1-9$ constitutes but one witness though they count up twelve codices, and that $\mathbf{A}$ by itself in point of originality balances the whole array. At one sweep, therefore, we lay aside all the codices a, b, 1-9, with all their various readings, and are enabled to confine our sole attention to $\mathrm{A}$ and $\mathrm{B}$-the only two independent witnesses we have. This is an imaginary result in our present schedule, but in the codices of Cicero's “ Orator," as worked out by Dr. Heerdegen, it actually occurs: one whole rather numerous class are codices (the codices mutili, as they are called), of for swept critical purposes into the waste-basket 
at once, because the source of them all, Codex Abrincensis, is still extant and in critical use.

Let us, however, come back nearer to the facts of our present case. B, a, and b, are lost, and we have just ten codices, we shall say-A, 1, 2, 3, 4, 5, 6, 7, 8, 9 . How is the matter affected? If, before, B, a, b, $1-9$, twelve codices, constituted but one witness, surely $1-9$, nine of the same codices, have not become more than one witness by the destruction of three of their companions. This were to emulate the Sibyl and estimate value in inverse proportion to number. No more, then, in this case than in the preceding, can we allow equal weight to each codex-to A, say, and to 9 . Plainly $1-9$ are here combined, but one witness still, and must be counted as but one in opposition to $\mathrm{A}$, which in point of originality is still able by itself to balance the whole array 1-9. Now, however, we are not able to neglect these codices; they are our only extant representatives of $\mathrm{B}$, and taken together constitute $\mathrm{B}$. But we must not treat them as nine separate witnesses, or even, because they obviously form two groups, 1-6 and 7-9, as two separate witnesses. We must treat them as together constituting only one witness, and we must so marshal their testimony as to eliminate the errors that have been introduced into them since $\mathrm{B}$, before we match them against $\mathrm{A}$. In other words, we must reconstruct $B$ from them, and only then seek from $\mathbf{A}$ and recovered $\mathbf{B}$ their common original, the autograph. The effect of the classification on these ten codices, $\mathbf{A}, \mathbf{1}-9$, is, therefore, to reduce the ten apparent witnesses to two, 
- to eliminate the large body of variants that exist among $1-6$, or $7-9$, as too lately introduced to merit our notice,-and so in a great number of places to fix the text absolutely.

Thus far we have proceeded as if the ten codices were found already classified to our hand. Let us suppose, now, that they are simply handed to us as ten codices. Are we justified in assuming that each is independent of all the rest, and so beginning our textual criticism with an apparatus of ten witnesses ? Certainly not. The fact that we receive them unclassified does not alter the fact that they actually bear such relationship to each other as is expressed in this classification. We must begin by a close examination of the codices with a view to tracing their affiliations. And, so beginning, we should note, first, that codices $1-6$ are very closely alike, and that 7-9 draw likewise close together, leaving A standing apart; and then, secondly, that the group 1-6 is much more closely related to the group 7-9 than either is to $A$, and that the two groups contain even obvious errors (not found in A) in common. Whence it will be clear that while $1-6$ come from a different proximate ancestor from that of $7-9$, yet the groups unite in an ultimate common ancestor which is co-ordinate with $\mathrm{A}$. This reached, the classification is complete, and we may proceed with our criticism of the text.

If we may assume that the validity and importance of the genealogical method has been thus made apparent, we may next investigate this process of criticism in its use. We have arranged our ten MSS., 
A, 1-9, in their genealogical relations. What have we gained as an instrument for settling the text? First of all we are enabled to attack our problem in detail. It is easier to reconstruct $B$ from $1-9$, and then the autograph from $A$ and $B$, than it is to reconstruct the autograph from $A, 1-9$, directly. But, far above this, the classification of the codices actually gives us an instrument of criticism that settles much of the text of $\mathrm{B}$, or even of the autograph, for us at a glance. For example, if one reading is supported by $1,7,8,9$, while $2,3,4,5,6$ each give a divergent reading, it is clear beyond a peradventure that the first stood in B. For this combination of documents, $1+7,8,9$, cannot occur unless 1 inherits from a, and 7,8,9 from b, exactly the same reading, which, because in both $a$ and $b$, must also have been in B. Again, if 1, 2, 3, 4, 5, 6 present one reading, 7 another, and $A, 8,9$ another, this last with absolute certainty must have stood in $\mathbf{B}$ and in the autograph. For 8,9 cannot agree with $\mathbf{A}$ except by having inherited this reading from their common ancestor, and this involves its presence throughout the whole line of descent-i.e., in $\mathrm{b}$ and in $\mathrm{B}$; it was, therefore, the reading of both $\mathrm{A}$ and $B$ and of their common ancestor, the autograph. In cases of simple genealogy, therefore, the rule is obvious and exceptionless (in all such cases as cannot be accounted for as merely accidental conjunctions) that attestations including documents from two groups demonstrate the presence of the reading so attested in the common parent of these groups. All readings supported by $A$ and any descendant of $B$ 
(accidents excluded) were consequently in the autograph; all supported by any descendant of a and any descendant of $\mathrm{b}$ in common (accidents excluded) were in B. So far our results are certain. When A and restored B agree, the reading is, of course, that of the autograph. When they differ, in a case like the present, where we have but two primary witnesses, we are thrown back on the character of the witnesses to determine the probability of rectitude between them. Hence, we call in "internal evidence of classes," as we shall call it, to distinguish it from the same process when dealing with chance groups, instead of, as here, genealogically determined ones. In other words, we collect the various readings between $\mathrm{A}$ and the group $1-9$ considered as a unit, and that is as much as to say $B$, and try the relative value of the two by internal evidence, just as we did in the kindred processes of internal evidence of documents and internal evidence of groups. The class which supports the greater proportion of approved readings is the better class. Had we three primary classes instead of two, this process would need calling in only in cases of ternary variation; whenever there were two classes arrayed against one, the reading would be settled on purely genealogical grounds.

The essence of this whole procedure may be reduced to two simple rules: (1) First, work out a complete classification of the witnesses to any text by means of a close study of their affiliations, and thus determine how many independent witnesses there are; and (2) Then by internal evidence of classes deter- 
mine the relative value of these several independent classes. When these two processes are completed we have a method of criticism available which will, in all cases of simple and unmixed genealogies, carry us with the greatest certainty attainable to the text that lies behind all extant witnesses.

The limitation " in all cases of simple and unmixcd genealogies" was not unintentionally introduced into the last clause. Normally we may expect each document to be made simply and without intentional alteration from a single pre-existent document; and when this has been the actual course that has been taken, all documents, each having a single parent, arrange themselves in a simple genenlogy. It is possible, however, that a given document may not be thus simply copied from a single exemplar, but may have two or more parents. The scribe may place two copies (which may as well as not be of different types) before him, and make his new copy by following now one, now the other, either capriciously or with a conscious effort to act as editor. Or again, a scribe accustomed to a strongly marked type of text, when called upon to copy a codex of another type, may consciously or unconsciously allow his teeming memory to introduce into the new copy readings drawn not from the exemplar before him, but from the type of text to which he has been long accustomed. The result, in either case, is a document which is not a simple copy of a single exemplar, but which rather will be more or less intermediate between two types, and will therefore refuse to take its place in any scheme of simple or 
unmixed genealogies. There is yet a third way in which this "mixture," as it is technically called, is introduced into texts, and this is doubtless the way by which, in actual fact, most mixed texts have been formed. The student will remember that it was customary of old time, more or less completely, but usually very incompletely, to correct codices in the text or margin by other codices with which the owner chanced to become acquainted. All of our great codices have been so corrected, and often the process has been repeated several times. Thus we distinguish between $\aleph, \aleph^{\mathrm{a}}, \aleph^{\mathrm{b}}$, and between $\mathrm{B}, \mathrm{B}^{2}, \mathrm{~B}^{3}$, etc. Now, suppose a codex which has been thus corrected by a divergent type of text to be used as copy for the production of other codices. The scribe does not know what corrections are merely marginal readings and what are really corrections; he inevitably adopts some or perhaps all of them into his text as he writes it out. And the result is a " mixed text," having for its parents the original codex and all the divergent codices, readings from which had been written on the margin. A very interesting example of such a mixed text is furnished in Codex E of Paul,-Codex Sangermanensis. This MS. is recognisably a copy of the Codex Claromontanus $\left(D_{2}\right)$, but it does not give the original text of $\mathrm{D}$, but that text as corrected by the several hands which had diligently ornamented its margin with readings from other codices. The result is that $\mathrm{E}$ is a mixed text. Of course, if the corrections had all been taken from a single simple codex, and the correcting had been thoroughly done, and the scribe 
in copying from the MS. had noted and adopted them all, the result would not have been a mixed text, but a text of the type of the document to which the original had been conformed. But this completeness is not to be expected, and the result is, therefore, always a more or less mixed text.

Now, it is obvious that the effect of mixture is to confuse genealogies. Wherever it has entered, and in the proportion in which it has entered, the arrangement of the documents in their true genealogical relations is rendered difficult, as also the interpreta. tion of the evidence, after it has been arranged. The detection of the fact of mixture is generally, however, easy, and when it is once detected it can be allowed for; so that it will only force us to apply genealogical evidence with more care and discrimination, rather than render it inapplicable. Suppose, for instance, that in undertaking to determine the mutual relations of a body of five witnessing documents, we find that they separate easily into two pairs, each a representative of a marked type of text, while the fifth witness is intermediate between the pairs. Whether this intermediate position is due to mixture or not is usually possible to determine by the character either of the intermediate readings themselves or of the whole mass of readings furnished by the intermediate witness. If any of the readings are themselves composite readings, uniting the readings characteristic of the other types- "conflate readings" as they are called-and especially if many such readings occur, mixture may be assumed to be proved. If, again, in looking over the whole mass of its readings we find 
the intermediate witness to follow arbitrarily first one and then the other of the two pairs in their obvious errors, and especially if this is true of the obvious errors of a separate document from each (or either) pair, while its own obvious errors can be traced back by transcriptional evidence with equal arbitrariness now to the one and now to the other, mixture again may be assumed. The fact of mixture having been thus determined, it may be allowed for, and the elements in the witness under investigation be separated and placed in the genealogy accordingly.

Some such state of things as we have thus assumed seems actually to ozcur in the witnessing documents to the "Two Ways," or first section of "The Teaching of the Apostles," the scheme of which is apparently as follows :-

Original Text.

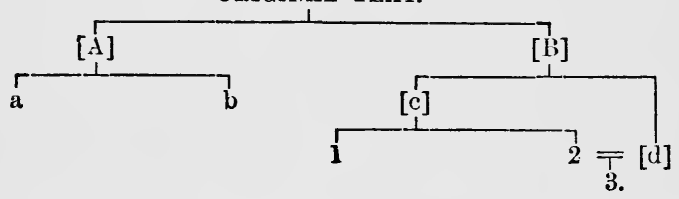

Here the extant witnesses are $a, b$, forming one pair, and 1,2, forming another, together with 3 , which proves to be a descendant of a lost $d$ mixed with 2 . A glance at the table will show the effect of the mixture. Without it, the combination 23 would necessarily determine both what was in c and d, and hence what was in B. But owing to mixture of 3 from 2 , the combination 23 may be only a corrupt 
reading peculiar to 2 ; and 1 may preserve the true reading of $c$, while the reading of $B$ may be that of $\mathrm{c}$ now extant in 1 , or the lost one which stood in $\mathrm{d}$ before mixture with 2 displaced it from its descendant 3 . So, again, without mixture, such a combination as b 1 against 23 would have been impossible. For $b$ and 1 could not agree (accidents apart), unless this reading had been inherited from their common ancestor, and this would imply its presence in all the links between that ancestor and each document-i.e., in $\mathbf{A}$ and in $\mathbf{B}$ and in c. But, again, 2 and 3 could not agree unless in like manner that reading stood in every link between each and their common ancestor-i.e., in d, c, and B. Thus both readings would have to stand in $B$ and in $c$ as well to allow this division of evidence. With the mixture, however, this combination is very possible; for though $b 1$ implies that the reading so supported stood in $c$ and $B, 23$ need not imply anything beyond the presence of its reading in 2 itself, whence it may have been borrowed by 3. A division or attestation of this kind is called a "cross attestation," and "cross attestations" are among the surest proofs that mixture hes taken place. Go back to the diagram from Catullus, for instance. If we find $\mathrm{A}, 1,2,3,4,5$ supporting one reading, and $6,7,8,9$ another; or $A, 8,9$ one, and $1,2,3,4,5,6,7$ another; or $1,2,3,4$, 5,7 one, and $6,8,9$ another,-we may be certain (accidents being excluded) that mixturo has taken place. For each of these divisions is such as cannot occur in a simple genealogy, inasmuch as it springs across from one group to another, and hence pre- 
supposes that its reading was in the parent documents.

The effect of mixture, then, on genealogical evidence is to limit the sphere of its application. Thus, in our present illustration, we no longer know at sight what 23 means. It may be $\mathrm{c}+\mathrm{d}$, and hence carry us back to $B$, or it may be only $2+2$, and so leave us at 2 . Even 123 may be nothing but a corruption introduced by c. In all cases in which $A$ and $B$ differed, 13 is the only combination that we can be sure will take us back to $B$. But mixture does not affect the validity of genealogical evidence wherever it can be applied. Thus, again, in our present illustration, a (or b) 1, or a (or b) 2, or a (or b) 3, all alike carry us back to the common original of all our witnesses despite the mixture of 3 from 2, and in general every combination of $a$ or $b$ with a descendant of $B$ still settles the original text with certainty. We gain somewhat fewer results from genealogy than we should have attained, had there been no mixture; but what we do gain are equally sound in this case as in that. The actual instance of mixture which we have been studying is no doubt a very uncomplicated one. It sufficiently illustrates, nevertheless, its effect, its dangers and its difficulties; and the most complicated case imaginable would differ from it only in degree. The one principle that unties, as far as may be, all the knotty problems that mixture sets for us, is that mixture acts simply like marriage in real genealogies, and we must allow the possibility of each combination of documents, into which it enters, meaning as many diverse things as there are diverse 
ways of tracing up their inheritance to a common original. Thus, the common original of 23 may be found at 2, or if it is the other element of 3 that here unites with 2, not until we reach $B$.

As mixture operates in a directly opposite direction to pure genealogy, - tending to bring together whereas it tends to separate the texts, to compress all lines of descent into one composite line whereas it broadens them out more and more, like a fan,-it is not strange that it introduces some paradoxes into criticism. One of these it is worth while to call attention to. Where mixture has been at work, it is often discovered that a group is weakened instead of strengthened by the addition of other witnesses. For example, in our illustration, 13 is a strong group; its readings must take us back at least to $\mathrm{B}$, the common original of this whole class. Add 2 to this group and at once its value is lowered. For 13 (2 dissenting) must be a combination of 1 descended from $\mathrm{c}$ and of 3 in that part of it which descends from $d$, inasmuch as the dissent of 2 proves that this is not the part of 3 that comes from 2. But 123 is a combination of 1 and 2 descended from $\mathrm{c}$ and 3 in a part that may well have been borrowed from 2 , and hence which also may descend from c. Hence, while 13 must be at least B, the larger group 123 may mean only $\mathrm{c}$, and is therefore a weaker group. Analogous findings crop out in the New Testament. For example, internal evidence of groups proves that B D in Paul is a better group than $B$ D , or than $B$ D $G+$ most uncials and most minuscules. Again, $\times \mathrm{A} \mathrm{C}$ in Paul is a better group than $\times A C D G$. The explanation 
of it lies in this: some mixture has taken place that makes $\mathrm{B} \mathrm{D}$ analogous to 13 in our diagram and B D G analogous to 123 .

The application of genealogical evidence to the New Testament has proved to be exceptionally difficult. Not only has the critic to face here an unheard-of abundance of matter, all of which has to be sifted and classified; but the problem is complicated by an unparalleled amount of mixture, which has reigned so universally that it has left scarcely a half-dozen witnesses entirely unaffected by it. The task of working out the genealogy of the New Testament MSS. has, therefore, been the labour not of one man, nor of one age, but of a succession of generations. The first dim signs of classification were mistily seen by Mill (1707) and Bentley (1720); the genius and diligence of Bengel (1734) and Griesbach (1775-1811) drew the lines of division with some sharpness; and Dr. Hort, in our own day, has at last so far perfected the details that this method of criticism can now be safely used for the settlement of much of the New Testament text. The multifarious abundance of mixture in our witnesses complicates and limits the use of genealogy sadly ; but, as elsewhere, leaves the soundness of its results unaffected wherever it can be applied. Genealogy, thus, does less for us in the New Testament than could have been hoped, but it does much for us nevertheless. In particular, the results attained by it so fully explain those reached by internal evidence of groups, which it is to be remembered is an entirely independent process, and those attained by that process so fully accord with those 


\section{TIIE METHODS OF CRITICISM. 157}

attained by this, that the two methods actually prove the soundness of each other, and place the text obtained by both combined in a very unassailable position.

It does not fall within the plan of this primary treatise to enter fully into the details or the justification of the genealogy which Dr. Hort has worked out for the New Testament witnesses. For this the student must be referred to the full exposition and proof which Dr. Hort has himself given in his epochmaking "Introduction" to the Greek Testament, which was published by Dr. Westcott and himself in 1881. Here, it must suffice to set forth only so much as will enable the beginner to make intelligent use of the method.

At the root of all genealogical investigation lies the classification of the documents according to their affinities; and Dr. Hort has shown that the documents representing the text of the New Testament part into four great and well-marked classes, which he would somewhat conventionally designate the Syrian, Western, Alexandrian, and Neutral. Next the difficult problem of the relation in which the several classes stand to one another is unravelled. And here, first, it has been shown that the Syrian class is not an independent witness to the text of the New Testament, but is rather the result of a critical editing of the New Testament text which was accom plished probably in Syria at some time not earlier than the last half of the third century. The evidence that proves this is of three kinds. First, the distinetive readings of the Syrian text, although common 
in the later fourth century and all subsequent fathers, cannot be traced in ante-Nicene patristic quotations; so that, journeying backwards in time, the favourite text of Chrysostom and his age has disappeared entirely from use by the time we reach Origen. Secondly, the distinctively Syrian readings, when tried by internal evidence, betray themselves as inferior to, and, when tried by transcriptional evidence, as derived from, those of the other classes. And, thirdly, this culminates in the presence among the Syrian readings of a body of "conflate readings," the simple elements of which occur in the other classes, so that it is certain that in some of its parts this text was made out of the Neutral and Alexandrian, or the Neutral and Western, or the Alexandrian and Western. When all the phenomena are closely scrutinised, it is made out positively that the Syrian text was made by a revision out of the other three classes, and preserves nothing from antiquity not already in them. In the presence of the other three classes its testimony is, therefore, collusive testimony, and is simply to be neglected. The case with reference to it is precisely similar to that with reference to the codices mutili of Cicero's "Orator," or the printed editions of the New Testament. We should have much the same warrant for introducing Westcott and Hort's Greek Testament among our witnesses that we have for introducing the Syrian text; in both cases the valuelessness of the text as a witness-bearer depends on the fact that it represents not testimony-i.e., inheritance, but the opinion of editors-i.e., revision. Setting aside, then, the documents containing the Syrian text, we are left 
with only three classes representing the New Testament text. That the Western class is an independent class is easily proved; and its character is so strongly marked that it stands quite apart from all other types. The Alexandrian is more difficult to deal with. Although there is much that would lead us to assign an independent position to it, too, on the whole it seems to be the truer disposition to join it with the Neutral, and arrange these two as two great subclasses of a greater class, including them both and standing over against the Western. With this disposition, the New Testament genealogy will have a form of descent worked out for it which is very closely analogous to that for Catullus, which we have used as a sample genealogy; and it may be graphically represented as follows :-

OrIgINAL TEXT.

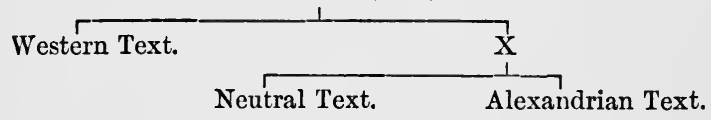

Had no complications of mixture entered into the descent of the various documents which at present represent these three classes, this genealogical scheme would teach us that a combination of the Western text with either the Neutral or Alexandrian would necessarily take us back to the common original of all. On the other hand, wherever each text appeared as sponsor for a different reading, or the Neutral and Alexandrian stood opposed to the Western, the bearing of the external evidence could be settled only by calling in internal evidence of classes. This last named process proves to speak with no doubtful voice. 
It condemns the Western text as the most corrupt of all known forms; it commends the Neutral as the most correct of all forms ; and it assigns a character somewhat intermediate between the two to the Alexandrian. The observed characteristics of the various classes account for this verdict. The licence which seems to have characterised the scribes whose copyings formed the Western text may be almost described as audacity: paraphrase, assimilation, modification, elaboration, extensive interpolation, abound everywhere, and result in the most corrupt text which has ever been current. The Alexandrian text is characterised rather by workmanlike and even scholarly corrections of forms or syntax, and petty modifications, which might easily creep in where the scribe was also partly editor. While honest and careful copying, with only the intrusion of the errors incident to all copying, seems to be the characteristic of the Neutral text. The Syrian text, formed on the basis of these preceding types, appears to have been an effort to replace by a purer and smoother text the corrupt Western type, which had been at that time, for probably a century at the least, practically the Textus Receptus of the Christian world. As such it was eminently successful; and gave to the Church for the next millennium and a half a textus receptus that is practically free from the gross faults of the Western text, that is noble and attractive in form and worthy in diction, and peculiarly suited for the cursory perusal of the closet or reading-desk. Considered as a representative of the New Testament, it is competently exact for all practical purposes; 
considered as an effort to reform a corrupt textus receptus, it is worthy of great admiration when the narrow opportunities of the time when it was made are kept in view; but, considered as a witness of what was in the original New Testament, it passes out of court simply because it is a good editoriallyframed revision of the text, and not a simple copy of it.

It will scarcely need repeating at this point, however, that mixture, so far from being absent from, has been specially active among New Testament MSS. To such an extent has it ruled, that we have perhaps only four codices that have escaped it altogether, to which may possibly be added one version. Codex B in the Gospels, Acts, and Catholic Epistles (not in Paul), seems to be purely, or all but purely, Neutral; $\mathrm{D}, \mathrm{D}_{2}, \mathrm{G}_{3}$, seem purely Western everywhere, and to them may possibly be added the African Latin version. No extant document presents an Alexandrian text unmixed; both Western and Neutral admixtures have entered even C, L, $\Delta$ (in Mark), and the Memphitic version, the most constant representatives of this type of text. It follows, therefore, that a combination of the Western and Alexandrian documents need not be a combination of these two texts, and therefore will not overbear the testimony of the Neutral class; and internal evidence of groups proclaims the Neutral usually the better reading in such cases. To $B, D, D_{2}$, and $G_{3}$ there need be added only some small fragments such as $\mathrm{T}, \Xi$, to complete the list of New Testament MSS. which have not received mixture from the Syrian text. $B$ has a 
Wostern element in Paul's epistles mixed with its Neutral base, but apparently has nowhere received Alexandrian admixture. $N$ has a Neutral base, but has received both Alexandrian and Western elements by mixture, although these elements are unequally distributed, being most abundant in the Gospels (especially in John and parts of Luke), and apparently in the Apocalypse, and least abundant in Paul. Among the versions the African Latin seems purely Western, and the Curetonian Syriac predominatingly so; while the Memphitic and Thebaic, though betraying some Syrian admixture in their extant forms, were originally probably Neutral-Alexandrian with a Western admixture,-largest in the Thebaic. All other documents have a larger or smaller Syrian element, and thus present very composite texts. A is fundamentally Syrian, in the Gospels; but in the other books has only a Syrian admixture on a base fundamentally Neutral, with Western and Alexandrian elements (the latter especially in the Acts and Epistles). $\mathrm{L}$ is AlexandrianNeutral with Western admixture. $\Delta$ is fundamentally Syrian (probably as copied from a MS. fully corrected by a Syrian codex) everywhere except in Mark, where it is very largely Alexandrian-Neutral. Among the codices which have a Syrian element such MSS. as $\mathrm{C}, \mathrm{L}, \mathrm{P}, \mathrm{Q}, \mathrm{R}, \mathrm{Z}, \mathrm{\Gamma}, \Delta$ (in Mark), 33, $81\left(=2^{\mathrm{pe}}\right), 157$ in the Gospels, A, C,E, 13, 61 in Acts and the Catholic Epistles, A, C, M, H, P, 17, 67** in Paul, and A, C, P in the Apocalypse, preserve the largest proportion of pre-Syrian readings.

The effect of this state of things on the genealogy 
of the MSS. of the Gospels, say, for example, may be roughly represented to the eye by the following diagram, which does not aim to arrange the MSS. in anything like their actual relations to one another, but only to represent in the simplest way the general effect of mixture.

Original Text.

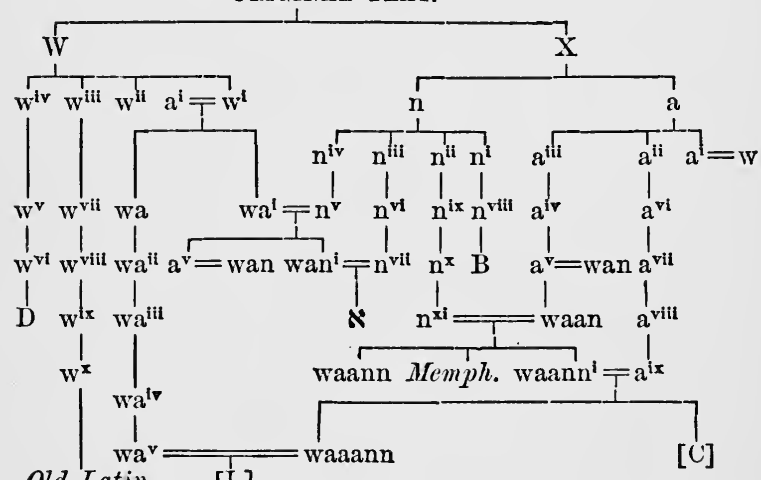

old Latin [L]

A few of the symbols of actual documents have been (very approximately) introduced into this diagram, in order to give point to its lessons. The letters $\mathrm{w}, \mathrm{n}$, and a are intended to represent respectively the Western, Neutral, and Alexandrian classes, each of which originated, of course, in a single copy, although it must be remembered that the peculiarities of each class grew progressively more and more marked, and took time and many copyings thoroughly to develop. In the lines of descent from $\mathrm{w}, \mathrm{n}$, and $\mathrm{a}$, the single letters variously primed-e.g., $\mathrm{w}^{\mathrm{1}}, \mathrm{w}^{\mathrm{ill}}, \mathrm{n}^{1}$, $\mathrm{n}^{\mathrm{iv}}, \mathrm{a}^{\mathrm{l}}, \mathrm{a}^{\mathrm{v}}$-are intended to represent unmixed descendants, while the ordinary genealogical sign of marriage 
$(=)$ is used to represent the union of two documents for the production of a third, the more or less composite character of which is indicated by the combination of letters which represents it,-e.g., wa, wn, an, wan, waan, waann, etc.

Now, the essence of the genealogical principle is that any combination of documents has weight in proportion to the distance from the autograph of the point in the genealogy at which the lines of descent of this combination unite. Assuming that the documents $\aleph, \mathrm{B}, \mathrm{C}, \mathrm{D}, \mathrm{L}$, Old Latin, Memphitic, have been justly placed in the genealogy, it is possible to estimate the value of each combination of these documents by tracing them out in the table. For example, the line that connects $\mathrm{B}$ with the autograph and the line that connects $\mathrm{D}$ with the autograph do not come together until they reach the autograph itself; accidental conjunction in obvious corrections or unavoidable corruptions apart, therefore, the combination B D should be equivalent to the original text itself. On the other hand, since $N$ traces back to the autograph through three different lines-viz., through $\mathrm{w}, \mathrm{n}$, and a-a combination of it with any other document, whether a Western one like $\mathrm{D}$, or a Neutral one like B, or a prevailingly Alexandrian one like $\mathrm{C}$, may, indeed, be a combination of classes, and so take us to their union; or it may be only a combination of documents within one class, and take us only to $\mathrm{w}$, or to $\mathrm{n}$, or to a. The combination $\mathrm{D}$, for instance, may be a combination of Western $D$ with $\aleph$ in its Western element; and so take us only to $w$; cr it may be with $\aleph$ in its Alexandrian or Neutral 
element, and so take us to the original text. It will be remembered that the Western element in $\boldsymbol{N}$ is particularly large in the Gospels; hence $\mathrm{D}$ N here is apt to be only a combination of two Western witnesses; we shall not be surprised, therefore, to note that internal evidence of groups usually condemns this group. For the same reason, however, the combination $\mathrm{B} \kappa$, which might carry us equally easily to $n$, to $X$, or to the autograph through $N$ 's Western element, is most apt to do the latter; and herein we see the reason why internal evidence of groups gives such high character to $B \aleph$. Let these instances suffice. The student will readily see that the genealogical evilence proper needs only supplementing by internal evidence of classes, by which we learn that $w$ is a very corrupt and $n$ a specially good line of descent, to make this distribution of the New Testament documents into their proper classes a very valuable engine of criticism.

The relative divergence of the three great classes from the line of pure descent is not illustrated by the diagram, and therefore it tells us nothing of the results obtained by the important process of internal evidence of classes. Perhaps even this may be roughly represented to the eye by a diagram of the following form. If $\mathrm{x} y$ be taken to represent the line along which all documents would have been ranged, had an absolutely pure descent been preserved and no errors introduced, z q may be taken to represent the actual line of descent which the Western documents have taken, $\mathrm{kv}$ that of the Alexandrian, and $\mathrm{t} \mathrm{s}$ that of the Neutral; while w $p$ will represent the line of 
descent of the Syrian class. Along the line z q may be placed, therefore, the Western documents, each later one representing a greater divergence from the true text; along $\mathrm{k} v$ the Alexandrian documents, and along $t \mathrm{~s}$ the Neutral ones. As $\mathrm{s}$ and $\mathrm{CL}$ are mixed, they may be assigned a more or less intermediate position, with dotted lines connecting them with their several sources. It is evident that the combination of any two documents will take us to the point in the descent of the text where their separate

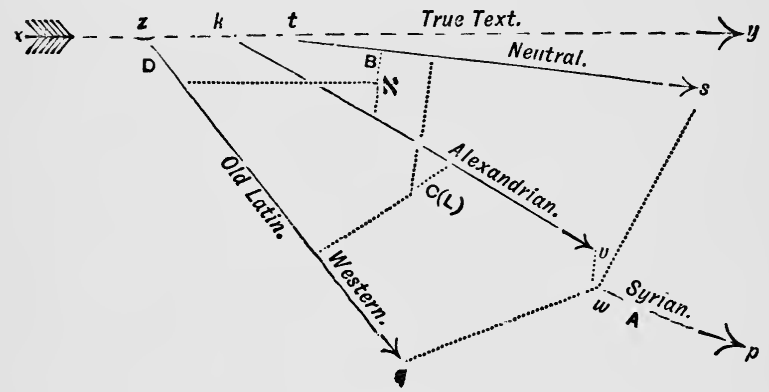

descents coincide. $B$, standing just beyond $t$ on $t s$, is nearest the true text of all single documents. The two lines of B's and of D's descent can unite, when traced back, only at $z$, on the line of true descent, and at a point very far back in time. $\boldsymbol{N}$ draws a contingent from the Western text, and hence $N D$ may only take us to some place on $\mathrm{zq}$; it also draws an element from the Alexandrian text, and hence $\leqslant D$ may take us to $z$ on the line of true descent; and it also draws an element from the Neutral text, and hence again $\times \mathrm{D}$ may take us to $\mathrm{z}$ on the line of true descent. Which of these is the true account can bo 
told in general only by internal evidence of groups, although in particular instances it may be discovered from the nature of the opposing party. For example, if $N D$ stands opposed to B C L $\Delta$ in a passage in Mark, we can argue that the element of $N$ represented here is neither the Neutral element (else would it stand with B), nor the Alexandrian element (else would it agree with $\mathrm{C} \mathrm{L} \Delta$ ), but the Western element; and hence $\mathrm{N}$ is here Western, and takes us only to some point on $\mathrm{z} q$, off of the true line of descent.

This exposition of the genealogical method has been but little successful unless it has shown, along with the nature of genealogies in general, somewhat also of the effect of mixture on the genealogies of the New Testament, and of the methods that must be adopted to overcome the difficulties raised by it. There remains, therefore, only to give a more extended list of the documents which represent each class before we can proceed to study the application of this method to practical use. Let the student only remember that we must treat, here too, each section of the New Testament separately, and that by reason of mixture a single document may find place equally well in more than one class, and the following list will be useful to him.

The Neutral text is more especially represented by the following documents, viz.:-In the Gospels : $B$ (purely), $\times$ largely, and then $\mathrm{T}, \Xi, \mathrm{L}, 33, \Delta$ (in Mark), C, Z, R, Q, P, Menph. (Theb.) (Syr $\left.{ }^{\text {hier }}\right)$. In the Acts and Catholic Epistles : B (probably purely), $\aleph, 61, \mathbf{A}, \mathrm{C}, 13, \mathrm{P}$ (except in Acts and 1 Peter), and 
such minuscules as $27,29,31,36,40,44,68,69,102$, 110, 112, 137, 180, etc., Memph. (Theb.) Syr ${ }^{\text {hier }}$. In Paul : B, , A, C, 17, P, 67**, M, H, Memph. (Theb.) In the Apocalypse: A, P, N, Memph. (Theb.)

The Western text is most fully represented by the following documents, viz :-In the Gospels: D (purely), $\aleph, X, \Gamma, 81\left(=2^{\mathrm{pe}}\right)$, lectionary $39,1-118-131-209$, 13-69-124-346, 22, 28, 157. Also C, $\Delta$ (in Mark), $\Xi, \mathrm{I}, \mathrm{P}, \mathrm{Q}, \mathrm{R}, \mathrm{Z}, \mathrm{N}, \mathrm{W}^{\mathrm{d}}, 33$, Afric $\mathrm{n}^{\circ}$ and European Latin, Syr ${ }^{\text {cu }}$, et hcl.mg. et hier, Theb. (Memph.) In the Acts and Catholic Epristles: D (purely), ↔, E, 31, 44, (of Hort), 61, 137, 180. Also A, C, 13, African and European Latin, Syr ${ }^{\text {hcl. mg. }}$, Theb. (Memph). In Paul : $\mathrm{D}, \mathrm{G},[\mathrm{E}, \mathrm{F}]$, (purely), then $\mathrm{N}, \mathrm{B}, 31,37,46,80,137$, 221, etc. Also A, C, P, 17, M, H, 67**, African and European Latin, Syr. hcl. mg., Theb. (Memph.). In the Apocalypse: $\aleph$, also A, P, African and European Latin, Theb. (Memph.).

The Alexandrian text is most prominently represented by the following documents:-In the Gospels : C, L, N, $\Delta$ (in Mark), X, 33, Z, $\Xi, \mathbf{R}, 1,57$, Memph. Theb. (Pst. Syr.). In the Acts and Catholic Epistles: A, C, , E, 13, 61, P (in Cath. Epistles except 1 John). Also 27, 29, 36, 40, 68, 69, 102, 110, 112, Memph. Theb. (Pst. Syr:). In Paul: A, C, , P, 5, 6, 17, 23, 39, 47, 73, 137, Memph. Theb. (Pst. Syr.). In the Apocalypse : $\aleph, \mathrm{P}, \mathrm{Memph}$. Theb.

The Syrian text is found in the following uncials, together with most minuscules:-In the Gospels: $\mathrm{A}, \mathrm{E}, \mathrm{F}, \mathrm{G}, \mathrm{H}, \mathrm{S}, \mathrm{U}, \mathrm{V}, \Lambda, \Pi$, and in less degree in $\mathrm{C}, \mathrm{L}, \mathrm{N}, \mathrm{P}, \mathrm{Q}, \mathrm{R}, \mathrm{X}, \mathrm{M}, \mathrm{\Gamma}, \Delta$. In the Acts and Catholic Epistles: H, L, P, K, and in large part $\mathrm{P}$, and in 
less degree in A, C, E. In Paul: K, L, N, also in $\mathrm{II}, \mathrm{I}^{2} \mathrm{M}, \mathrm{O}, \mathrm{O}^{\mathrm{b}}, \mathrm{Q}, \mathrm{R}$, and in less degree in $\mathrm{A}, \mathrm{C}$. In the Apocalypse : $\mathrm{B}$, and in large part $\mathbf{P}$, and in less degree $\mathrm{C}, \mathrm{A}$.

The post-Nicene father: generally, present a Syrian text in their citations, although Cyril of Alexandria,

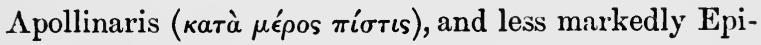
phanius, and even John of Damascus, are to greater or less extent exceptions to this rule. The ante-Nicene patristic citations are prevailingly Western; this is true of those of Marcion, Justin, Irenzeus, Hippolytus, Methodius, Eusebius, and even to some extent of Clement of Alexandria and Origen. A large nonWestern pre-Syrian element is found, also, however, in the Alexandrian fathers, Clement of Alexandria, Origen, Dionysius, Peter, and also in a less degree in Eusebius and others.

The ready application of the genealogical method to practical use in criticism will depend on our ability to read the digests of readings, where the evidence is expressed in terms of individual MSS., in terms of the classes of MSS., or, in other words, to translate testimony expressed in terms of individual MSS. into testimony expressed in terms of classes of MSS. The proper procedure may be tabulated somewhat as follows :-(1) First, sift out all Syrian evidence from the mass of witnesses recorded in the digest, and thus confine attention to the pre-Syrian testimony. If, on sifting out the Syrian evidence, only one reading is left, it is, of course, the oldest transmitted reading, and as such is to be accepted. (2) Next, identify the pre-Syria:n classes, Western, Alexandrian, and Neutral, 
by separating the chief representatives of each from the body of the witnesses, allowing everywhere for mixture. (3) If, now, we have three readings, one supported by each of the pre-Syrian classes, the Neutral reading should have the preference. (4) If we have only two readings, that supported by the Neutral and Western against the Alexandrian is to be preferred; or that supported by the Neutral and Alexandrian against the Western is to be preferred; or (since all prominent Alexandrian documents have a large Western element) that supported by the Neutral against the Western and Alexandrian is to be preferred.

A few examples are needed to illustrate practice under these rules. The sifting out of the Syrian evidence is rendered necessary by the relation which the Syrian class bears to the others as dependent on them and made out of them, by which its evidence is made collusive and confusing. It will be sufficiently accurately accomplished at first by confining attention to the following documents, viz.: in the Gospels: $\aleph, \mathrm{B}, \mathrm{C}, \mathrm{D}, \mathrm{L}, \mathrm{P}, \mathrm{Q}, \mathrm{R}, \mathrm{T}, \mathrm{Z}, \Delta$ (in Mark), 五, 33, Latin versions, Curetonian and Jerusalem Syriac, Memphitic,

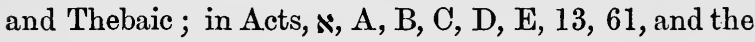
same versions (except the Curetonian Syriac, which is not extant here); in the Catholic Epistles, א, A, B, C, 13, the Latin versions, Memphitic and Thebaic; in Paul, $\times, A, B, C, D, G, 17,67 * *$, and the same versions; and everywhere the certain quotations of the anteNicene fathers. Any reading which has the support of no one of these witnesses may be safely set aside as Syrian or post-Syrian; and even if a few 
of these witnesses which contain a large Syrian element join with the mass of later witnesses against the body of those named here, the reading may still be safely neglected as Syrian. Not infrequently the reading is settled by the sifting out of the Syrian docuinents: when they are removed, the variation is removed too. An instance may be found in Marki. 2, where "in the prophets" is read by $\mathrm{A}, \mathrm{E}, \mathrm{F}, \mathrm{G}, \mathrm{H}, \mathrm{K}$, $\mathrm{M}, \mathrm{P}, \mathrm{U}, \mathrm{V}, \mathrm{\Gamma}, \mathrm{II}$, many minuscules, the text of the Harclean Syriac, the Armenian according to Zohrab's edition, the Athiopic, and some late fathers, including the Latin translation of Irenæus in opposition to the Greek elsewhere. Only $\mathrm{P}$ in this list occurs in the test list given above, and the whole support of the reading is, therefore, distinctly Syrian, so that when the Syrian testimony is sifted out we have left only " in Isaiah the prophet," supported by the whole pre-Syrian array-viz., $\mathrm{B} \wedge 33, \mathrm{I}, \Delta, \mathrm{D}$, about twenty-five minuscules, the Latin versions, the Memphitic, Peshitto, Jerusalem, and margin of the Harclean Syriac, the Gothic, and codices of the Armenian versions, with Irenæus and Origen among the fathers.

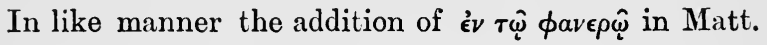
vi. 4 and 6 is sifted out with the Syrian testimony, leaving the whole body of pre-Syrian witnesses at one for its omission. In such cases our work is easily done, and the text is restored with the very greatest certitude. Any reading supported only by the Syrian class is convicted of having originated after A.D. 250.

Often, however, we seem no nearer our goal, after the Syrian evidence has been sifted out, than we were 
at the start. Two or sometimes three readings may still face us, and our real task is yet before us. The next step is to identify the classes represented in the groups of witnesses supporting each reading, by attending very carefully to their constituent elements, whether pure representatives of any one class or mixed representatives of more than one. This is often a very delicate piece of work, but it is often also easy, and is generally at least possible. It is usually best to begin by identifying a class of which we have pure representatives, and to proceed thence to those the only extant representatives of which are mixed. In the Gospels it is nearly equally easy to identify the Neutral and the Western readings; in Paul we should begin with the Western; in Acts and the Catholic Epistles, again, we may almost equally well begin with either the Western or Neutral. Let us look at Mark iii. 29 as an example. Here the reading "judgment" sifts out with the Syrian testimony, and we are confronted with the pair of readings $\dot{\mu} \mu \alpha \rho \tau \dot{\eta} \mu \alpha \tau o s$ supported by $\aleph, \mathrm{B}, \mathrm{L}, \Delta, 28,33$, $81\left(=2^{\mathrm{pc}}\right)$, and á $\mu a \rho \cos ^{2}$ supported by $\mathrm{C}^{*}$ vid $, \mathrm{D}, 13$, 69,346 , Ath. The versions here can give but littie help, and we omit them altogether. We note at once that purely Western D is united with a small body of adherents, all of which have Western elements, in support of a $\mu a \rho$ rias, which we may thus recognise as Western. On the other side, the purely Neutral B stands in the midst of a group which therefore certainly embraces the Neutral class. Whether $\dot{\alpha} \mu a \rho \tau \eta^{\prime} \mu a \tau o s$ is also Alexandrian is more doubtful, inasmuch as the Alexandrian documents supporting 
it have all Neutral elements. On the whole, however, this reading may be safely set down to the credit of both the Alexandrian and Neutral classes. But in either contingency internal evidence of classes determines for it as probably the true reading. A similar example may be found in the vivid insertion of $\tau o$ in Mark ix. 23, which has the support of $\mathrm{B} \aleph, \mathrm{C} L \Delta, \mathrm{X} \Gamma$, involving the typical Neutral and Alexandrian witnesses against the omission by $\mathrm{D}, 13$, $28,69,81\left(=2^{\text {pe }}\right), 124,131$, which is recognisably Western. In the next verse (ix. 24) the $\mu \in \tau \dot{u} \delta a \kappa \rho v i \omega \nu$ is in the same way recognised as Western, supported as it is by D, N, X, T, the European, Italian and Vulgate Latin, Peshitto and Harclean Syriac and Gothic versions, while its omission is testified by $\mathrm{B} \kappa$, C $\mathrm{L} \Delta$, $28, \mathrm{k}$ of the African Latin, the Memphitic, Armenian and Athiopic versions-i.e., by the combined Neutral and Alexandrian witnesses. A considerable insertion of the Western text is found in Mark ix. 45 and 46, supported only by D, N, X, $\Gamma$, Latin, Syriac, Gothic and Athiopic versions, while the onission is supported by $\mathrm{B} \kappa, \mathrm{C} \mathrm{L} \Delta, 1,28,81\left(=2^{\mathrm{pe}}\right), 118,251$, $\mathrm{k}$ of the African Latin, Memphitic, and Armenian. On the same kind of evidence Mark ix. 49, last clause, and xi. 26, are recognised as interpolations of the Western text. In all these cases we have proceeded by identifying and rejecting the Western reading, and the help in determining the text has been sure and immediate.

In such a reading, on the other hand, as the addition of $\dot{\rho} \hat{\mu} \mu a$ in Matt. v. 11, which is witnessed by C, $\Gamma, \Delta$, Peshitto and Harclean Syriac, and Origen, 
against $\aleph, \mathrm{B}, \mathrm{D}$, Latin, Memphitic, Jerusalem Syriac, and Aithiopic versions, and Cyril of Alexandria; or such an one as the addition of roîs ápxaîos in Matt. v. 27, by $\mathrm{L}, \Delta$, 33, later Latin, Curetonian Syriac and Harclean Syriac versions, Irenæus, and Eusebius, against $\mathrm{B} \aleph, \mathrm{D} \Gamma$, African and European Latin, Memphitic, Peshitto Syriac, Armenian, Athiopic, and Gothic versions, and Origen; we must proceed by identifying and rejecting the Alexandrian reading, which appears to be opposed by the combined Neutral $(\mathrm{B}, \aleph$, etc.) and Western $(\mathrm{D}$, etc.) witnesses. In such cases the Alexandrian reading is identified by a process of exclusion : for example, in the former case C, $\Delta$, are not Neutral, for they separate from the Neutral documents, and they are not Western, for they separate from the Western documents; they must be, then, either Alexandrian or Syrian, and the presence of the reading in Origen seems to point to the former. In these cases, too, the reading is settled securely by the combination of Western and Neutral witnesses.

Still another class of variations may be illustrated by the insertion or omission of "which art in heaven " at the opening of the Lord's Prayer in Luke's account of it. The insertion is supported by the Syrian text, and also by $\mathrm{D}, \mathrm{C}, \Gamma, \Delta, \mathrm{X}, 33$, etc., Old Latin codices, Curetonian, Peshitto and Harclean Syriac, Memphitic, and Athiopic; and the omission by B, N, L, 1, 22, 57, 130, 346, Vulgate Latin, and Armenian versions, Origen and Tertullian. The Neutral text certainly is for omission ( $\mathrm{B}, \mathrm{N}$, etc.), and the Western for insertion (D, Old Latin, Curetonian Syriac). But representą- 
tives of the Alexandrian text are on both sides : $\aleph, \mathrm{L}$, 1,57 , on one, and C, $\Gamma, \Delta, X, 33$, Memph., on the other. If we could be sure that this latter group represented the Alexandrian here, its union with the Western would carry our decision with it; but every single member of it is so strongly mixed with Western readings that it would be dangerous in the extreme to count it anything but Western here. So that we can only believe that we have here a case of Neutral versus Western, and follow the former accordingly. As for the Alexandrian reading, it is either lost or else represented by $\mathrm{L}, 1,57$. Internal evidence of groups not only supports this conclusion, but forces it upon us. Quite similarly "Let Thy kingdom come, as in heaven, also on the earth " is inserted at the end of the same verse by $\aleph, C, \Gamma, \Lambda, X, D$, Old Latin, Peshitto and Harclean Syriac, Memphitic, and Ethiopic, against the protest of $\mathrm{B}, \mathrm{L}, 1,22,130,346$, Vulgate Latin, Curetonian Syriac, Armenian, and Origen and Tertullian. The transference of $\aleph$, which has a very marked Western element in Luke, makes no essential difference in the testimony; every codex arrayed here with $\mathrm{D}$ has a large Western element, and the whole combination is explicable as a Western inheritance. So that again we treat the matter as an instance of Western versus Neutral, and decide accordingly, by internal evidence of classes, for the Neutral.

A special but very small class of readings, called by Dr. Hort “Western non-interpolations," deserves a separate notice. An example may be found in the odd insertion into Matt. xxvii. 49, to which attention was called when we were speaking of internal evidence 
of groups. The insertion is supported by $\mathrm{N}, \mathrm{B}, \mathrm{C}, \mathrm{T}_{\text {, }}$, $\mathrm{U}, \Gamma, 5,48,67,115,127$, Athiopic,-including the Neutral ( $N, \mathrm{~B}$, etc.), and Alexandrian (C, L, $\mathrm{\Gamma}, 5$, 48,67 , etc.) witnesses. The omission has the support of only D, A, E, F, G, H, K, M, S, V, $\Delta$, I, most minuscules, the Latin, Peshitto and Harclean Syriac, Memphitic, Gothic, and Armenian versions, and the like,--which are easily seen to be Syrian and Western. Yet, as already pointed out, internal evidence of readings seems to forbid our accepting these words as genuine, and thus forces us to decide against the combination of the Neutral and Alexandrian and for the Western standing alone. In this reading, and possibly in some others like it (for each must be treated apart), we have the exception to the general rule that the Neutral-Alexandrian class is better than the Western, which the genealogical scheme on which we are working allows for and hence presupposes. If the Neutral and Alexandrian have been rightly accounted two branches of one stem set over against the Western, it would be difficult to understand how it could happen that the Western should be always wrong, without exception, and this stem always right. The process of internal evidence of classes, like internal evidence of groups and documents, determines only general and usual relations, and the exceptions to the general rule can be detected only by internal evidence of readings. If, for the moment, we conceive of the line $x t$ in the last diagram as not the line of absolutely true descent, but the actual line of descent of codices, from which $\mathrm{zq}$ diverges when the descent becomes Western, $\mathrm{k} \mathrm{v}$ when it becomes Alexandrian, 
and $t \mathrm{~s}$ when it becomes Neutral, it will be evident to the eye that the Neutro-Alexandrian descent coincided for the space representel by $\mathrm{z} k$, after tho separation of the Western descent had taken place, and hence it is to be expected that the combination Neutral-Alexandrian will testify to some errors introduced into their common stem during the series of copyings represented by the space $\mathrm{z} \mathrm{k}$. In other words, reverting to the former diagram, the very fict that the Neutral and Alexandrian classes are arranged, not as two independent classes co-ordinate with the Western, but as two sub-classes of $\mathrm{X}$, which is coordinate with the Western, presupposes that they will combine against the Western in some errors. From all which we learn that textual criticism, even with the aid of the genealogical evidence, cannot, any more than in the case of other methods, be prosecuted mechanically; but each reading must be very carefully considered, separately, ere our conclusion concerning it be announced.

Procedure under the genealogical method in Paul's Epistles has enough of speciality to render it desirable to give some illustrations of it. It is a good practical rule to go by in the Gospels, to follow the group which contains $B$, at least provisionally. The best practical rule to go by in Paul is, to suspect the group which contains $\mathrm{D}, \mathrm{G}$, unless practically all the primary witnesses join with them. This difference of procedure results from the fact that $\mathbf{B}$ is purely Neutral in the Gospels, and hence forms there the rallying point for the documents of the best class to gather around. In Paul B has a Western element, and hence may stand 
with only Western documents - the worst classaround it. With no pure representative of either the Neutral or Alexandrian class, we are reduced in Paul to identifying, as our first step, the Western class by the aid of its pure representatives D and G, and this we identify only to reject, if it stands alone. And as all codices have a Western element, it follows further that any addition to $D G$ need not alter its character as Western and probably corrupt. Hence A D G, B D G, $N$ D G, C D G, or A B D G, A N D A A D G, B C D G, C D G, alike, need represent nothing better than a Western error. No à priori reason exists why $\mathrm{B} \aleph \mathrm{DG}$ might not equally do so; but internal evidence of groups here steps in and proclaims this group so good that we are obliged to account it usually a union of Neutral (BN) and Western (D G) classes. This only shows that $\mathrm{B}$ and $\mathrm{N}$, although both having Western elements, get their Western elements independently, and do not usually coincide in the same Western corruption; hence, while thoroughly consistent with the genealogical scheme, this finding is inconsistent with the supposition that these two codices come from a proximate original only a step or two older than themselves. The larger combinations, even, such as $\mathrm{AC} \times \mathrm{DG}$, or $\mathrm{ABCDG}$, may still ke merely Western; and we are thus led to give the preference, on genealogical grounds, often to small groups which include only one or more primary uncials when opposed by a group including D G.

As an example, we may look at 2 Cor. ii. 9, where 
after the Syrian evidence is sifted out, we have $\epsilon$, read by $\aleph, C, D, G, P$, Latin versions, whereas $i$ is the reading of $B, A, 17,109$. Here, although all the recent editors read $\epsilon i$ in their text (Westcott and Hort placing $\dot{\eta}$ in their margin), the genealogical evidence is distinctly in favour of $\eta$, the group $\times \mathrm{C} \mathrm{D} \mathrm{G} \mathrm{P}$ being distinctly Western. It may be added that the transmutation of $\eta$ into $\epsilon \iota$ either by itacism $(\eta, \iota, \epsilon \iota)$ or by mistake of the uncial letters ( $\epsilon I$ for $H$ ) is very easy and frequent: a case of it occurs in the neighbouring 2 Cor. iii. 1 , where $\epsilon i \mu \eta^{\prime}$ is read by $A, P$, and

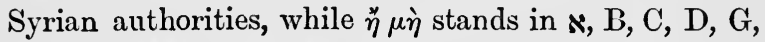
$31,37,67^{* *}$, Latin, Memphitic, etc. Here we have a combination of the Neutral and Western at least, if not of all pre-Syrian classes against Syrian or possibly Syrian and Alexandrian, and easily follow this group even though it contains the ominous $\mathrm{D} \mathrm{G}$, since along with D G stands $\times$ B C, which is differentiated from other. groups including $\mathrm{D} \mathrm{G}$, by a very emphatic verdict of internal evidence of groups. The complications that can arise by dividing the testimony a step further are well illustrated in 2 Cor. ii. 7, where $\mu \hat{a} \lambda \lambda o \nu$ is placed before í $\mu a \hat{s}$ by $\aleph, \mathrm{C}, \mathrm{L}, \mathrm{P}, \mathrm{Vulgate}$ Latin, Memphitic, Harclean Syriac, Armenian, and Syrian authorities, after $i \mu \hat{\alpha} s$ by D, E, F, G, 17, Goth., and omitted altogether by B, A, Peshitto Syriac, and Augustine. Tischendorf and Tregelles follow the first array, although Tregelles places "omit" opposite in the margin, and Westcott and Hort follow the last, placing $\mu \hat{a} \lambda \lambda o \nu$ in their margin before $i \mu \hat{\alpha} s$. Who is right? Prima facie the first group is Alexandrian, the second Western, and the third Neutral; and were this the 
true finding it would be difficult to resist the com . bined evidence of the Western and Alexandrian texts in an insertion in which they did not stand in collusion. More likely, however, the insertion of $\mu a \hat{\lambda} \lambda o v$ is Western, and the misplacing of it a later divergence; in which case Westcott and Hort's conclusion will result. Another instructive reading occurs in 2 Cor. xii. 7, where $s$, B, A, G, 17, Athiopic, insert a $\delta \iota$, which D, P, the Latin, Gothic, Syriac and Armenian versions and the Syrian evidence omit. The omission is here easily seen to be Western, while the insertion has the combined support of the Neutral and Alexandrian documents and on genealogical grounds is preferable. In Gal. ii. 12, where $\aleph, \mathrm{B}, \mathrm{D}^{*}, \mathrm{G}, 73,45$, Origen read $\hat{\eta} \lambda \theta \in \nu$ against $\eta^{\mathfrak{y}} \lambda \theta$ ov read by $\mathrm{A}, \mathrm{C}, \mathrm{D}^{\mathrm{b} \text { and } \mathrm{c}}, \mathrm{H}, \mathrm{K}, \mathrm{L}, \mathbf{P}$, most minuscules, Vulgate Latin, Syriac, Memphitic, Armenian, Gothic versions and fathers, we have one of the rare cases in which $\lesssim B$ together unite with $\mathrm{D}, \mathrm{G}$, in a Western corruption; for corruption this is certainly shown to be by internal evidence. Again, we learn that the rule ascertained by internal evidence of groups that $\mathrm{B}$ is usually right is not exceptionless; and that though $\mathrm{N}$ and $\mathrm{P}$ do not usually unite in the same Western readings, they do unite in one occasionally. This is an example of this rarity.

The difficulty of dealing with variations on genealogical grounds culminates in that portion of the Epistles (Heb. ix. 14 to Philemon inclusive of the Pastoral Epistles) where B is lost. Shall we read, for instance, "priest" or "high priest" at Heb. x. 11 ? All three of the great editions read "priest," but Tregelles and Westcott and Hort put the alternative 
in the margin. Fu:" "priest" we have $s, \mathrm{D}, \mathrm{E}, \mathrm{K}, \mathrm{L}, 17$, 47, most minuscules, Old Latin codices, Vulgate Latin, Memphitic, the text of the Iarclean Syriac, Chrysostom, Euthalius, Theodoret; while for "high priest" we have $\mathrm{A}, \mathrm{C}, \mathrm{P}, 31,37,46,73,74,80,137$, and sixteen others, Peshitto and Harclean Syriac (with asterisk), Armenian, Athiopic, Cyril of Alexandria. We long for B : if B should stand by $\mathrm{N}, \mathrm{D}$, etc., we should have the approved group $\leqslant \mathrm{B} D=$ Neutral + Western; if it should take its place alongside of A, C, P we could recognise it as Neutral versus $\ltimes, 1$, Western. Internal evidence of readings and a careful study of grouping inclines us to suppose the former most likely to be the right solution. The weight of genealogical evidence is more clearly traceable in the case of three interesting readings in the first verse of the same chapter, where $\leqslant P$ adds

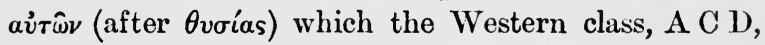
omits; $\times \mathrm{C}$ reads ås against the Western class, D H I, which supports ais; and $\times$ A C P 1767 **

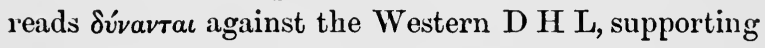
$\delta$ v́varal. In no one of these cases would the presence of $\mathrm{B}$ on either side change the determination.

In the Apocalypse, finally, genealogical evidence can as yet be scarcely employed at all, without the greatest doubt and difficulty. 


\section{CHAPTER III.}

\section{TIE PRAXIS OF CRITICISII.}

T $N$ the foregoing pages the available methods of 1 criticism have been considered separately, anà thus stock has been taken of the instruments within reach for the performance of this very delicate work. It remains to inquire how these instruments are to be used in the actual prosecution of criticism. Each method makes its own promises and attains for us its own results. But we must not permit ourselves to be satisfied with results obtained by one method only. The best criticism is rather that which makes the fullest use of all the methods, and checks and conditions and extends the results of each by the results of all. The value of combination of the methods is twofold. We thus obtain a system of checks: we may test the results obtained by ono method by the results obtained by another, and by repeated trials preserve ourselves from error. And we obtain what may be called a system of relays: where one method fails to give a confident verdict, another may be called in, and thus their combination may enable us to carry criticism several stages farther than would be possible by one method alone. The effect of using a variety of methods, therefore, 
Is both to extend the sphere which our criticism is able to reach and more firmly to settle the text over its whole extent. 'The first rule for the application of these methods, therefore, is to apply them all. Let no one be slighted; let each be used carefully and independently, and the results obtained by each carefully compared together. When the findings of the various methods agree the conclusion is certain, and we may feel sure that we have attained the autographic text. When they disagree, opportunity is given for review and revision of the whole process, with the not infrequent result of the discovery of an error, the correction of which will harmonise the evidence. By this repeated and, if need be, again repeated verification of our processes, our conclusions attain ever firmer standing; and it is very seldom indeed that the verdicts of the different kinds of evidence may not be brought into agreement. Until they agree some doubt continues to cling to our conclusions; and the canon may safely be formulated that no reading can be finally accepted against which any form of evidence immovably protests.

Experience further indicates to us that it is not a matter of entire indifference in what order we use the various methods of criticism. Certain of them are more liable than others to be swerved by the mental state of the critic, and it is a good rule to begin with the most objective. Certain of them yield at best only probable results, and it is a good rule to begin with the most decisive. Certain of them are largely negative in their findings, and it is a good rule to begin with the most positive. For 
each of these reasons it is safest to begin with the external evidence, and only when its bearing has been at least provisionally determined, to proceed to the internal evidence of readings. To begin with internal evidence of readings, especially with intrinsic evidence, runs very great lisk of so filling the mind with the feeling that such or such a reading ought to stand in the text, that we may end by unconsciously making it stand there, against the evidence. The best procedure, and that most likely to issue soundly, is to begin with the consideration of the genealogical evidence, and when its results are obtained, to proceed to internal evidence of groups, and thence to internal evidence of readings,- - usually in the order of, first, the transcriptional, and, secondly, the intrinsic evidence. When genealogical evidence speaks with force, it yields a testimony which ranks above all others in ease and certainty of interpretation, and consequently, by beginning with it, we consider, first, the surest evidence, and gradually proceed to that of more doubtful interpretation, although of no less finality when its meaning is certainly attained. After the evidence is all in, our next duty is to compare and harmonise the several results. When they are finally and hopelessly discordant, nothing is left us but to consider whether the oldest transmitted text may not itself be corrupt, and thus differ from the autographic text.

Perhaps the best way to exhibit the right procedure in criticism is by means of an example or two. Let us look at the famous reading in Acts $\mathrm{xx} .28$, where we have the following variations :- 
кvpıov, A, C** D, E, 13, 15, 36, 40, 69, 110, 118, and eight others; $g$ of the Old Latin, Memphitic, Thebaic, margin of the Harclean Syriac, Armenian, Irenæus (Latin), (Athanasius), Didymus, Jerome, etc.

$\theta \epsilon o v, \mathrm{~B}, \aleph, 68$, lectionary 12 , and twelve others; Vulgate Latin, (Peshitto), text of the Harclean Syriac, Epiphanius, Basil, Theodore of Mopsuestia (Latin), Cyril of Alexandria, etc.

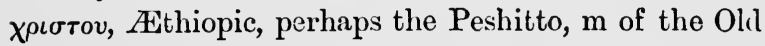
Latin (Jesu Christi).

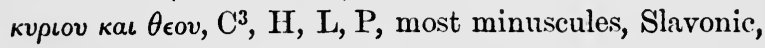

Theophylact, etc.

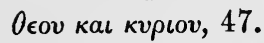
кvрเоv $\theta \epsilon o v, 3,95 * \%$.

If we should undertake to estimate the relative weight of these groups of testimony by the weight of the separate codices included in each, we might well despair of ever reaching a conclusion. The best uncials are for $\Theta \epsilon o \hat{v}$, the best minuscules and versions

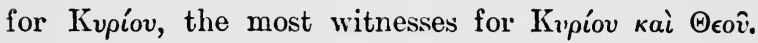
Fortunately there is a better way. Beginning with the genealogical evidence, we sift out all readings but Kupíov and $\Theta \epsilon o \hat{v}$ in sifting out the Syrian evidence. We observe next that the typical Western document D stands on the side of Kvo'ov, and the typical Neutral B on the side of $\Theta \epsilon o \hat{v}$, and considering the other testimony for each, we see that this much is certain : ⿶eov is the Neutral reading, and Kupiov the Western. The most constant representatives of the Alexandrian class stand by the side of $D$ and tho 
Western witnesses, in support of Kvpiov; here are A, C, 13, 36, 40, 69, 110, Memph., Theb. Were not all these documents full of Western readings, we might find the Alexandrian reading in Kvpiov, but this is not presumable in the mixed condition of all these documents, and internal evidence of classes gives us no ground to believe that the union of the Western with the chief Alexandrian documents is a union of the two classes. We must treat this reading, therefore, as a case in which the Western and Neutral classes oppose one another, and internal evidence of classes forces us to accept in such cases the Neutral reading as presumably right. Thus the genealogical evidence supports $\Theta_{\epsilon o \hat{v}}$. On turning to internal evidence of groups we obtain the same result. The high character given to $\mathrm{B} \boldsymbol{N}$ by this process, whether it stands alone, or in whatever combination with other documents, affords strong ground for pref zrring $\Theta \epsilon o \hat{v}$, especially as it has the important further support of the Vulgate Latin and Cyril of Alexandria. This result is cumulative to the former, so that the external evidence throws a very strong cumulative probability in favour of $\Theta \epsilon o \hat{v}$.

We next appeal to the transcriptional evidence.

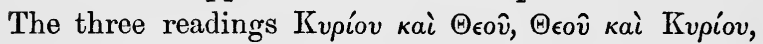
and $\mathrm{K} v i^{\prime} o v$ $\Theta \epsilon \hat{v}$, are clearly all conflate readings, and presuppose the previous existence of both the others.

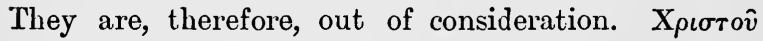
is easily accounted for either as a substitution of a synonym for Kvpíov or $\Theta \epsilon o v$ (for whichever word was used, Christ was the person meant), or a misreading of an abbreviation, $\overline{K Y}$ or $\overline{\theta Y}$ being taken 
for $\overline{X Y}$, or even perhaps $\overline{K P Y}$ (cf. $\overline{K P N}, 1$ Cor. i. 1 of Codex Augiensis) for $\overline{X P Y}$ (D. sæpe: cf. Rom. vii. 4 in $\aleph$ ). In either case it is a derivative reading and may be neglected. The problem of transcriptional evidence, then, is to decide between the relative originality of Kupiov and $\Theta \epsilon o \hat{v}$, the difference between which again concerns only a single letter: $\overline{k Y}$ and $\overline{\theta Y}$. As a mere blunder, either might cqually easily pass into the other. They are equally brief. Either reading would be characteristic enough; the phraso "Church of God" is as common as the phrase "the

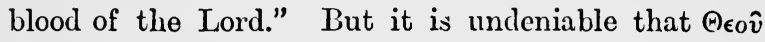
is the more difficult reading, and this commends it to us as probably genuine. If $\Theta \epsilon o \hat{v}$ were original, it is easy to see that it would be startling, and that the scribe's mind working upon it might (scribe-like) intrude its mental explanation into the text; so that the very unusual character of the phrase here becomes, transcriptionally considered, its strongest commendation. On the other hand, if Kvpiov were the original reading, there is no jag in the phrase to eatch the mind of the scribe and throw it off its balance; he would write smoothly on and find full satisfaction in the language as it stood. It seems, indeed, impossible to find any reason for altering $\mathrm{K}_{v p i o v}$ into $\Theta \epsilon o \hat{v}$ except a dogmatic one, and if dogmatic considerations be brought into the case they certainly authenticate $\Theta \epsilon o v$ rather. For a dogmatic alteration of $\mathrm{K} v$ piov into $\Theta \epsilon o \hat{v}$ could have no incitement except a cold determination to manufacture a proof text: there is nothing offensive to any one in the reading Kvpiov, and nothing that could 
suggest alteration. But $\Theta \epsilon \hat{v}$ might give offence to many : to extreme Arians, and to the orthodox antiPatripassians alike, and even to simple orthodox souls whose philosophical way of looking at theological language would be offended at this sharp paradox. Like language horrified Athanasius himself (Cont A pollinar., ii. 11, 12, 13). If dogmatic alteration has taken place, therefore, it certainly has softened the original $\Theta \epsilon o v$ into the less startling Kvpíov. And from every point of view the transcriptional evidence supports $\Theta \epsilon o \hat{v}$.

Does intrinsic evidence unalterably oppose this conclusion, commended alike by genealogical evidence, internal evidence of groups, and transcriptional evidence? For this is the way in which this branch of evidence may be fairly approached, seeing that it delivers negative judgments with far more force than positive ones. It is difficult to see how the reading $\Theta \epsilon o \hat{v}$ fails to accord with the contextual flow of thought or the rhetoric. There is rather a fine propriety in it, and a solemn and moving motive lies beneath it. Paul incites the elders to more heedful attention to their duties to their flock by the considerations-(1) that it was the Holy Ghost who made them bishops, and (2) that it was the blood of God Himself that bought the flock now placed under their care. It is said, however, that it is un-Pauline to call Christ God. The argument is a merely verbal one, and hence of small weight. And it is easy to point to Rom. ix. 5 and Titus ii. 13, where Paul does call Jesus God; and when it is objected that these are disputed passages, it is just to remind tho 
objector that this will exclude his original statement as well as our rebuttal of it. Apart from such passages, however, it is very easy to show that Paul held a very exalted doctrine of Clirist's person, and might as well as John (John i. 1) have given Him the name which his descriptions imply; and this is enough to set aside the force of the objection that the unwontedness of the phrase is fatal to its genuineness. This very unwontedness is from the transcriptional point of view its best proof of genuineness, and it is not the part of intrinsic evidence to pare down the unusual. The phrase would oppose its own genuineness only if it contradicted Paul's otherwise known opinions, or at least were not only unexampled but inexplicable. But since this same Paul has elsewhere declared that Christ was begotten before every creature, we need find nothing to stumble at in his applying to Him here, where the context bids us look for a solemn enhancing of the greatness of the gift of His blood, the name which is elsewhere implied. 'The effect of these considerations is not merely neg:ative; it is corroborative of the other evidence. And since all forms of evidence unite to commend $\Theta_{\epsilon} \hat{v}$ here, their cumulative effect makes it certain that this is the original reading.

Our next example shall be the very important variation that is found at John i. 18. Here the chief rival readings are :-

o $\mu$ ovo $\epsilon v \eta$ s vios: A, Cc, E, F, G, II, K, M, S, U, V, X, $\Gamma, \Delta, \Lambda, I$, and all minuscules except 33 ; the Old and Vulgate Latin, the Curetonian Syriac, 
the text of the Harclean Syriac, the Jerusalem Syriac, the Armenian in Platt's edition [Irenæus (Latin)], Eusebius, Athanasius, Theodore of Mopsuestia, Chrysostom, etc.

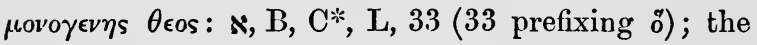
Memphitic, Peshitto Syriac, margin of the Harclean Syriac, the Valentinians [Irenæus (Latin)], Clement, Origen, Epiphanius, Didymus, Basil, Gregory of Nyssa, Cyril of Alexandria, etc.

Genealogically, it is to be noted that $\delta \mu o \nu 0 \gamma \epsilon v \grave{\eta} s$ viós is the reading of the Syrian class, and when the Syrian testimony is sifted out, of the typical Western witnesses. $\mathrm{D}$ is defective here; but the union of A X, Old Latin and Curetonian Syriac, cannot well have more than one meaning. On the other hand, the Neutral documents $(B, \aleph)$ unite with the most constant Alexandrian documents (C, L, 33, Mem-

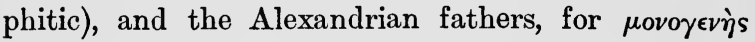
®eós, which thus seems to have the combined support of the Neutral and Alexandrian classes. Internal evidence of classes very strongly commends the Neutral-Alexandrian readings, and genealogical evi-

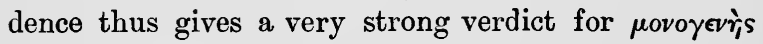
$\Theta \epsilon o ́ s . \quad$ Internal evidence of groups casts its weighty vote in the same scale, -as B , supported by an additional body of important witnesses, advises us. So that again external evidence is cumulatively set

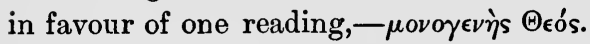

The chief divergent words in the two readings differ from one another in this case, too, by a single letter, since they stand in the MSS. $\overline{\gamma c}$ and $\overline{\theta c}$; and transcrip. 
tionally either one of these might very readily pass into the other by a mere scribe's blunder. The case is complicated, however, by the connection of the insertion or omission of the $\delta$ nine letters back with the variation in the main word. This seems to exclude a mere error of the eye as the cause of the change ; and dogmatic considerations stand in this case just as in Acts xx. 28. The insertion of @eós for dogmatic reasons would be a barefaced manufacture of a proof text, as the reading viòs could give offence to no one, while, on the other hand, the reading $\Theta$ eós might be an offence to a great body of readers. If dogmatic considerations, therefore, are responsible for either reading, surely they have produced the softening vios, and not the startling @єós. The canon that the harder reading is to be preferred, again, commends @eós. If ô... viós stood here originally, there would be nothing to attract a scribe's attention or to suggest a change. "The only-begotten Son" is a sufficiently common phrase in

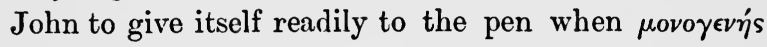
is being written. On the other hand, " only begotten God" is unique; if the scribe observed it, his mind might unconsciously transmute it into the more familiar phraseology, and if he merely glanced at the phrase he might readily take it for the more familiar " only begotten Son." In every way, thus, transcrip-

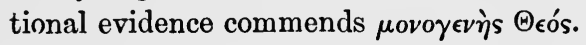

Intrinsically, either reading, had we known it alone, would be satisfactory enough. "The only begotten Son" is a Johannean phrase, and John might be expected to use it here too. But to call the Logos "God" is also Johannean, and "only begotten God" 
only unites here the two predicates which had just before been assigned to the Logos (®€ós ver. 1, and $\mu o v o \gamma \epsilon v \eta^{\prime}$ ver. 14). When the sequence of the thought; in the prologue is carefully examined, a fine appropriateness for "only begotten God" just here emerges, which goes far towards authenticating that reading. John describes to us, first, the Word in His eternal relations (verse 1 ); then, the Word in His relations to creation (verses $2-13$ ) ; and then the revelation of God through theWord (14-18) - culminating with putting into words in verse 18 what was already implied in the facts, that the Word was God (ver. 1), and yet Himself became flesh (ver. 14), - viz., that this revelation was self-revelation. If no one has seen God at any time, who is His revealer if not the Word who was God (ver. 1), and only begotten (ver. 14)-God only begotten (ver. 18)? The intrinsic evidence, thus, not only fails to oppose the reading commended alike by genealogical evidence, internal eviderce of groups, and transcriptional evidence, but even corroborates it. And again we may accept the fourfold support as giving us a reading which is certainly the original one.

It is natural to take as our next example the famous reading in $1 \mathrm{Tim}$. iii. 16 . Here three variations denand our attention :-

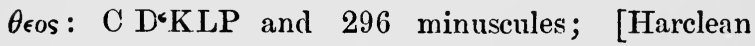
Syriac], Georgian and Sclavonic versions ; PseudoDionysius, Didymus, Gregory of Nyssa, [Diodorus] Chrysostom, Theodoret [Cyril of Alexandria], etc. os: $\boldsymbol{N}\left(A^{*}\right)\left(C^{*}\right) G, 17,73$ [181] and lectionaries 12, 
85, 86; [Memphitic], [Thebaic], [Peshitto], Harclean Syriac's margin, Gothic, [Athiopic], [Armenian], [Origen] Epiphanius, (Theodore of Mopsuestia), etc.

o: D, Zahn's Codex (Supplementum Clementinum, p. 277), Old Latin, Vulgate, [Peshitto], [Harclean Syriac], [Memphitic], [Thebaic], [Atthiopic], [Armenian], Latin fathers, etc.

The greatest difficulty that faces the critic here lies in the uncertainty that attends so much of the evidence. Expert palieographers differ diametrically as to what the reading of $\mathrm{A}$ is, whether $\overline{\theta c}$ or oc ( $\Theta$ cós or ös), and in the present worn state of the MS. decision by renewed examination is impossible. The same kind of controversy has been held as to the reading of $\mathrm{C}$, although apparently with much less reason; and although we have inclosed $\mathrm{C}$ also in doubting parentheses we entertain no great doubt as to its support of os. A large proportion of the versions so deliver their testimony as to make it indeterminable whether they read of or ö; they have been placed in both lists inclosed in square brackets. Codex 181 has also been inclosed in brackets, as its existence has been doubted. Codex 73 has been personally examined by Dr. Schaff, and certainly reads ös.

On applying genealogical considerations to this evidence, all the testimony that is at all certain for @eós sifts out with the sifting out of the Syrian testimony. This reading appears in no father until late in the fourth century, in no version until at least the seventh century, and in no MSS. until long after tho 
Syrian text had become everywhere the virtual textus receptus. If $\mathbf{A}$ be adjudged to read @eós the determination of its Syrian character would not be affected; and the very late character of all other witness for it is itself an argument against the likelihood of either $\mathrm{A}$ or $\mathrm{C}$ having ever had this reading, and much more against both having it. On genealogical grounds, thus, $\Theta \epsilon o ́ s$ is at once set aside, and the choice rests between os and o. It can scarcely be doubted that of is Western; while the attestation $\times(\mathrm{A}) \mathrm{C} 17$ gives of the appearance of having the support of the Neutral and Alexandrian classes. The doubt that hangs over the testimony of the versions is of the less moment because of the certainty of the Latin reading, which enables us to identify the Western type; and the absence of $B$ is here of no importance, as its presence on either side would not affect our determination. Genealogical evidence thus very pointedly commends ös. Internal evidence of groups corroborates this finding. $\aleph \mathrm{A} \mathrm{C}$ or $\times \mathrm{C}$ alone is one of the best groups attainable in this part of the New Testament, and although the absence of $\mathrm{B}$ disturbs us here, yet the transcriptional evidence comes to our help by making it improbable that : can be the correct reading, and hence enabling us to account all the testimony for both os and $o$ combined against that for $\Theta$ eós. The result is to condemn ®eós hopelessly.

The transcriptional evidence is thus in a true sense the key to the problem. As between os and o: the succession of round letters, IONOC€\$d, would render the change easy either way, whether by mistaking the $c$ for the succeeding $\epsilon$, or the already written $c$ for the 
half-finished $\epsilon$. Unless, however, os were original, it could never have been written except by a mere blunder, and could scarcely escape the eye of the "corrector" ; while ö could easily be passed over on account of the easy sense which it introduced, and would be apt to be written by the scribe after the neuter ante-

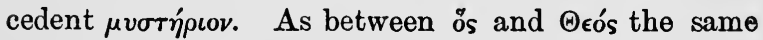
canon of the harder reading decides for oss. Here the difference is only in the fine lines that distinguish the $o$ from $\theta$ and mark the contraction : $\overline{\theta c}$ and oc; and thus one reading may easily pass into the other. But again, as $\Theta \epsilon o$ s is grammatically easy, forming a proper apposition for $\mu v \sigma \tau$ ípเov, while os is grammatically hard, nothing but a mere blunder could have originated os, while the difficulty of the sense would have operated as an incitement to the conscious or unconscious transmutation of os into $\Theta$ còs.

Unless, then, intrinsic evidence immovably protests against os it is to be accepted as the true reading. It is indisputable that it introduces a difficult reading, and the difficulty seems to disappear with the change to o̊ or @eós; on these facts the transcriptional evidence founded its preference for os. But does the difficulty rise to so high a pitch that os is impossible? The difficulty is wholly grammatical, and the grammar is not made intolerable by os, but only relatively hard. Moreover, @eós, while apparently reducing everything to an easy smoothness, introduces difficulties of its own. It accords well with the first of the following clauses, but immediately becomes an unnatural antecedent to the next, and continues so throughout. It is thus a fair sample of scribes' work, and combines the surface 
appearance of fitness with a real unfitness for its place. When, next, the antithetic and rhythmical character of the succeeding phrases is observed, suggesting that we have here a fragment of a hymn, which would allow us to suppose that the grammatical antecedent to os is to be sought in the hymn rather than in this context, or, better, that the first clause is the subject followed by five predicates; the intrinsic evidence, so far from immovably opposing os, appears to be slightly in its favour. No doubt, o would be intrinsically unobjectionable, but it is not preferable to os save in the strict and narrow grammatical sense; and intrinsic evidence readily gives way here to transcriptional evidence in its strong preference for oss. In this reading, therefore, difficult as it at first seems, all varieties of evidence come finally to agreement upon a single reading o̊s, - which we may, therefore, confidently accept.

Our next example shall be one of those few readings which affect large sections of the New Testament text: Shall we insert or omit the famous pericope of the adulteress, John vii. 53-viii. 11 ? The evidence is as follows :-

Insert : D, F, G, H, K, U, $\Gamma$ (also $\mathrm{E}, \mathrm{M}, \mathrm{S}, \Lambda, \Pi$, etc., with asterisk or obelus), more than three hundred minuscules ; many codices known to Jerome ; the Latin MSS. b, c, e, $\mathrm{ff}^{2}, \mathrm{~g}, \mathrm{j}, \mathrm{l}$; the Vulgate Latin, Jerusalem Syriac, Athiopic; “Apostolical Constitutions," Nicon, Euthymius, Ambrose, Augustine, Jerome, and later Latin fathers.

Omit : $\mathbf{N},(\mathrm{A}), \mathrm{B},(\mathrm{C}), \mathrm{L}, \mathrm{T}, \mathrm{X},(\Delta)$; codices known to 
Jerome, 22, 33, 81, 131, 157, and many other minuscules; the Latin MSS. a, f, q, rhe, and others known to Jerome and Augustine, Curetonian, Peshitto and Harclean Syriac, best MSS. of the Memphitic, Thebaic, Armenian, Gothic; (Origen), (Eusebius), (Theodore of Mopsuestia), (Apollinaris), Chrysostom, etc.

On sifting out the Syrian witnesses, the testimony for insertion plainly becomes merely Western, including $\mathrm{D}$ and the European Latin; but not certainly the African Latin, although e contains it, inasmuch as the early Latin Fathers are strangely silent about this passage. The testimony for omission includes everything typical in both the Neutral and Alexandrian classes. The only difficulty that meets us in determining the genealogical classes arises when we try to trace the Syrian class. Most of the later documents contain, the section, but it cannot be traced in the Antiochian and early Constantinopolitan fathers. Whence it seems that this pericope found no place in the Syrian revision, but has passed into the Syrian text from the Western, say, at some time about the seventh century. Whatever its relation to the Syrian class, however, the section is strongly discredited by genealogical evidence. The finding of internal evidence of groups, which is very strongly given, is in the same direction. So that the external evidence is solidly arrayed against the genuineness of the section.

Transcriptional evidence is generally ambiguous in readings of great length; insertion or omission must have been alike a mere blunder. It seems difficult to 
account for such a blunder as its omission, however, except by some such accident as the loss of a leaf or two from the exemplar. Mr. J. R. Harris has shown that the matter of this section corresponds, in extent, very exactly to two leaves of what seems to be a form which might very well belong to an ancestor of $B$.. But he also shows that it would not all have fallen on four pages, if belonging to the present place in John. On the other hand, its insertion may readily be accounted for as an incorporation into the text of an explanatory gloss drawn from some extraneous source. When we add that some codices place it at the end of John's Gospel and some after Luke xxi., instead of here, it becomes still more probable that we are dealing with phenomena of insertion rather than of omission. On the whole, the transcriptional evidence, while able to accept the passage if otherwise commended, is itself rather in favour of its omission.

Intrinsic evidence is more strongly so. For the fact that the story is worthy of our Lord and bears every mark of historic truth has no bearing on the question whether it is part of John's Gospel ; any true story of Jesus would be beautiful, especially if it came ultimately from the apostolic circle. While, on the other hand, the style and diction are very unlike John's writing elsewhere; several words are used which seem strange to his vocabulary; and some matters of detail fit ill with the context,-e.g., Jesus is left alone with the woman at verse 9 , and yet addresses " them" at ver. 12, and the Pharisees answer at ver. 13. This last fact might be of small moment, except that in these very matters verses 12 and 13 fit on directly 
with verses $45-52$ of the seventh chapter, and so the omission of the disputed verses restores verses $12 \mathrm{sq}$. to a context with which they seem to belong. Nor is this close connection of verses $12 s q$. with the seventh chapter merely verbal; the presence of the pericope of the adulteress seriously disturbs the progress of a discourse the order of which would be admirable without it. This intrinsic evidence is so strong that it would almost cast doubt on this section of itseif ; and in union with the external evidence, and with the allowance of the transcriptional, it forces us to omit the passage. Here too, therefore, we may feel that we have attained the original text.

It is appropriate to draw our next example from the only other various reading that involves so large a section,-that which concerns the last twelve verses of Mark. The evidence may be stated as follows :-

Insert: $\mathrm{A}, \mathrm{C}, \Delta, \mathrm{D}, \mathrm{X}, \mathrm{\Sigma}, \Phi, \Gamma$, etc., $1,33,69$, and nearly all minuscules; all Old Latin codices except $\mathrm{k}$; the Vulgate Latin ; the Curetonian, Peshitto, Harclean and Jerusalem Syriac; the Memphitic, and Gothic ; Justin, Tatian, Irenæus, [Hippolytus], Macarius Magnus; and post-Nicene fathers generally.

Omit: B, א, L, 22, 743 (on the authority of the Abbé Martin); codex k of the Latin; the Armenian, and Athiopic; [Clement], [Origen], Eusebius, [Cyril of Jerusalem], and, among the post-Nicene fathers, the $i \pi \circ \theta \epsilon \sigma i s$, Jerome, Victor of Antioch, Severus of Antioch. Also such minuscules as 15, 20, 
$300,199,1,206,209$, which preserve knowledge of the doubt.

Some words are necessary in explanation of this evidence. $\ll$ simply omits the passage. B omits it, but leaves a blank space, which is apparently intended for it; this seems to prove that the exemplar from which $B$ was copied lacked these verses, but that they were known to B's scribe. As the weight of $\mathbf{B}$ is due to the character of its exemplar, not to the knowledge of its scribe, this does not affect B's testimony. L closes at verse 8 , but adds at the top of the next column: "These also are somewhere current : 'But all things that were commanded, they immediately announced to those about Peter. And after this Jesus also Himself, from the east even to the west, sent forth by them the sacred and incorruptible proclamation of eternal salvation.' These are also, however, current, after 'For they were afraid.' " . . . And then our usual twelve verses are inserted. The existence of this shorter conclusion (to which $\mathrm{L}$ gives the preference) is a fortiori evidence against the longer one. For no one doubts that this shorter conclusion is a spurious invention of the scribes; but it would not have been invented, save to fill the blank. L's witness is, then, to MSS. older than itself, which not only did not have our twelve verses, but had invented another conclusion in their place. The Abbé Martin tells us of another codex, which he numbers 743 , that repeats the arrangement of $\mathrm{L}$. Codex 22 closes the Gospel at verse 8, marking it as "The End," and then adds: "In some of the copies the Evangelist mnishes at this point; in many, however, these also 
are current," ... and inserts our verses 9-20, closing again with "The End." The Old Latin MS. $\mathrm{k}$ contains the shorter conclusion only, and hence is a specially strong witness to the omission of our twelve verses. The Thebaic version might possibly be added to the witnesses for insertion, but we have from it only a mediocre paraphrase of verse 20 , and it cannot be confidently determined what disposition was made of it.

Proceeding now to estimate the evidence, we note first that the Syrian text inserts the passage, and, when the Syrian witnesses are sifted out, it is left with Western (D, Latin, Curetonian Syriac), and apparently Alexandrian (C, $\Delta, 33$, Memphitic) witnes:es only, and since all Alexandrian witnesses are full of Western readings, this means with Western witnesses only. For omission we have the Neutral witnesses $(\mathrm{B}, \mathbb{N})$ with $\mathrm{L}, 22$, and other support. Where the Alexandrian reading stands we cannot discover ; but on appealing to internal evidence of classes the apparent conjunction of Western and Alexandrian witnesses is discredited, and we must decide that the genealogical evidence is in favour of omission. I may represent the Alexandrian text and $\mathrm{k}$ the primitive Western; and in the case of either of these hypotheses, the rerdict for omission receives additional strength. Internal evidence of groups, which throws strong favour on $\mathbf{B} \kappa$, only confirms genealogical evidence, and we have the whole weight of external evidence for omission.

The transcriptional evidence leads to the same conclusion. No good account can be given of the 
omission of these verses. To suppose that they were omitted in a harmonic interest is to presuppose a freedom and boldness in dealing with the Gospel narratives never elsewhere experienced, and that to serve a purpose far more easily attained. To suppose the omission to have arisen from the misunderstanding of a note placed here to mark the end of a liturgical lesson is to assign a greater age to the present lessonsystem and to this method of marking MSS. than can be proved for either. To suppose that a leaf was lost from the end of the Gospel, containing these verses, will best of all account for their omission, but will not account for its wide distribution, nor for the failure of the beginning of the next Gospel, on the other side of the leaf, to get lost too. Mark stands very rarely in Greek MSS. at the end of the book of the Gospels, and the loss of a leaf early enough to affect the ancestors of $\mathrm{N}$, of $\mathrm{B}$, of $\mathrm{L}$, and of Western $\mathrm{k}$, must have affected nearly all MSS. as well. On the other hand, the insertion of such an ending is transcriptionally easy to account for. The abrupt ending of verse 8 demanded something more. That the scribes felt this is evidenced by their invention of the certainly spurious shorter ending. Why should not other scribes have sought and found another tolerably fitting close for the Gospel? And that this ending does not belong here, but fits its place only tolerably, is clear on careful examination. The tear at verse 8 is not mended by verses 9-20. Only Matthew and Luke tell us what actually happened after verse 8 . And if verse 8 demands a different succeeding context, verses 9-20 no less need a different preceding one from 
that here furnished them. Jesus is presumed to be the subject in verse 9 ; but the subject that would be taken over from verse 8 is the women. The "but" that opens verse 9 does not introduce anything adversative to verse 8 . The new specification of time in verse 8 is surprising, after verse 2. "First" looks strange here. The identifying description of Mary Magdalene in verse 9 is very remarkable after verse 1 . Every appearance, in a word, goes to show that the author of the Gospel did not write verses $9-20$ as the conclusion of the narrative begun in verses $1-8$. And if so, the transcriptional evidence that makes an insertion here easier to conceive of than an omission has full play, and we can recognise verses $9-20$ as only another way of filling up the gap left by the unfinished appearance of verse 8 . The intrinsic evidence is not fully stated, however, until we add that there are peculiarities of style and phraseology in verses $9-20$ which render it easy to believe that the author of the Gospel did not write these verses.

The combined force of external and internal evidence excludes this section from a place in Mark's Gospel quite independently of the critic's ability to account for the unfinished look of Mark's Gospel as it is left or for the origin of this section itself. The nature of the matter included in them, and the way they are fitted to the Gospel, seem, howf:ver, to forbid the supposition that these verses were composed for this place by any scribe. It is nearly as hard to believe that anybody wrote them for this place as it is that Mark did. They seem to be a fragment rather, adopted from some other writing and roughly fitted 
on to the end of Mark. This fragment is certainly as old as the first third of the second century, and may -as may also the pericope of the adulteress inserted into John-be taken from the book of illustrations of the Gospel narrative which Papias composed, apparently about 120 A.D. Neither is it necessary for the critic to be able to give an account of the mutilated condition of Mark's Gospel. To recognise that this fragment does not belong at the end of it does not make it any more mutilated than it was before. The evident incompleteness of verse 8 is evidence against the opinion that the Gospel was intended to close at that point; but no evidence that just this conclusion, -which does not fit on to verse 8 nor complete it, nor the subject then in hand,--was the conclusion intended. Why Mark's Gospel has come down to us incomplete, we do not know. Was Mark interrupted at this point by arrest or martyrdom before he finished his book? Was a page lost off the autograph itself ? Or do all of our witnesses carry us back only to a mutilated copy short of the autograph, the common original of them all, so that our oldest transmitted text is sadly different from the original text? There is room for investigation here; but, apparently, no room for accepting this conclusion for the one that Mark wrote or intended to write.

We have purposely chosen all these examples of such a sort that the evidence can readily be seen to be harmonious through all the methods. But we have also purposely placed last among them a case in which the intrinsic evidence, while uniting with the other forms of evidence in determining this reading, is left still 
somewhat unsatisfied by its determination. It opposes the acceptance of the last twelve verses of Mark as genuine: but it no less opposes the acceptance of verse 8 as the end of the Gospel. It consents that this is not the limb that belongs here, but it no less insists that some limb does belong here. This may remind us that the work of the critic may not always be done when he has passed on all the readings which have been transmitted to us in our extant witnesses. It is at least conceivable that the oldest transmitted text may not yet be the autographic text, or in other words, that all our extant documents spring from a common original that is removed by a few copyings from the autograph, and may, therefore, contain some errors. Of course, this is not to be assumed to be the fact; but neither is it to be assumed not to be the fact. This, too, is to be settled only on trial and by the evidence. And here it will be of use to us to remember that the office of textual criticism is not merely to restore a text where it is known to be in error, but to examine all texts in every part in order to certify their correctness or discover that and where they are corrupt. Where the several documents give various readings the presence of error in some of them is already demonstrated, and the office of criticism is to determine which, if any, is right. But by this very act it contemplates the possibility that none of them are right, and it very frequently actually determines that the most documents may be in error. How narrow the chance that has preserved for us the true reading in all those cases in which we adjudge the palm to the few old documents as against the miny! 
By the destruction of $\mathrm{B}$ and a half-dozen other docu ments we should destroy all extant evidence for several quite important readings which we now adjudge right; and in all these readings a false reading is prevented from standing in all texts without variation only by the accident of the preservation of these half-dozen documents. The possibility must be frankly confessed that other false readings may stand in all our extant documents. So that, even where there is no variation, criticism is still necessary to certify to us that the text is free from error or to correct it when in error.

Wherever, therefore, the evidence for any body of variations is so hopelessly in conflict that it cannot be harmonised, and in all that part of the text on which there are no variations, it is right to consider the text only provisionally determined, and to subject it to further criticism. In all cases of variation in which the evidence is in ineradicable conflict the high probability is that the oldest transmitted text is itself in error, and we may assume that here is a case that needs further criticism. In all that part of the text on which there are no variations the strong presumption is that we have not only the oldest transmitted text (which is certain, since it is identically transmitted in all witnesses), but also the autographic text: but nevertheless this presumption may not be everywhere equally well grounded, and examination is necessary in order to conviction. Only in that part of the text which has been settled by the combined and har. monious testimony of all kinds of evidence may we confidently accept it as the autographic text. For 
in all these cases alike, the only evidence that is valid -whether to discover if the text be corrupt where no various readings occur, or to suggest the right reading wherever we know or suspect it to be corrupt-is internal evidence; and in all cases where the text has been already settled on the harmonious finding of all kinds of evidence, this has already spoken and has already been satisfied.

Before we close our discussion of the praxis of criticism, therefore, we must explicitly recognise the legitimacy and duty of examining the text of the whole New Testament with the most scrupulous care, with a view to discovering whether its transmission has bcen perfect; and of appealing to internal evidence to suggest and settle for us the true text in all cases of variation where the evidence is hopelessly in conflict, and in all cases where, in the absence of variation, an examination of the text has resulted in leading us to suspect corruption. It is evident that we are not here calling in a new method of criticism beyond those enumerated ; but only extending the practice of criticism a step further than we had need to go in the examples which we have adduced. And it is further evident that the validity of this extension is involved in any use of internal evidence for settling readings at all. The technical name given to this extension of criticism is "conjectural emendation," which is meant to describe it as a process which suggests the emendation which the text is shown either by the presence of irreconcilable variations or by internal considerations to need, from the conjecture of the mind, working on internal hints. 
The need of calling upon conjecture to aid us in determining the text of the New Testament depends on the provable presence of variations the evidence as to which is in hopeless conflict, or of passages which, while without variation, are clearly corrupt. In dealing with this question of fact, the utmost tact, good judgment and candour are necessary. Two extremes are equally to be avoided. We must neither allow ourselves so to sharpen our acuteness that we discern an error in every corner, and lose the power to catch the plain intent of a plain man's plain speech; nor must we so blunt our minds, by attempting to explain as correct and good Greek what we could not tolerate in any other language, that no amount of evidence can convince us of the presence of a textual error. Licence has not been unknown in either direction. Some critics have seemed ready to cast the whole text into "pie," and set it up again to suit their own (and no one else's) conceits. Others have even savagely guarded each fragment of the transmitted text as if the scribes had wrought under Divine inspiration. The whole matter is nevertheless simply a matter of fact, and is to be determined solely by the evidence, investigated under the guidance of reverential and candid good sense. The nature of the New Testament as a Divine book, every word of which is precious, bids us be peculiarly and even painfully careful here : careful not to obtrude our crude guesses into the text, and careful not to leave any of the guesses or slips of the scribes in it.

Drs. Westcott and Hort enumerate in their edition some threescore or more passages in which they (or 
one of them) suspect that a "primitive error" is found in the text-i.e., an error older than our transmitted text, for the removal of which we are confined to conjectural emendation. Our own judgment would greatly reduce this number. Withont discussing, however, the special cases, it is enough for our primary purposes to lay down two rules of action : (1) Critical conjecture is not to be employed in settling the text of the New Testament until all the methods of criticism have been exhansted, and unless clear occasion for its use can be shown in cach instance. (2) No conjecture can be accepted unless it perfectly fulfil all the requirements of the pasange as they aro interpreted by intrinsic evidence, and also perfectly fulfil all the requirements of transcriptional evidence in accounting for the actual reading, and if rariants exist also for them (either directly or mediately throngh one of their number). The dangers of the process are so great that these rules are entirely reasonable, and indeed necessary. The only test of a successful conjecture is that it shall approve itself as inevitable. Lacking inevitableness, it remains doubtful.

Few as the passages are that can be shown to need conjecture to settle their text, the passages in which successful conjectures have been made are still fewer. Perhaps no absolutely satisfactory one has yet been made. The best examples are probably two on Col. ii. 18, one by Bishop lightfoot and the other by Dr. C. Taylor. Instend of the best attested reading, \& є́ó $\alpha \kappa \epsilon \nu$ '̇ $\mu \beta \alpha \tau \epsilon v^{\prime} \omega v$, the former scholar

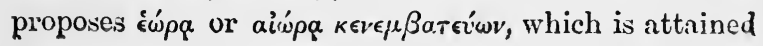


by a change of only a single pair of letters, co into

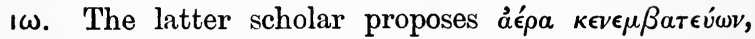
which simply omits $o$. In such matters we may well listen to the advice of the Jewish sage and "bo deliberate in judgment." 


\section{CHAPIER IV.}

TIIE IIISTORY OF CLITICISYY.

7 III history of the earlier periods of the text of the 1 New Testament is naturally enough a history of progressive corruption. The multiplication of copies was the chief concern of an ever-increasing body of readers; and though we early hear complaints of corruption, as well we might from the rapidity with which corruption seems to have grown, and from the grossness of the corruptions which found their way particularly into the Gospels, we hear of little serious effort to secure a correct text. Nevertheless, the earliest fathers show themselves in some sense guardians of the text, and ready to distinguish between the common and the best and oldest copies. The autographs of the sacred writings disappeared exceedingly early, and an Irenæus and an Origen were already without appeal to aught but the more accurate copies. Already by their time the current type of text hwd long been that which is now known as the WVestern, and which attained early in the second century the position and circulation of a virtual textus receptus, and retained this position for about two centuries. A purer and more carefully guarded text was, nevertheless, throughout this whole 
period in use in various places, apparently most commonly at Alexandria, where also in one line of its transmission it suffered before the middle of the third century sufficient deflection from the absolute standard to give rise to another strongly marked type of text-that which is now called the Alexandrian. Tradition has not handed down to us account of any very early attempts to provide a standard edition. Although Jerome tells us that Origen in Palestine, Lucian at Antioch, and Hesychius in Egypt, each revised the text of the New Testament, as well as that of the Greek Old Testament, it is not clear how much dependence can be placed on this statement, which is not free from difficulties. The scribes give us occasional notes which betray a belief in the existence of something like a standard copy in the library of "the holy martyr Pamphilus" at Cæsarea, conformity with which was the norm of correctness; but of this we know nothing but this fact. Nevertheless, the more unmistakable evidence of the textual remains that have come down to us prove that at least one set revision of the text was made in Syria, and probably at Antioch, at about the time that would fall in with the period of Lucian's activity. The object of this revision,- - the earliest attempt to issue a critical edition of the New Testament text of which we can be sure, and of which we possess documentary knowledge,-seems to have been to furnish for the use of the Syrian churches a sounder substitute for the very corrupt Western text which had for so long held the ground. The revision was well done for the purpose in view and for the times. It is an honour 
to the scholarship and good judgment of the school of Antioch, and presents characteristics quite in keeping with the exegetical reputation of that school. It was impossible at that time and under the ruling views of criticism to form a sound text; but these scholars succeeded in substituting in popular use for the exceedingly corrupt textus receptus then current, a text free from all the gross corruptions that disfigured it, smooth and readable in structure, and competently exact for all practical purposes.

The Christian world, which has been the heir of their labours for a millennium and a half, owes a debt of thanks to a superintending Providence for the good work done thus in a corner, and probably with only a local intent. For the scholars of Antioch were, in God's grace, doing a greater work than they knew. Soon the persecutions of the dying heathenism broke out with redoubled fury, and everywhere the Christian books were sought and destroyed. Then came Constantine and the Christian empire, established with its seat on the Bosphorus. Antioch became ecclesiastically the mother of Constantinople, and the revised text of Antioch the ecclesiastical text of the centre of the world. The preparation of the magnificent copies of Scripture ordered by Constantine for the churches of Constantinople was intrusted to Eusebius of Cresarea, whose affiliations were with Antioch ; and everywhere the Syrian text began to make its way. The separation of the Eastern and Western Empires was followed by the separation of the Fastern and Western Churches, with the effect of confining the use of Greek to narrower limits, and giving increased 
power to the Constantinople tradition wherever the Greek Scriptures were used. Though some serious alterations were suffered by it in the process of time, it was, thus, the Constantinopolitan text that became the text of the Greek world, and with the revival of Greek letters in the West, under the teaching of Byzantine refugees, of the whole world. How the process of substitution took place it is not necessary to trace. Sometimes it was, no doubt, by direct importation of copies from the capital. At others it was by the correction of copies of other types by Syrian models, which secured that their descendants should be Syrian. Thus, Codex $\mathbf{E}$ of Paul is largely Syrian, although it is a copy of the purely Western $\mathrm{D}$; and thus, too, probably, is it to be explained that Codex $\Delta$ in the other Gospels is Syrian, while in Mark it remains mostly pre-Syrian. The great popularity of the Antiochian exegetes and of the homilies of such orators as Chrysostom carried with it a preference for their text. What effect on this process the edition of Euthalius had, in the last half of the fifth century, which was rather a handy edition than a purified text, it is impossible to determine. At all events, traces of other texts became rarer and rarer as time passed; although mixed texts were exceedingly abundant at first, even these gradually gave way; and throughout the middle ages and down to the invention of printing the Syrian text reigned everywhere, as indisputably the received text of the Church universal, as the Western text had been from the second to the fourth century.

The passing of a text through the printing press 
has no tendency to revise it. The first printed Greek Testament was that included in the "Complutensian Polyglot," and is dated 1514. But as its issue was delayed, the first published Greek Testament was Erasmus' first edition, published by Froben, at Bâle, in 1516. Hurried through the press at breakneck speed, in the effort to forestall the "Complutensian Polyglot," it was taken from late and almost contemporary manuscripts, and mirrored the state of the received text of the time. It bore, indeed, sundry printer's boasts on its title-page; but its editor felt free to say in private that it was "precipitatum verius quam editum." The "Complutensian" itself, when it did appear (1520), proved to have been made, as was natural, from older manuscripts of the same type. And thus the printed text of the New Testament simply continued the history of the written text, and, leaving its character unchanged, gave it only a new mode of reproduction.

The normal history that is worked out by the printed text of any work which has previously been propagated for a long time in manuscript is something like this:-The first edition is taken from the manuscripts nearest at hand; then some one edition gains such circulation and acceptance, usually from its convenience or beauty, as to become the standard, and thus also the received text; and then efforts are made critically to restore the text to its original purity. Just this history has been wrought out by the New Testament text. The editions immediately succeeding those of Erasmus differed little in detail, and nothing in type, from the text he published; but the magni- 
ficence of Stephens' editio regia (1550), and the convenience and beauty of the small Elzevirs, especially those of 1624 and 1633, enabled these editions to determine the standard text, the one for English and the other for continental readers. Reverence for the Word of God, perversely but not unnaturally exercised, erected the standard or received text into the norm of a true text; and although preparations for critical editions began very early, and were seriously undertaken by the editors of Walton's "Polyglot" (1657), yet many years passed away before the hardening bondage to the received text could be shaken, and it was not until 1831 that it was entirely broken by the issue of Lachmann's first edition.

The history of the editions from 1657, therefore, falls into two periods; the one containing the editions which were striving to be rid of the bondage to the received text (from 1657 to 1831), and the other those which have been framed in conscious emancipation from it (from 1831 until our own day). During the former period, the task men set before them was to correct the received text, as far as the evidence absolutely compelled correction. During the latter, the task has been to form the best attainable text from the concurrence of the best evidence. The chief editions of the former period were those of the Walton "Polyglot," 1657; John Fell, 1695; John Mill, 1707 ; Wells, 1709-19 ; Bentley's proposed edition, 1720 ; Bengel, 1734; Wetstein, 1751-2 ; Griesbach, 1775-1807 ; Matthæi, 1782-88 ; and Scholz, 1830-36. The chief editions of the later period have been those of Iachmann, 1831, and espe- 
cially 1842-50 ; Tischendorf, 1840-72, especially his eighth critical edition, published in parts from 1864 to 1872 ; Tregelles, in parts from 1857 to 1879 ; and IVestcott and Hort, 18s1. In one way or another the sequence of these editions marks a continuous advance, although in special points an eddy now and then sets backwards. For instance, Wetstein, Matthai, Scholz, all mark a retrograde movement in principles of criticism and in the text actually set forth; but each an advance in the collection of materials for framing the text. It will be desirable, therefore, to present the history of eriticism briefly under four heads, including :-

1. The collection of the documentary evidence for the text.

2. The classification of this ever-increasing material.

3. The formulation of critical rules for the application of the evidence in reconstructing the text.

4. The actual formation of the text.

1. The work of collecting the matcrial, heralded by Stephens and Beza, was commenced in earnest by Walton's "Polyglot" (1657). The great names in this work include those of Archbishop Usher, Bishop Fell, Mill (who already could appeal to his thirty thousand various readings), Bentley, and those in his employment, Wetstein (who marks an advance on Mill, chiefly in accuracy and completeness, comparable to Mill's advance on his predecessors), Matthæi, Birch, Alter, Griesbach, Scholz, Tischendorf (whose editions of MSS. exceeded in number all that had been put 
forth before him), Tregelles, and Scrivener, with whom may be also named Dean Burgon. Until Tischendorf's labours were undertaken, a satisfactory edition of the New Testament was impossible, if for no other reason than insufficient knowledge of the testimony. Now, practically all the uncials, and a large body of the minuscules are accurately known, and have been included in the digests. $N$ was not published until 1862 ; no satisfactory edition of $\mathrm{B}$ existed until 1868 ; C, Q, D, $\mathrm{D}_{2}, \mathrm{~N}, \mathrm{P}, \mathrm{R}, \mathrm{Z}, \mathrm{L}, \Xi, \mathrm{E}_{2}, \mathrm{P}_{2}, \mathrm{~S}$, have all been issued since 1843. $\Sigma$ was not discovered until 1879, and $\mathrm{W}^{\mathrm{g}}$ and $\Phi$ not until 1881 . The versions are not even yet critically edited. But we have at last attained the position of having evidence enough before us to render the sketching of the history of the text possible, and to certify us that new discoveries will only enlighten dark places, and not overturn the whole fabric.

2. It was inevitable that in the first youth of textual criticism all documents should be treated as practically of equal value. We cannot blame Erasmus that he set aside the only good MS. he had because it differed so much from the others. Nor is it difficult to see why the collations of Stephens and other early editors rather ornamented their margins than emended their texts. By Mill's time (1707), however, enough material was collected for some signs of classification to be dimly seen. Bentley (1662-1742) profited by his hints, and perceived the great division line that runs between the old and the late codices-i.e. (speaking generally), between the pre-Syrian and the Syrian. John Albrecht Bengel (1687-1752) was 
the first, however, to do a great work in this department of investigation. His acuteness perceived the advantages of a genealogical classification, and his diligence worked out the main outlines of the true distribution. Like Bentley, he drew a broad line of demarcation between the ancient and more modern copies, which he classed under the names of the African and Asiatic families. And, then, he made the new step of dividing in a more or less firm manner the African family itself into two sub-tribes, represented respectively by $\mathbf{A}$ (the only purely Greek uncial at that time in use), and the Old Latin version. He held the African class to be the more valuable, and it was a critical rule with him that no reading of the Asiatic class was likely to be genuine unless supported by some African document. Semler (1764) followed, 'and handed down Bengel's classification to the even greater Griesbach (1745-1812). Griesbach $(1775+)$ divided all documents into three classes, which he called respectively-

(1) The Alexandrian, represented (in the Gospels, by $\mathbf{B}$ (except in Matthew, where he deemed it Western), C, L, 1, 33, 69, Memphitic, etc. ;

(2) The Western, represented by the Græco-Latin codices, the Old Latin, etc. ; and

(3) The Constantinopolitan, represented by A, E, F, $\mathrm{G}, \mathrm{H}, \mathrm{S}$, and the minuscuies as a class, etc.

He perceived that a somewhat different distribution was needed for the other parts of the New Testament (thus, A elsewhere rose to the height of Class 1); and also that a number of texts occupied inter- 
mediate positions. Classes 1 and 2 he held to present texts at least as old as the third century; Class 3 one not older than the fourth or fifth. A misunderstanding of the meaning of the phenomena of mixed texts (shared in part by Griesbach himself) did much to prevent this theory from receiving the acceptance it deserved, though it obtained the hearty adherence of some of the best scholars of the day. Hug's (1808) vagaries, who sought to prove historically that three texts represented respectively by B C L, E R minuscules, and A K M, were alike set revisions of one corrupt text represented by $D$ and the Old Latin, which was universally current in the second century, still further blinded men to the value of these classifications. Hug, however, recognised the three classes of Griesbach (though trying unsuccessfully to add a fourth to them), and brought out the important new fact of the early broad currency of the Western text. And his publication had the good effect of bringing Griesbach once more before the public (1811), to redemonstrate the main outlines of his classification, and reiterate his mature conviction that on the study of "recensions," as on a hinge, all criticism of the text must turn. The peculiarities of Nolan and Scholz succeeded, however, in throwing an undeserved discredit on stich studies, until it became common to assert that no divisions could be traced among the documents, of any practical utility in criticism, except the broad one that separates the ancient and modern copies into classes corresponding to Bengel's African and Asiatic, and Griesbach's Alexandrian-Western and Constantino- 
politan. Tregelles (1813-75), by his method of comparative criticism, redemonstrated this distribution, and put it upon an invincible basis of observel fact. Nevertheless it has been everywhere practically acknowledged-by writers as widely separated as Tregelles and Scrivener-that the farther facts of affiliation brought out by Griesbach, although not available for criticism, yet rest on a basis of truth, and further that the documents that class with $B$ are greatly better than those that class with $D$. At this point Dr. Hort's investigations (1881) have entered the field, with the result of justifying Griesbach's general conclusions, and so adding to and elucidating them as to develop a usable system of textual criticism by a genealogical method. The outlines of his conclusions have been already explained under the caption "Genealogical Method" above.

3. The continued efiorts of a succession of scholar's to revise the text of the New 'Testament necessarily issued in a critical practice, and a critical practice is capable of being formulated in critical rules. We can mention only the leader's in this work. It was Bentley (1720) who first laid down the great principle that the whole text is to be formed, apart from the influence of any edition, on evidence; a principle which, obvious as it is, only succeeled in conquering universal adoption through Lachmann's example (1831). It was due to Bengel (1734) that transcriptional probability received early recognition, and one of its great generalisations was formulated by him in words that have become classic: "proclivi scriptioni prestat ardua," which, beyond doubt, he meant in a 
transcriptional sense. After him its principles have been developed by many critics, especially by Griesbach; and more latterly they have been carefully re-stated by Tischendorf, Bishop Ellicott, and Dr. Hort. Intrinsic evidence has never lacked its often too earnest advocates; some have pushed it to the verge of subjecting the whole text to re-writing according to the personal idiosyncrasies of the editor, and many have been willing to give it occasionally overweening powers. Its true character as mainly negative, and its true uses, have been lately admirably elucidated by Dr. Hort. Since Tregelles (1854, 1856, $1860)$ the suffrages of scholars have been given to the doctrine that the documentary evidence is decisive if at all capable of sure interpretation, so only that both varieties of internal evidence of readings are not arrayed against it, or, at least, that intrinsic evidence is not unalterably in opposition. The tendency has also been ever more and more pronounced, since Tregelles developed the method of comparative criticism, to rely on the ancient evidence, and to count its witness decisive whenever its testimony is undivided or nearly so. But not until Dr. Hort's "Introduction" appeared (1881) was a sufficiently safe procedure indicated for all those cases where ancient evidence is itself divided. Dr. Hort's main canons of criticism are as follows: (1) Knowledge of documents should precede final judgment on readings ; and (2) All trustworthy restoration of corrupted texts is founded on a study of their history. By the former he means to assert the necessity of attending to a carefully weighed external evidence before we 
decide on readings, and to exclude thereby crude appeals to internal evidence alone. By the latter he means to emphasize the necessity of understanding the genealogical affiliations of documents before they are appealed to as witnesses, and to exclude thereby crudely allowing each document equal weight, no matter what its relation to the autograph may be, as well as allowing each document weight according not to its purity, but to the chances of reproduction that have preserved many or few of its kindred.

4. No satisfactory text could be formed so long as editors set before them the task of emending the received text, instead of drawing from the best evidence the best attainable text. Not until Lachmann, therefore, who put forth in 1831 the first text framed entirely on evidence, can we expect to find more than efforts towards a good text. Nevertheless much that was done before Lachmann deserves our notice and admiration. The Greek Testament of Simon Colineus (1534) may be considered the earliest attempt to prepare what may be called a critical text by emending the received text on MS. authority. Edward Wells published so early as 1709-19 a text emended from the Elzevir type in some two hundred and ten readings, the most of which have been commended by later critics. And Richard Bentley in 1720 proposed to set forth an edition founded on ancient authority only, which, had he completed it, would have antedated the step of Lachmann by a century. Walton, Fell, Mill, Bengel (except in ninetcen reaciings in the Apocalypse), and Wetstein, did not venture to introduce new readings into the printed text, but confined 
their suggested improvements to the margin and notes. Griesbach (1775-1807) made a great advance, and by the acuteness of his criticism and the soundness of his judgment did all that could be done at his day and with his material for reforming the text. No text of the earlier period can be compared with his, and his accomplishment with his insufficient material constitutes no less than a wonder of critical skill. But not only did even he seek to emend the received text, but the insufficiency of the material at that time within reach of critics would alone have rendered the formation of a satisfactory text impossible. The retrograde movement of Matthæi and Scholz, who returned to the received text, was suddenly reversed by the bold step of Lachmann (1831) in casting off its influence altogether, and giving the world for the first time a text founded everywhere on evidence. Lachmann's actual text was, however, not yet satisfactory; both because of the still continuing insuficiency of evidence, and because he did not set himself to form the true and autographic text, but only an early text, current in the fourth century, which should serve as the basis for further criticism. The use which has sometimes been made of Lachmann's text, therefore, as if it might be accepted as the earliest attainable text, is thoroughly mistaken. We cannot go further back than the texts of Tischendorf and Tregelles for examples of what criticism has attained, as the original text of the New Testament. Tischendorf's text fluctuated considerably in the various editions which he put forth, but it is unfair to judge his results now by any but his great 
and final eighth edition, the text of which was completed just bofore his death. The comparative values of the three great modern texts-the eighth edition of Tischendorf (1864-1872), the one great edition of Tregelles (1857-1879), and the recently issued edition of Westcott and Hort (1881, and reissued 1885)-need hardly be discussed here. It is enough to set down plainly the fact that these three editions indicate the high-water mark of modern criticism, and to point out that they agree in their settlement of the greater part of the text. Where they differ, we may decide now with one, now with the other, most frequently with the latest: and in these comparatively few passages future criticism may find her especial task. 


\section{CORRIGENDA.}

Page 37, line 2. This statement is misleading. The Arabs appear to have brought cotton paper to the Western world about the eighth century. The oldest dated Arabic MSS. on cotton paper come from the ninth century, e.g., the Leiden Gharibu 'l-Hadith from 866 . The earliest examples in European languages come from the countries which were most closely in contact with the Arabs, e.g., Sicily (1102, 1145, and the like). The oldest dated Greek MS., on cotton paper, is the Vienna Codex, dated 1095 ; next we have a Euchologium (No. 973 of Gardthausen's Catalogus Codd Gracorum Sinaiticorum), dated 1153; and by the middle of the thirteenth century they are somewhat numerous. The Lectionary referred to in the text is No. 191 of the lists (Scrivener, III., p. 292). An Asceticum (No. 468 of Gardthausen's Catalogus, just quoted), on cotton paper, is written in uncials of the tenth or eleventh century.

Page 67, line 12. The age of the European Latin may be more accurately set from Prof. Sanday's investigations. He shows that it was certainly used by Novatian (fl. 251), and hints that it may be older than Tertullian (see Studia Biblica, p. 245).

Page 70, last line. This exception may probably be deleted. 


\section{THE EXPOSITOR'S BIBLE.}

EDITED BY REV.

W. ROBERTSON NICOLL, M.A., LL.D.

FIRST SERIES.

Price 75. 6d. each Volume.

THE BOOK OF GENESIS.

By the Rev. Professor MARCUS DODS, D.D.

Sixth Edition.

\section{THE FIRST BOOK OF SAMUEL.}

\section{THE SECOND BOOK OF SAMUEL.}

By the Rev. Professor W. G. BLAIKIE, D.D., LL.D.

Fourth Edition, Two Vols.

"Very full of suggestive thought."-English Churchman.

"A solid and able piece of work."-Academy.

THE GOSPEL OF ST. MARK.

By the Very Rev. G. A. CHADWICK, D.D., Dean of Armagh.

Fourth Edition.

"This exposition is original, full of life, striking, and relevant. He has given us the fruit of much careful thought."-British Weekly.

\section{THE EPISTLES TO THE COLOSSIANS AND PHILEMON.}

By the Rev. ALEXANDER MACLAREN, D.D.

Fifth Edition.

"In nothing Dr. Maclaren has written is there more of beauty, of spiritual insight, or of brilliant elucidation of Scripture. Indeed, Dr. Maclaren is here at his best." -Expositor.

\section{THE EPISTLE TO THE HEBREWS.}

By the Rev. Principal T. C. EDWARDS, D.D.

Fourth Edition.

"There is abundant evidence of accurate scholarship, acute criticism, patient thought, and faculty of lucid exposition. However thoroughly any one has studied the Epistle here explained, he will certainly find in Dr. Edwards' volume fresh suggestions."-Dr. Marcus Dods. 


\section{THE EXPOSITOR'S BIBLE SECOND SERIES.}

Price 7s. 6d. each Volume.

\section{THE BOOK OF ISAIAH.}

Vol. I. Chapters I.-XXXIX.

By the Rev. GEORGE ADAM SMITH, M.A.

\section{Sixth Edition.}

"This is a very at tractive book. Mr. George Adam Smith had evidently such a mastery of the scholarship of his subject that it would be a sheer impertinence for most scholars, even though tolerable Hebraists, to criticise his translations. ... A lucid, impressive, and vivid study of Isaiah."-Spectator.

\section{THE EPISTLE TO THE GALATIANS.}

By the Rev. Professor G. G. FINDLAY, B.A.

Third Edition.

"In this volume we have the mature results of broad and accurate scholarship, exegetical tact, and a firm grasp of the great principles underlying the Gospel of Paul presented in a form so lucid and attractive that every thoughtful reader can enjoy it."-Dr. Beet.

\section{THE EPISTLES OF ST. JOHN.}

By the Right Rev. W. ALEXANDER, D.D., D.C.L., Lord Bishop of Derry and Raphoe.

Second Edition.

"Full of felicities of exegesis. . . B Brilliant and valuable."-Literary Churchman.

\section{FIRST EPISTLE TO CORINTHIANS.}

By the Rev. Professor MARCUS DODS, D.D.

THIRd Edition.

“Dr. Dods' writings are always excellent, and the one before us is no exception to the rule."-Record.

\section{THE BOOK OF REVELATION.}

By the Rev. Professor W. MILLIGAN, D.D.

Second Edition.

"Dr. Milligan's scholarly and attractive exposition."-Aberdeen Free Press.

\section{THE PASTORAL EPISTLES.}

By the Rev. ALFRED PLUMMER, D.D., Durham.

THIRd Edition.

" The treatment is throughout scholarlike, lucid, thoughtful."-Guardian. 


\section{THE EXPOSITOR'S BIBLE.}

THIRD SERIES.

Price 7s. 6d. each Volume.

\section{THE GOSPEL OF ST. MATTHEW.}

By the Rev. J. MONRO GIBSON, D.D.

Second Edition.

"This running commentary upon St. Matthew's Gospel sets before the reader our Lord's words, deeds, and sufferings as recorded by that Evangelist in a vivid light."-Guardian.

\section{THE BOOK OF EXODUS.}

By the Very Rev. G. A. CHADWICK, D.D.

Second Edition.

"This is, to a great extent, a model of what an expository commentary should be. To exhibit the Old Testament in the light of the New, and to point out the spiritual and permanent truth under the type by which it was in that early age expressed, and through which it still shines, cannot fail to render a commentary extremely valuable."-Literary Churchman.

\section{JUDGES AND RUTH.}

By the Rev. R. A. WATSON, M.A., Author of "Gospels of Yesterday."

"This is an unusually attractive volume. His pages will give many a valuable hint to the preacher."-Literary Churchman.

\section{THE GOSPEL OF ST. LUKE.}

By the Rev. HENRY BURTON, M.A.

"His chapters are full of vivid illustration, and fresh, bright exposition." -Record.

\section{THE PROPHECIES OF JEREMIAH.}

With a Sketch of His Life and Times.

By the Rev. C. J. BALL, M.A., Chaplain of Lincoln's Inn.

"The critical portion will be prized most as it exhibits deep learning, breadth of view, and clear insight into the prophet's meaning."-Manchester Examiner.

\section{THE BOOK OF ISAIAH.}

Vol. II. By the Rev. GEORGE ADAM SMITH, M.A.

SECONd Edition.

"The results of thorough scientific study are here presented, not as the bare and wintry stem which too often repels, but rich and attractive, with the foliage and fruit which sound criticism yields."-Dr. Marcus Dods. 


\section{THE EXPOSITOR'S BIBLE.}

FOURTH SERIES.

Price 7s. 6d. each Volume.

\section{THE GOSPEL OF ST. JOHN. VOL. I.}

By the Rev. MARCUS DODS, D.D., Professor of Exegetical Theology, New College, Edinburgh.

"An excellent contribution to the series. Dr. Dods has the gift of lucidity of expression."-Guardian.

\section{THE EPISTLES OF ST. JAMES AND ST. JUDE.}

By the Rev. A. PLUMMER, D.D., Master of University College, Durham.

"It is even a better piece of work than his former volume on the Pastoral Epistles. It contains everything that the student can desire by way of introduction to the two Epistles, while for those who read with an eye to the manufacture of sermons, or for their own edification, the doctrinal and moral lessons are developed in a style redolent of books, yet singularly easy and unaffected. Points of interest abound."-Saturday Reviez.

\section{THE BOOK OF ECCLESIASTES.}

With a New Translation.

$$
\text { By the Rev. SAMUEL COX, D.D. }
$$

"The most luminous, original, and practical exposition of Ecclesiastes which is within the reach of ordinary English readers."-Speaker.

\section{THE BOOK OF PROVERBS.}

By the Rev. R. F. HORTON, M.A., Hampstead.

"In each of these lectures will be found much strong and vigorous thought, firm and logical reasoning, and the results of high culture and ability."-Literary Churchman.

\section{THE BOOK OF LEVITICUS.}

By the Rev. S. H. KELLOGG, D.D., Author of "The Light of Asia and the Light of the World."

"He has certainly succeeded in investing with fresl interest this old book of laws, with whose spirit he seems so heartily in sympathy.:Scotsman.

\section{THE ACTS OF THE APOSTLES. VOL. I.}

By the Rev. Professor G. T. STOKES, D.D.

"A very valuable addition to Biblical literature."-British Weekly. 


\section{THE EXPOSITOR'S BIBLE.}

FIFTH SERIES, $1891-92$.

Price 7s. 6d. each Volume.

\section{THE BOOK OF JOB.}

By the Rev. R. A. WATSON, D.D., Author of "Gospels of Yesterday," etc.

THE EPISTLES TO THE THESSA. LONIANS.

By the Rev. JAMES DENNEY, B.D.

THE PSALMS. VOL. I.

By the Rev. ALEXANDER MACLAREN, D.D.

THE ACTS OF THE APOSTLES. VOL. II. By the Rev. Professor G. T. STOKES, D.D.

THE EPISTLE TO THE EPHESIANS.

By the Rev. Professor G. G. FINDLAY, B.A.

THE GOSPEL OF ST. JOHN. VOL. II. By the Rev. Professor MARCUS DODS, D.D 


\section{THE EXPOSITOR'S E 3LE.}

- SIXTH SERIES.

Price 7 s. 6d. each volume.

\section{THE EPISTLE TO THE PHILIPPIANS.}

By the Rev. Principal RAINY, D.D.

THE FIRST BOOK OF KINGS.

By the Ven. Arclideacon FARRAR, D.D., F.R.S.

EZRA, NEHEMIAH, AND ESTHER. By the Rev. Professor W. F. ADENEY, M.A.

\section{THE BOOK OF JOSHUA.}

By the Rev. Professor W. G. BLAIKIE, D.D., LL.D

\section{THE BOOK OF DANIEL.}

By the Rev. Professor J. M. FULLER, M.A.

\section{THE BOOK OF PSALMS. VOL. II.}

By the Rev. ALEXANDER MACLAREN, D.D. 


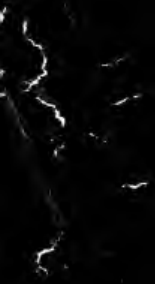




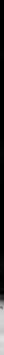




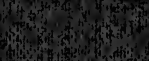

if

5.

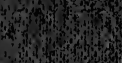

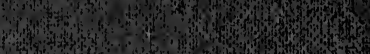

(5.

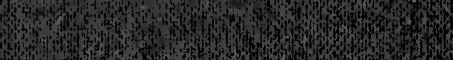

(5)

15.

20

3.32 .

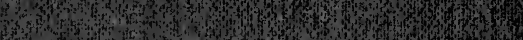

53 -

Fo

(6)

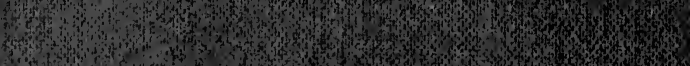

20.5.

d:

-2. 3.

2. 4

STH

then

5.

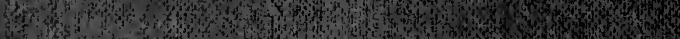

W.

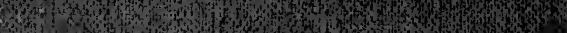

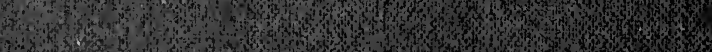

3.4.

S.

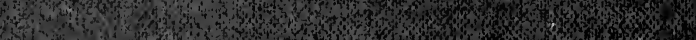

of

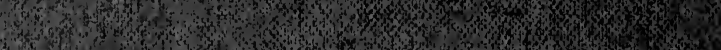
Q1.

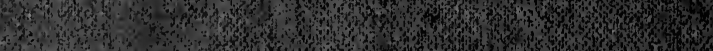

d.

Th n

w.t.

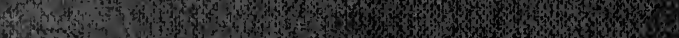

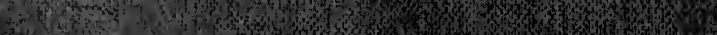

H.

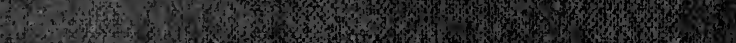

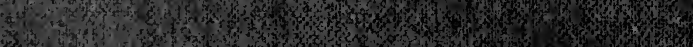

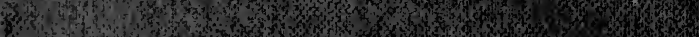

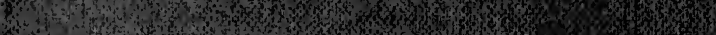

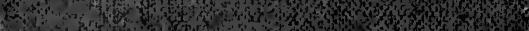

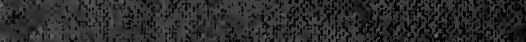

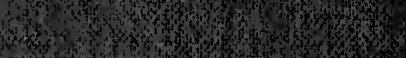

10.

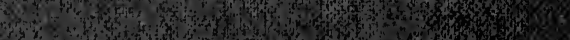

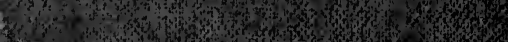

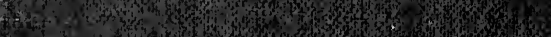

H.

s.m. 